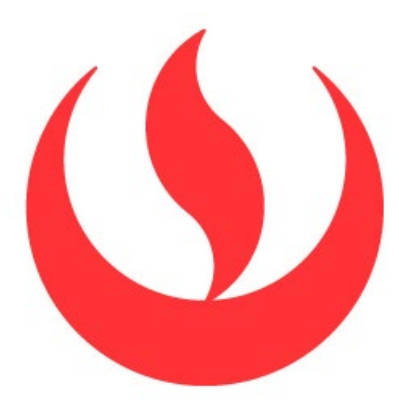

UNIVERSIDAD PERUANA DE CIENCIAS APLICADAS

FACULTAD DE NEGOCIOS

PROGRAMA DE ADMINISTRACIÓN Y NEGOCIOS INTERNACIONALES

\title{
LOS MILLENNIALS CON LAS COMPETENCIAS PARA FUTUROS LÍDERES DISRUPTIVOS EN LA TRANSFORMACIÓN DIGITAL EN LAS COMPAÑÍAS DE SEGURO DE LIMA METROPOLITANA
}

\section{TESIS}

para optar el título profesional de: Licenciado en Administración

AUTOR:

Cordova Allcca, Eder Francisco (0000-0002-6034-9146)

Maldonado Layme, Gina Estefany (0000-0003-3838-4321)

ASESOR:

Senmache Sarmiento, Ana Elena (0000-0002-9052-5067)

Lima, diciembre de 2017 
$A$ nuestros Padres 


\section{RESUMEN}

La Generación Y o también llamada Millennials se convertirán en la mayor fuerza laboral del mercado y guiará a sus compañías durante el proceso de transformación digital. Por tal motivo, se planteó una serie de interrogantes sobre los diversos planes de transformación digital de las compañías, principalmente las del sector de Seguros de Lima Metropolitana. Actualmente, la transformación digital tiene un gran impacto a nivel global en todos los sectores, pero en algunos sectores se desarrollan o toman mayor relevancia debido al cambio más acelerado y a las necesidades del mercado. El sector Seguros de Lima es uno de los sectores que recién están invirtiendo en áreas de transformación digital ante el inminente cambio.

La presente investigación se desarrolló con la información obtenida de estudios sobre competencias laborales y nuevas tendencias globales de los futuros trabajadores y/o fuerza laboral, en este caso los Millennials.

En cuanto a la metodología de investigación, se utilizó herramientas cualitativas y cuantitativas para poder comprobar o rechazar la hipótesis planteada. Se realizó entrevistas a las principales compañías de Seguros de Lima Metropolitana. Para las encuestas, se tomó una muestra significativa de la población de Millennials de Lima Metropolitana entre 21 a 35 años de edad con estudios Universitarios completos e incompletos. Ambos métodos permitieron conocer si las empresas solicitan Millennials con las competencias requeridas para el proceso de transformación digital. Las encuestas permitieron saber si, en el mercado laboral de Millennials, existen personas con las competencias requeridas para el proceso de transformación digital.

Palabras claves: Millennials, transformación, digital, competencias, seguros. 


\section{ABSTRACT}

The Generation Y, also known as Millennials, will soon become the greatest workforce in the market. This generation will guide companies during the process of digital transformation. For this reason, many questions were contemplated about the different plans of digital transformation of companies, mainly the ones from the insurance sector located in Lima Metropolitan Area. Currently, the digital transformation has a great global impact in all the sectors. However, it develops or becomes more relevant in some sectors because of the vertiginous change in market needs. Lima's insurance sector is one of the recent investors in digital transformation.

This research was made with the information obtained from studies about labor skills and the new global trends of the future employees or workforce, in this case, the millenials. Additionally, several papers related to digital transformation and disruptive leadership were consulted

In regards to the research methodology, qualitative and quantitative tools were used to confirm or dismiss the proposed hypothesis. Four interviews were made to the main insurance companies in the Lima Metropolitan. For the surveys, a representative sample of Millennial population in Lima Metropolitan Area was taken (people between 21 and 35 years old with or without University studies). Both methods allowed us to find out if the companies in Lima are actually looking for Millenials with the required skills for the process of digital transformation. Also, the surveys helped us find out if there are Millenials with the required skills for this digital transformation process at Lima's laboral market.

Keywords: Millenials, transformation, digital, competitions, insurance 


\section{ÍNDICE GENERAL}

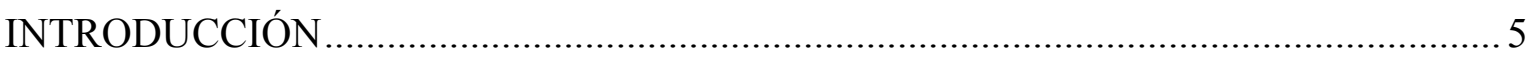

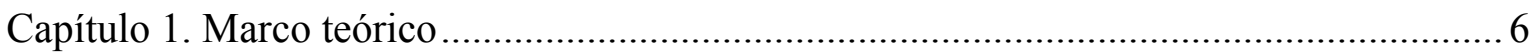

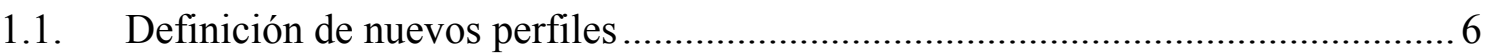

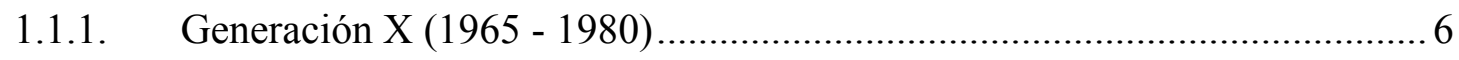

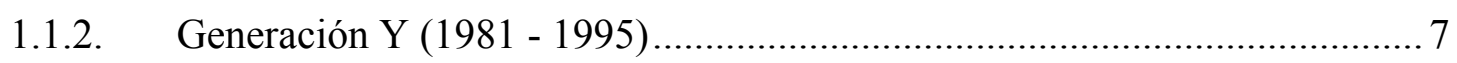

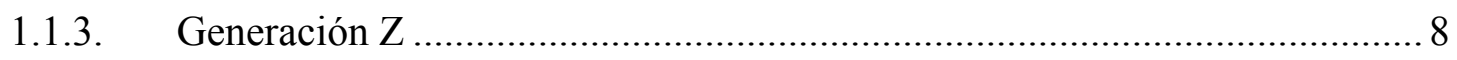

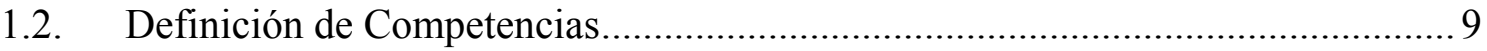

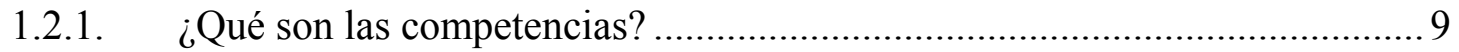

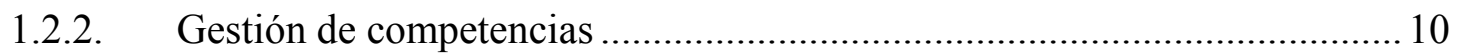

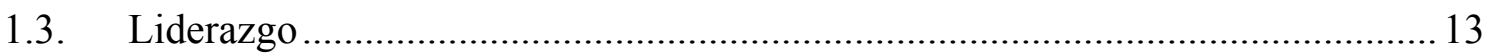

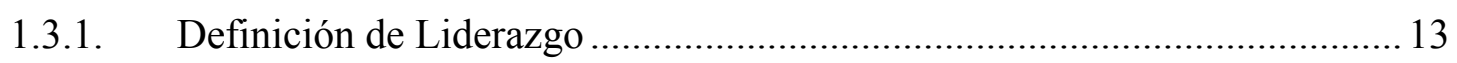

1.3.2. El liderazgo en la transformación digital................................................ 14

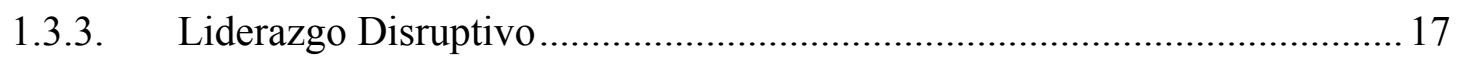

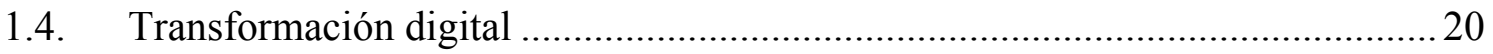

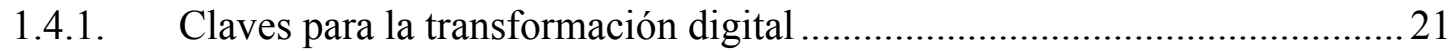

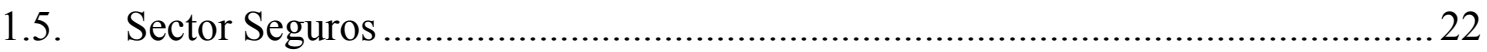

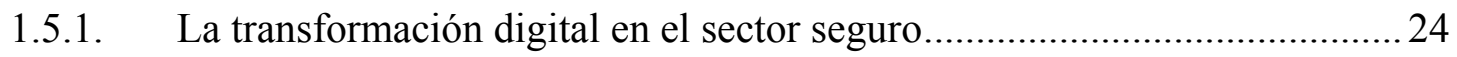

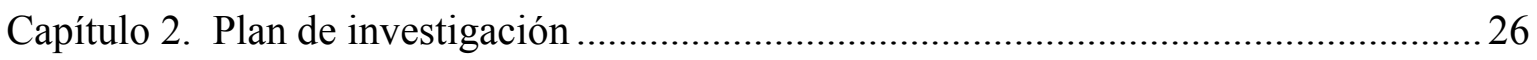

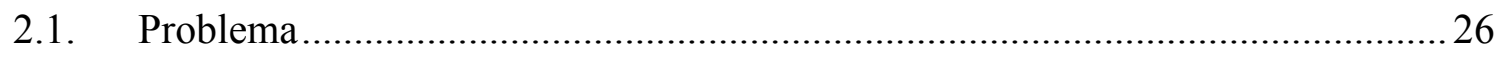

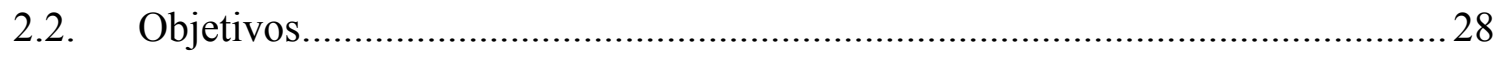

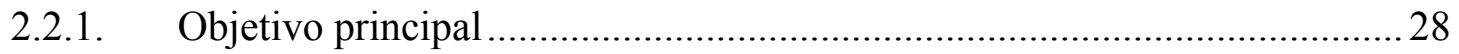

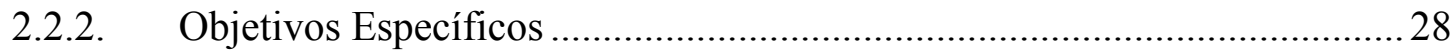

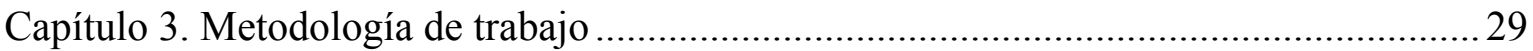

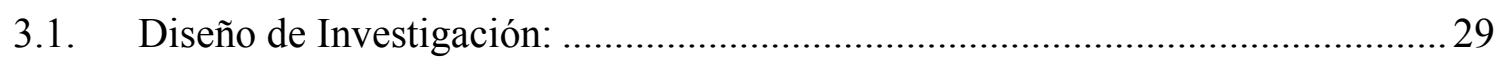

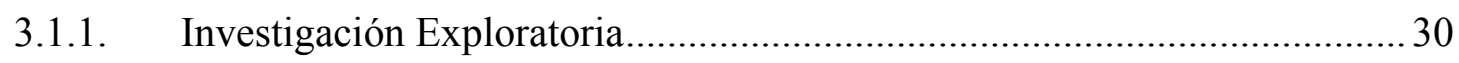

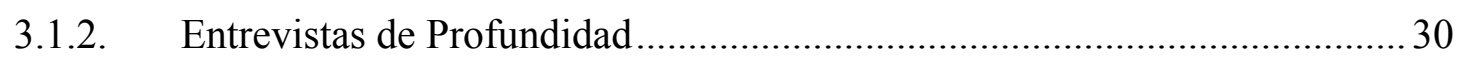

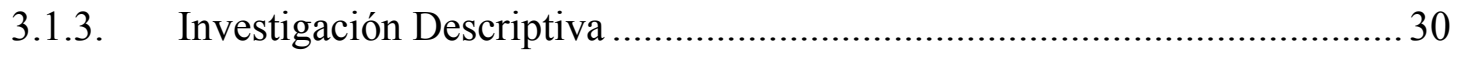

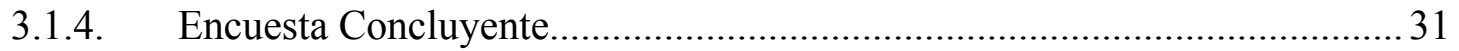

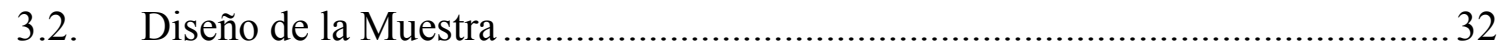

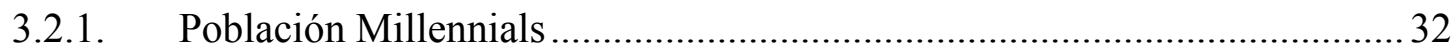




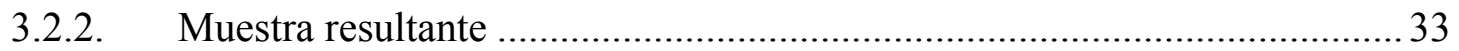

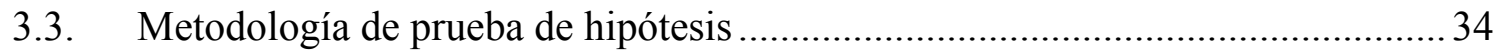

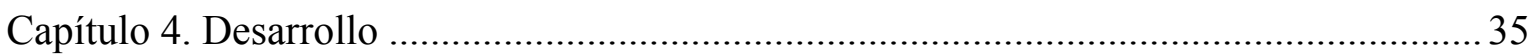

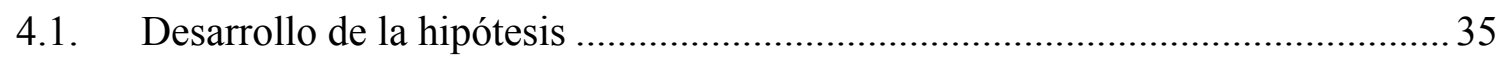

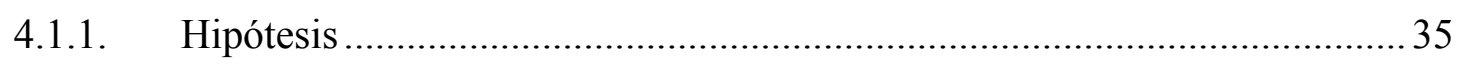

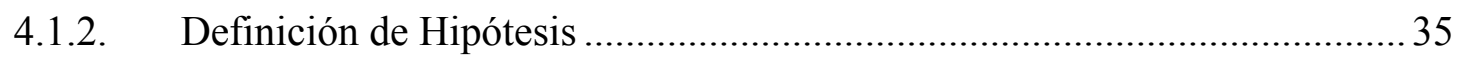

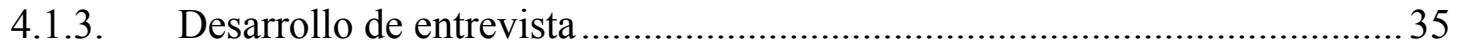

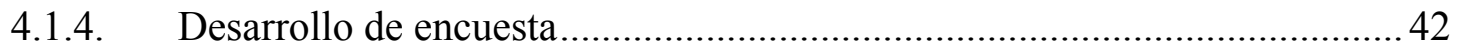

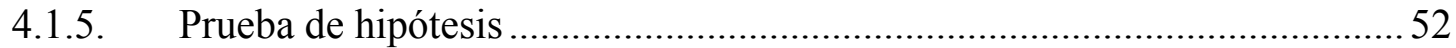

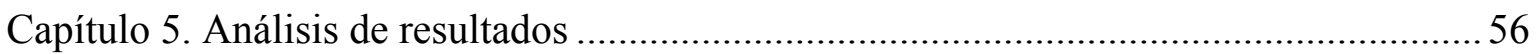

5.1. Millennials con las competencias requeridas para el futuro líder disruptivo .......56

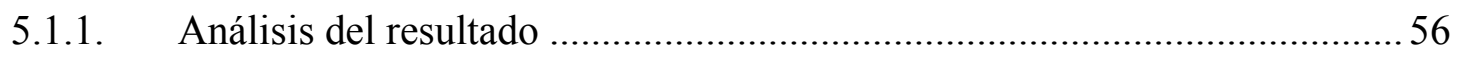

5.2. Competencias requeridas por las compañías de seguros ....................................59

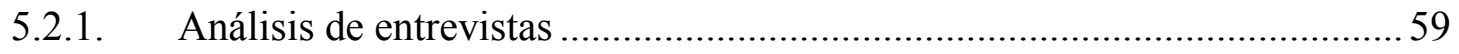

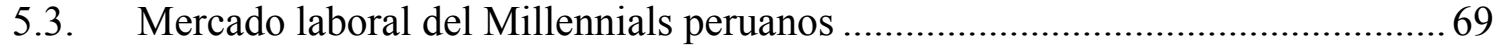

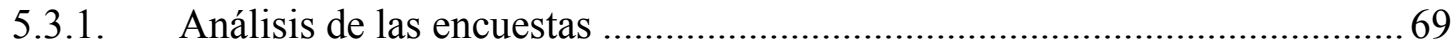

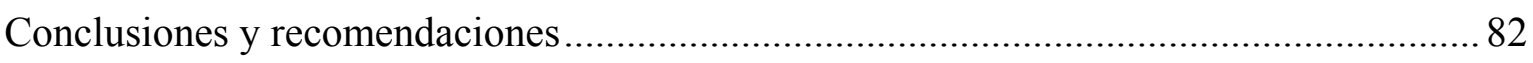

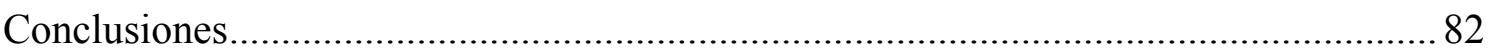

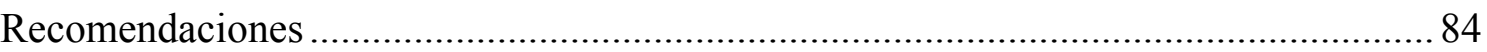




\section{INDICE DE TABLAS}

Tabla 1. Valores críticos de la distribución Chi cuadrado..................................................55

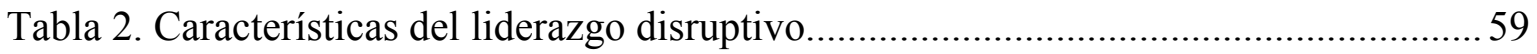

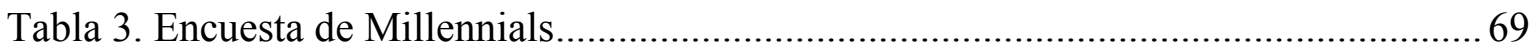

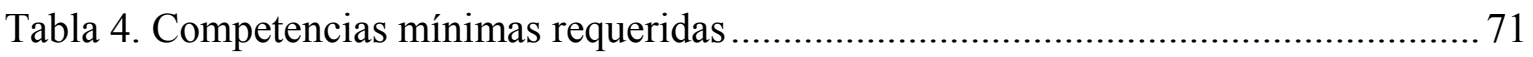

Tabla 5. Cantidad de encuestados por género y edad...................................................... 72

Tabla 6. Cantidad de encuestados por género y situación laboral ....................................... 73

Tabla 7. Situación laboral por nivel de estudios............................................................... 73

Tabla 8. Encuestados por nivel de estudio, género y situación laboral ............................... 74

Tabla 9. Cantidad de competencias correctas vs presentación a procesos de selección ..... 75

Tabla 10. Cantidad de competencias correctas vs rechazos de ofertas laborales ................ 75

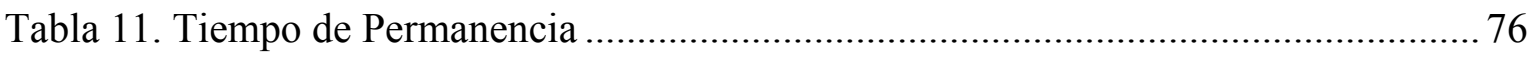

Tabla 12. Cruce de competencias, beneficios y tiempo de permanencia en una empresa .. 77

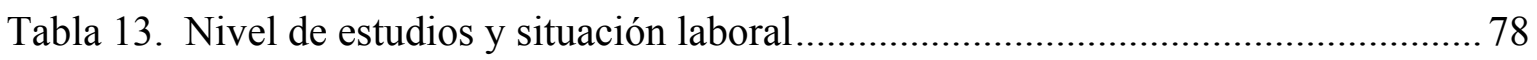

Tabla 14. Nivel de estudio, género y competencias cumplidas......................................... 78

Tabla 15. Situación laboral, género y competencias cumplidas ......................................... 79

Tabla 16. Tiempo de permanencia y competencias cumplidas ......................................... 80

Tabla 17. Tiempo de permanencia, motivación y competencias cumplidas ........................ 81 


\section{INDICE DE FIGURAS}

Figura 1. Capacidades de liderazgo necesarias para tener éxito en un mundo digital ........ 19

Figura 2. Primas acumuladas de seguros netas - Ramos generales .................................. 23

Figura 3. Primas acumuladas de seguros netas - Ramos de vida ...............................2 24

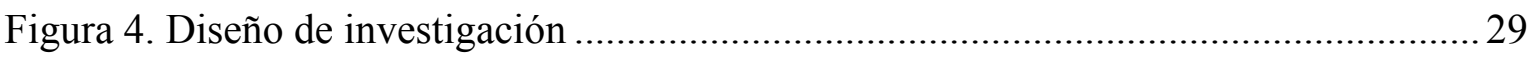

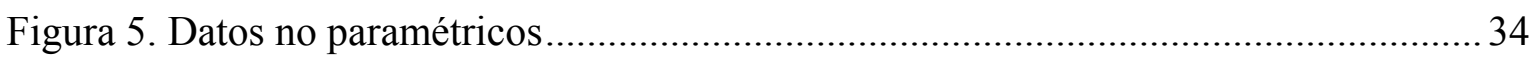

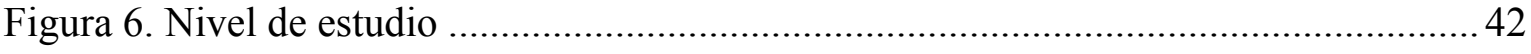

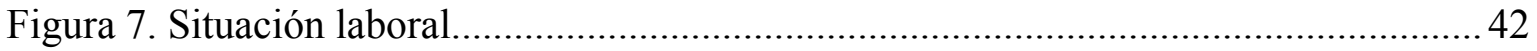

Figura 8. Principales industrias donde laboran los Millennials.......................................... 43

Figura 9. Millennials que se presentaron a un proceso de selección ................................... 43

Figura 10. Rechazo de ofertas laborales de Millennials ...................................................... 44

Figura 11. Razón de rechazo de la propuesta laboral ........................................................ 44

Figura 12. Tiempo de permanencia de los Millennials en una empresa............................ 45

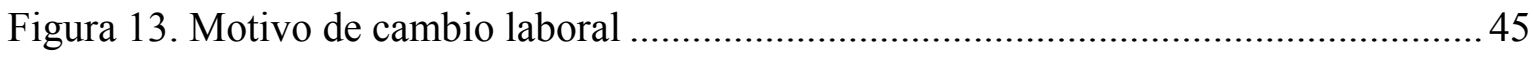

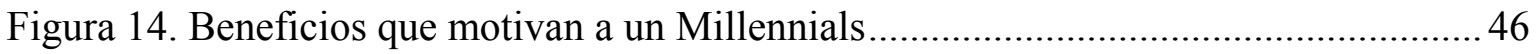

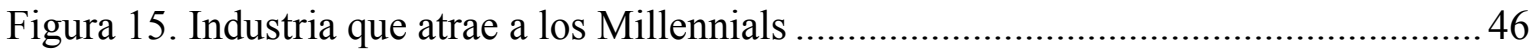

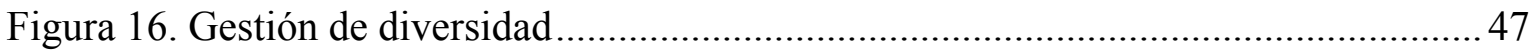

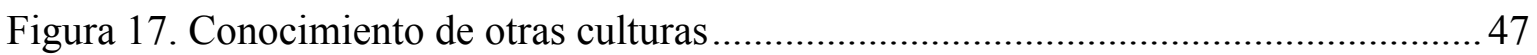

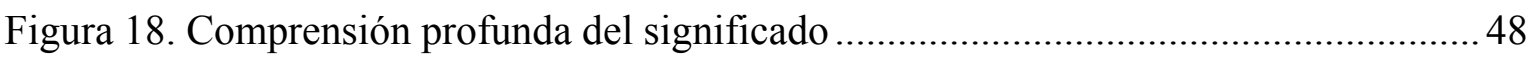

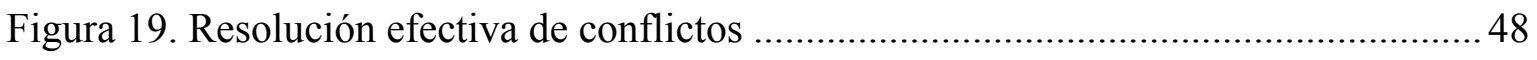

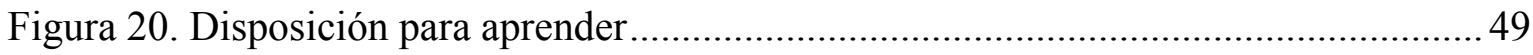

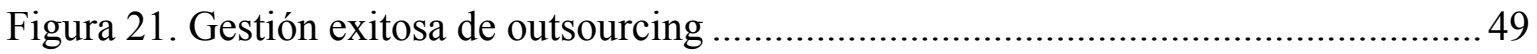

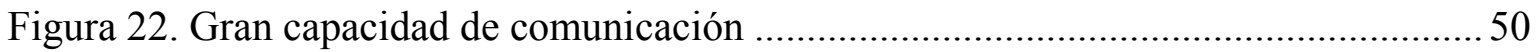

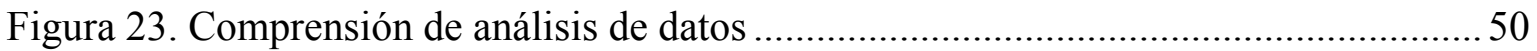

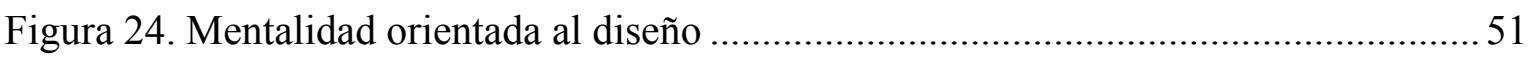

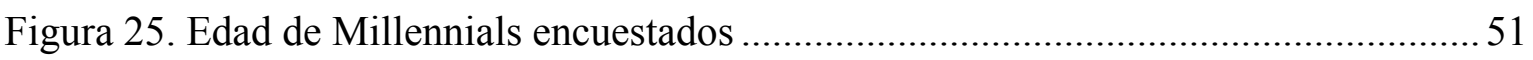

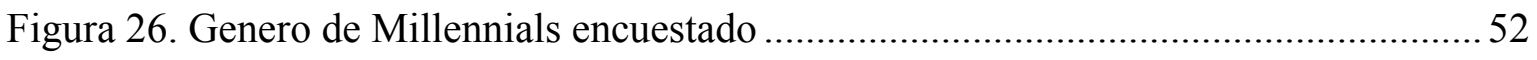

Figura 27. Capacidades del liderazgo necesarias para tener éxito en un mundo digital .....57

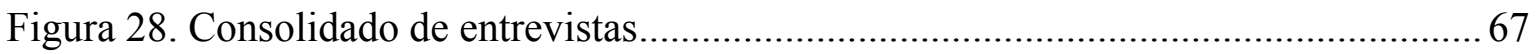




\section{INTRODUCCIÓN}

Actualmente, las empresas en el mundo están afrontando La transformación digital, pero ¿Qué es “Transformación Digital”? La transformación digital tiene como definición generar un nuevo modelo de negocio o un cambio profundo respecto al actual. Deloitte lo define como "Dar el siguiente paso de nivel en la evolución de negocios, frente a una sociedad que crece y cambia a ritmo acelerado y que va adaptándose a los avances tecnológicos". Para las empresas, es fundamental adaptarse para generar una experiencia única a sus clientes internos y externos, transformando la mentalidad, procesos y las tecnologías tradicionales que tienen las organizaciones.

Por tal motivo, existen diversas industrias que están realizando cambios organizacionales como crear áreas de Innovación o Lab para generar un cambio. Sin embargo, para realizar la transformación digital es necesario que se realice un cambio de mente, cultural y profesional de gran impacto en toda la organización con la finalidad que estas puedan identificar y formar a los nuevos líderes que cumplan con los objetivos de la transformación digital.

La presente investigación, tiene como objetivo principal analizar si en el mercado laboral existe Millennials con las competencias requeridas para convertirse en el futuro líder disruptivo que logre la transformación digital y cubra las necesidades de las compañías de seguros de Lima Metropolitana. Es así que ante la creciente necesidad que presentan las empresas y el mercado realizamos un análisis para identificar los planes y/o acciones tomadas por las compañías peruanas, en especial de las compañías de seguros de Lima Metropolitana. Actualmente, las aseguradoras con mayor participación en el mercado están invirtiendo en áreas de transformación digital, por lo cual poseen posibilidad de crecimiento en la industria. 


\section{Capítulo 1. Marco teórico}

Las empresas están afrontando un cambio acelerado en el contexto de fuerza laboral impulsada por la revolución digital. Las organizaciones están siendo impactadas de forma positiva y negativa, puesto que el cambio no es solo tecnológico. Comprende la sociedad y la demografía, lo cual requiere que las empresas adopten nuevas formas de pensar y actuar. A continuación, se presentará las definiciones de los tres últimos rangos generacionales, competencias, liderazgo, la transformación digital y el sector de negocios al cual nos enfocaremos. Nuestras principales fuentes son bibliográficas, estudios de consultoras globales, artículos periodísticos, revistas de investigación, entre otras.

\subsection{Definición de nuevos perfiles}

Se iniciará con los tres últimos rangos generacionales para conocer las características, contexto y entre otros datos relevantes. Finalmente, será los Millennials en quienes nos enfocaremos para la presente investigación.

Según el estudio "Generational divide" de Alison Stein detalla que existen siete tipos de Rangos generacionales en Estados Unidos, estos son: Generación Gi, Generación de la depresión, Bebés de la Guerra, Baby Boomers, Generación X y Generación Y. El "Generational divide" es la base de los estudios que se utilizan actualmente, los definen bajo el mismo nombre, pero difieren en el rango de edades. (Mitta, D. \& Dávila, C., 2015) De los seis rangos generacionales, tendremos un foco especial en la generación $\mathrm{Y}$.

\subsubsection{Generación X (1965 - 1980)}

Llevan este nombre, porque según Coupland viven en la sombra de los Baby Boomers y carecen de características distintivas. Kotler los define como la primera generación que crecieron en un hogar donde la madre era la cabeza del hogar, por consecuencia son personas que valoran las experiencias y no las adquisiciones. Consideran su familia como primer lugar de relevancia y como segundo su vida profesional. Muchos de ellos son dueños de viviendas 
con familias pequeñas y representan un fuerte poder de compra anual. (Kotler, P. \& Armstrong, G, 2012)

Chirinos indica que son personas escépticas y ferozmente independientes, pragmáticas y enfocadas a resultados. Se consideran leales con las empresas y personas que se organizan alrededor de su trabajo. (Chirinos, 2009) Según recientes estudios revelan que la mayoría de estos adultos trabajan de forma independiente, más del 50\% utilizan laptop, un $79 \%$ usan redes sociales lo cual muestra que se adaptan al cambio digital. (Mercado negro, 2017)

\subsubsection{Generación Y (1981 - 1995)}

Según Kotler la Generación Y o generación del milenio, nacidos entre 1977 y 2000. Los describe como la primera generación que nació en mundo lleno de tecnología, haciendo que sea parte de su estilo de vida. (Kotler, P. \& Armstrong, G, 2012)

Por otro lado, Chirinos indica que son los nacidos entre 1982 y 2000, fueron los bebés que crecieron con las vidas planificadas a diferencia de sus antecesores. Actualmente, están entrando al mercado laboral, tienden a recibir comentarios frecuentes de elogios y reconocimiento. Su capacidad digital es claramente superior por haber tenido un fácil acceso a la tecnología y es parte de su estilo de vida. La mayoría tiene un conocimiento global, aprecian la diversidad cultural y valoran a las personas por su capacidad de respuesta más no por sus características. (Chirinos, 2009)

El rango de edad definida por Karsh y Templi, en su libro Gerente 3.0, es de 1981 al 2000. El cual coincide con el Fondo de Pensiones de las Naciones Unidas. Este último, los describe como sociales, morales, confidentes, diversos, con espíritu heroico, tenaces, coleccionadores de acciones y necesitados de flexibilidad. (Karsh, B. \& Templin, C., 2013)

El Centro de Nacional de Planeamiento Estratégico (CEPLAN) los define como “Ciudadanos globales, creativos, críticos, exigentes, innovadores, buscan un balance entre su trabajo y su vida personal, gozan de un aprendizaje rápido, conocedores de idiomas y tienen movilidad laboral". (CEPLAN, 2015) Sin embargo, no todos poseen estas características, un reciente estudio de Semana Económica indica que los Millennials 
peruanos no son tan diferentes a sus antecesores, pero que tratan de equilibrar su vida profesional con la laboral. (Semana Ecónomica, 2014)

Deloitte proyecta que para el 2025 el 75\% de la fuerza laboral mundial será Millennials y según Ceplan estima que para el 2025 el 68\% de la fuerza laboral sea conformada por ellos. Según Ipsos Apoyo 2016, el rango edad de los Millennials se encuentra entre los 21 y 35 años, es decir los nacidos entre 1981 y 1995, estudio que está enfocado a la realidad peruana, por lo cual será base en la que enfocaremos nuestra investigación. (IPSOS Apoyo, 2016)

\subsubsection{Generación $Z$}

La información sobre esta generación es limitada, puesto que recién se está investigando. El Diario Gestión indica que son los nacidos desde 1994, cabe resaltar que el rango de edades difiere con la Generación Y. Esto sucede porque aún no se ha establecido algo concreto a comparación de las otras generaciones. La Generación Z tienen altas expectativas por cambiar el mundo y hacerlo realidad, a comparación de la generación $\mathrm{X}$, busca un camino entre el idealismo y el materialismo. Son nativos digitales, creativos, autosuficientes, autodidactas y aprenden en internet. Representa un $25.9 \%$ de la población mundial, no tienen poder de compra, pero es el futuro del mercado. (Gestión, Generación Z: Cuatro claves para venderles con éxito. Gestión, 2017)

Forbes indica que según Soy Entrepreneur, presentan las siguientes diferencias: Mientras lo Millennials tienen tendencia a la multipantalla (2 pantallas) la generación $\mathrm{Z}$ puede controlar hasta 5 pantallas, se comunican mejor con imágenes, crea contenido y los Millennials lo comparte, son realistas y trabajan para obtener éxito personal. Además, entre sus principales características mencionan que son autodidactas, maduros, creativos, trabajadores enfocados, reyes de zapping, prefieren la privacidad y nativos digitales. (Forbes, 2014)

Por otro lado, IPSOS Perú (2016) los describe como un grupo inseguro y voluble, la mayor parte de sus decisiones se basan en impulsos o deseos momentáneos. Su rango de edad está entre 14 a 20 años, $49 \%$ son mujeres, $46 \%$ son estudiantes, $97 \%$ son digitales, $56 \%$ tiene en 
su hogar smartphone y el 92\% cuenta con redes sociales. (Mercado Negro, 2017)

\subsection{Definición de Competencias}

Mediante las competencias podremos identificar las principales capacidades que debería tener el futuro trabajador que afronte la transformación digital y con esto tener la base de un futuro líder en transformación. Por lo cual, primero se definirá el concepto de competencias, luego gestión de competencias y por último las competencias requeridas para la transformación digital según Institute for the future y Semana Económica.

\subsection{1. ¿Qué son las competencias?}

Martha A. y Claude Levy-Leboyer (2009 y 2002) hacen referencia y estudio sobre los distintos significados en las diversas lenguas y contextos. La cual tiene como resultado tres significados de competencia: competir, competente y autoridad.

Según Martha Alles, lo define como una serie de características de personalidad que provienen de comportamientos, generando un desempeño exitoso en el puesto de trabajo. "es una característica subyacente de un individuo que está causalmente relacionada con un nivel estándar de efectividad y/o con un desempeño superior en un trabajo o situación”. (Spencer, L., \& Spencer, Signe, 1993) Claude Levy-Leboyer indica que es una serie de características individuales que son actitudes y rasgos de personalidad. (Lévy-Leboyer, 2002)

Alles divide las competencias en laborales y conductuales, la primera se vincula con las profesiones $\mathrm{u}$ oficios $\mathrm{y}$ se enfoca a ver si un individuo puede o no pertenecer a una organización. Para trabajar bajo este enfoque se necesita implementar modelos de management o de gestión, de esta manera recursos humanos identifica sus objetivos y se alinean a la estrategia del negocio logrando una modelización para generar una relación de ganar-ganar entre la compañía y el colaborador. Estos modelos tienen origen en las competencias conductuales que en teoría solo se denominan como "competencias". (Alles, 
Comportamiento Organizacional. Cómo lograr un cambio organizacional a traves de la gestión por competencias, 2007)

Spencer y Spencer (1993) introduce el Modelo Iceberg, dividiendo en dos grupos: las más fáciles de desarrollar y visualizar como las habilidades y conocimientos; y las menos fáciles, las actitudes, valores y rasgos de personalidad.

Un modelo de competencias, para lograr un cambio cultural, permite un cambio en todas las direcciones. En primer lugar, de arriba hacia abajo, al definirse desde el máximo nivel organizacional. De lado a lado, modificar los subsistemas de Recursos Humanos y de abajo hacia arriba, cuando desarrollan las competencias de los colaboradores en todos los niveles. (Alles, 2007)

\subsubsection{Gestión de competencias}

Martha Alles define la gestión por competencias como una herramienta de trabajo, que servirá para alcanzar la visión que tiene planteada la compañía. El modelo de competencias será vehículo para lograr el cambio cultural que desea la empresa. Los aspectos más relevantes que se definen a partir de la estrategia organizacional, se basan en la misión, visión, valores y estrategia de la empresa. Además, representa las características que las personas que integran la organización deberán poseer para alcanzar la estrategia, la cual es posible aplicarse en periodos de corto plazo. Alles, nos explica lo importante que es definir los perfiles laborales por competencias y la importancia de la formación del colaborador. (Alles, Comportamiento Organizacional. Cómo lograr un cambio organizacional a traves de la gestión por competencias, 2007)

En la investigación se han encontrado dos estudios enfocados en competencias que debería tener el colaborador con perfil digital. El primer estudio, es elaborado por Institute for the future, el cual plantea en su informe Future Work Skills 2020, 10 competencias claves para el futuro colaborador: (Institute for the future, 2011)

1. Dar sentido: Es la capacidad de dar consecuencia a los puntos claves para poder realizar una toma de decisión efectiva con ideas únicas. 
2. Inteligencia social: Entender de manera profunda y directa, para identificar y estimular ante reacciones e interacciones de la manera idónea. Las personas que poseen esta habilidad son capaces de identificar rápidamente dichos puntos y lograr construir relaciones de confianza, necesarias para interactuar entre grupos de personas diferentes.

3. Pensamiento adaptativo: Capacidad de dar solución a los problemas con soluciones respuestas novedosas e innovadoras.

4. Competencias interculturales: Implica más que saber distintos idiomas, es la capacidad para adaptarse a contextos y realidades diferentes. Estar en un mundo totalmente conectado hace necesario tener la capacidad de entender distintas culturas, edades, habilidades, disciplinas, estilos de trabajo y formas de pensar.

5. Pensamiento computacional: Poseer la habilidad de entender grandes cantidades de datos y transformarlos para obtener información valiosa. Dar sentido y saber emplearla de manera adecuada será una capacidad que se distinga con las máquinas.

6. Alfabetización en nuevos medios: Hacer uso de nuevos medios de comunicación para crear contenido persuasivo. El futuro colaborador tendrá que ser capaz de entender, evaluar de forma crítica y comunicar por diferentes canales.

7. Transdisciplinariedad: Ser capaz de entender y conversar en múltiples disciplinas, va requerir que la persona tenga disposición y curiosidad de seguir aprendiendo más allá de lo usual.

8. Mentalidad de diseño: Capacidad de reconocer las tareas y reestructurar de acorde al entorno del trabajo para mejorar procesos o tareas.

9. Gestión de carga cognitiva: Saber diferenciar y filtrar la información relevante para aprovecharla de la manera adecuada.

10. Colaboración virtual: Las tecnologías hacen que trabajar sea más fácil y eficiente, puesto que se utiliza un entorno virtual. La capacidad de desarrollar estrategias para involucrar y motivar a grupos dispersos será clave para utilizar estas plataformas colaborativas, retroalimentación inmediata y desafíos escalonados que puedan impulsar significativamente la participación y motivación.

Sin embargo, las competencias que serán tomadas como referencia para realizar la presente investigación se basará en el estudio de la revista “Semana Económica - Trabajo 3.0”. Dicho estudio tuvo como base diversos estudios y entrevistas realizados a especialistas en Perú, por lo cual se ajusta más a la realidad del País. (Semana económmica, 2016) A continuación, se detalla cada una de ellas:

1. Gestión de la diversidad: Saber identificar rápidamente las emociones de quienes los rodean, interpretar sus palabras y lenguaje corporal, será el mayor reto del futuro. La inteligencia social será indispensable para entornos colaborativos y de construcción de confianza, el cual le otorga al colaborador una ventaja competitiva. 
2. Conocimientos de otras culturas: No solo implica saber otro idioma, es saber trabajar con personas de diferentes culturas y perspectivas. Es un proceso que implica el aprendizaje continuo, cometer errores, recibir feedback y practicar comportamientos apropiados de acuerdo a cada cultura.

3. Comprensión profunda del significado: Entender la condición humana o tener la capacidad de comprender el significado de las cosas será unos de los principales activos que poseerá una persona frente a los robots y la inteligencia artificial.

4. Resolución efectiva de conflictos: Se ha demostrado que trabajar en equipo ayuda a resolver velozmente los problemas. Los equipos eficientes se escuchan entre sí, muestran empatía a los sentimientos y necesidades del otro.

5. Disposición para aprender: Las personas tienen que estar abiertas a aprender y comprender que siempre habrá nuevas habilidades, de esta manera serán capaces de resolver problemas.

6. Gestión exitosa del Outsourcing: El surgimiento del teletrabajo hace necesario tener un líder capaz de gestionar talento a distancia con bases claras y objetivos bien establecidos. Si bien es forma de trabajo poco explotada, es la que va a traer más productividad y ahorros para las empresas. Jack Nilles, ingeniero y físico, aplicó su propuesta durante 6 meses en una aseguradora de los Ángeles. Los resultados fueron: mejoró la productividad en un $18 \%$ y aumentaron sus utilidades netas de US\$4 millones a US\$5 millones de dólares.

7. Gran capacidad de comunicación: La capacidad de comunicación e interactuar es una de las capacidades transversales en toda profesión. De nada sirve tener tecnología de última generación, si la persona no es capaz de utilizarla y explicarla.

8. Comprensión del análisis de datos: Actualmente, poseemos inmensas cantidades de información por lo cual es importante identificar cuáles son confiables y útiles. El trabajar con la información correcta será una ventaja, pero más aún si a pesar de tener poco alcance, tenga capacidad de tomar decisiones y no paralizarse.

9. Mentalidad orientada al diseño: Se denomina la habilidad clave del futuro trabajador, será capaz de representar y desarrollar visualmente procesos de trabajo. Conocidos ahora como design thinking, contiene el pensamiento lógico, la imaginación, la intuición y el razonamiento sistemático. 


\subsection{Liderazgo}

A continuación, se definirá el concepto de liderazgo, el papel del liderazgo en la transformación digital y el liderazgo disruptivo, siendo esta última, pieza clave para que las empresas puedan cumplir sus metas en transformación digital. Por ello, será importante exponer los cambios que han surgido en torno del liderazgo y la transformación digital.

\subsubsection{Definición de Liderazgo}

Gary Yukl lo define como un fenómeno en que el líder ejerce influencia sobre otras personas, de esta manera pueda dirigirlas, estructurarlas y facilitar las actividades y relaciones dentro de la organización o grupo. También, expone que muchos de los investigadores discrepan en los conceptos de liderazgo, puesto que eligen distintos objetos de estudio y lo interpretan de manera distinta. (Yukl, 2008)

Para Lussier y Achua (2011) indican que no existe una definición universal o única, pero lo explican como un "proceso de influencia entre líderes y seguidores para alcanzar objetivos organizacionales por el medio del cambio”. (Lussier, R., \& Achua, C, 2011) Es así como se divide en 5 elementos:

- Líderes y seguidores: Explica que es un camino de dos sentidos, puesto que el líder influye a sus seguidores. las organizaciones lo dividen en dos categorías: personas que tienen subordinados y autoridad sobre ellos, y a los empleados. No obstante, las personas que poseen poder no son necesariamente líderes efectivos. Los líderes son los que poseen la habilidad de influencia en los demás, sea o no un gerente.

- Influencia: Es la esencia del liderazgo, si bien los gerentes pueden ejercer presión a sus subordinados, no pueden influir en ellos para lograr compromiso y entusiasmo de sus seguidores.

- Objetivos organizacionales: Mediante la influencia hacia los seguidores no solo se busca el beneficio del líder; sino compartir una visión común para la organización estableciendo metas claras.

- Cambio: Toda organización busca reinventarse de manera continua para ser competente, por tal es necesario tener líderes capaces de afrontar retos y adaptarse a dichos contextos de cambio. 
- Personas: Si bien no se menciona en el proceso de liderazgo, sin ellas no es posible lograrlo. Los líderes eficaces buscan ayudar y llevarlos al éxito, puesto que las habilidades de las personas son más valiosas para lograr los objetivos planteados

Gary Yukl (2008) identifica algunos tipos de liderazgo dentro de su libro, los cuales son:

- Liderazgo participativo: Contiene diversos procesos que permiten a las personas influir en las decisiones del líder. Pueden tomar varias formas en el proceso de toma de decisiones, tales como: Decisión autocrática, consulta, decisión conjunta y delegación. Dicha línea toma forma desde la no influencia de los demás hasta la elevada influencia de los demás.

- Delegación de responsabilidades: se explica como la asignación de nuevas responsabilidades al subordinado y la autoridad para asumirlo. A diferencia del participativo que puede actuar en forma conjunta entre subordinados, iguales o superiores.

- Delegación de poder: Utiliza la delegación con los subordinados, la delegación de poder da mayor importancia en otorgar poder para la toma de decisiones y así potenciar la iniciativa y la autodeterminación.

- Liderazgo carismático: Weber precisa que este líder tiene una visión radical y ofrece soluciones a las crisis, traer consigo seguidores que creen en la visión y objetivos. la teoría del liderazgo carismático proviene de la relación líder -seguidor, los seguidores creen incondicionalmente en el líder y actúan de acuerdo a ella.

- El liderazgo transformacional: Según Bass, es aquel que aumenta la motivación y el rendimiento de sus seguidores. De esta forma hace que sean más conscientes de la importancia de los resultados, induciendo el bien del equipo o organización y activando exigencias superiores.

\subsubsection{El liderazgo en la transformación digital}

Diversas compañías globales están incorporando dentro de sus estructuras organizacionales el puesto de director de cambio, esto se debe a que un $85 \%$ de todas las organizaciones están 
inmersos en un proceso de cambio, especialmente a la tecnología digital. La segunda razón se debe a que el $60 \%$ de las compañías fracasan en el proceso de la transformación digital, esto es a causa de que los directivos no tienen conocimiento de los principios y leyes básicas que rigen el proceso de cambio y suelen confundir el fin con el medio. El tercer motivo es porque no se tiene conocimiento, capacidad y metodología para la gestión de cambio, mejora de procesos, Lean Six Sigma, gestión de proyectos, Agile, Scrum, entre otras.

Asimismo, indica que los nuevos negocios digitales y las necesidades del mercado están poniendo en jaque a la mayoría de sectores y los están empujando a la gran convergencia. La gran convergencia se debe a las confluencias de datos (Big Data o Analytics), personas (redes sociales), dispositivos que incrementan la movilidad (devices o weareables), internet de las cosas y sistemas (cloud), todo lo antes mencionado hace posible la aparición de los nuevos negocios digitales. En resumen, el fin de la transformación digital es que las personas piensen y actúen diferente para incrementar los resultados con el debido uso de las tecnologías digitales que permita crear nuevos productos, servicios y experiencia a través de nuevos modelos de negocio. (Casado, 2017)

Tres de los principales motivos de fracaso al realizar la transformación digital se debe a la falta de compromiso de la Alta dirección con el proceso, la resistencia de las personas a cambiar y la cultura de la empresa. Por otro lado, está realizar un cambio a medias, es decir las compañías saben lo importante que es trabajar la digitalización de sus procesos y operaciones, pero no saben a quién asignarlo. Saben que se debe incorporar jóvenes (nativos digitales), pero no saben en qué nivel organizativo lo deben hacer para que no haya choques. Esto se ve evidenciado en las palabras de Francisco Román, presidente de Vodafone:

Estamos en un momento muy emocionante de la curva de aprendizaje colectivo, porque aquellos que tienen influencia y poder en las organizaciones -es decir, los altos directivos- no son nativos digitales, y hacen un esfuerzo por entender de qué va todo eso de la digitalización. Sin embargo, aquellos que son nativos digitales y tienen una familiaridad tremenda con ese mundo disponen de las herramientas, comprenden su manejo y repercusión, pero no tienen el poder ni la influencia en los esquemas tradicionales de las empresas para cambiar las cosas. (Casado, 2017) 


\subsubsection{Características de un líder de la trasformación digital}

Según Zemsania Global Group, indica que no hay perfiles nativos para la transformación digital, ya que son híbridos. Ellos no tienen una especialización concreta, pero tienen capacidades de liderazgo, sociabilidad especial, conocimiento de todas las áreas de la compañía y tener determinación. (zemsania Global Group , 2015) A continuación, se mencionará algunas de las habilidades de un líder adaptado a las nuevas tecnologías:

- Liderazgo: A diferencia del liderazgo tradicional, para el líder en transformación digital debe estar enfocado en guiar al equipo para conseguir los objetivos planteados y lograr adherir el sentimiento de entrega de los colaboradores, siendo más enfático que los demás.

- Innovación: Una persona capaz de plantear nuevas ideas más eficientes para realizarlas, resiliente, sin miedo al cambio y el primero en hacerlo.

- Disruptivo: La disrupción implica romper todos los esquemas ya establecidos. Estos líderes deben saber hacerlo, pensar de manera independiente, buscar alternativas eficientes y asumir riesgos. En conclusión, la transformación digital es disruptiva.

- Camaleónicos: la capacidad para adaptarse a los cambios continuos es esencial para afrontar nuevas situaciones que el mercado y la transformación digital empuje a la empresa.

- Socialmente activos: la comunicación efectiva es clave para poder transmitir de forma exitosa, saber escuchar y respetar las opiniones de los colaboradores para aprovechar al máximo el potencial humano. Asimismo, saber utilizar dicha habilidad para convencer a su equipo de la necesidad de un cambio disruptivo.

- Determinación: Tener en claro las metas y objetivos, ser persistente en lograrlos, capaz de cambiar la hoja de ruta cuando sea necesario con la voluntad de alcanzar siempre sus objetivos. 


\subsubsection{Liderazgo Disruptivo}

CEDE lo define como liderazgo adaptativo y a lo que las empresas deben buscar para poder construir grupos colaborativos y transversales. Asimismo, menciona que la manera de potenciar dichas competencias es modificando los estándares para facilitar una ejecución efectiva y en equipo. La necesidad que el futuro líder vaya más allá del autoritarismo y jerarquía hace más cercano crear ambientes colaborativos donde la disrupción en el liderazgo pueda modelar cohesión colaborativa para actuar de acuerdo a los objetivos en común. (CEPLAN, 2015)

Ricardo Mesesses, en su estudio para FORO ISTMO 2014 menciona que es importante romper paradigmas para hacer crecer las organizaciones. Asimismo, indica que las empresas que no piensan en realizar estos cambios están destinadas a desaparecer en el tiempo. Comprender la disrupción en la empresa requiere: repetir el concepto, interiorizarlo como parte de ella, explicarla con acciones concretas, innovar, implementar lo que se interiorizo y ser capaz de exponer. En resumen, define al liderazgo disruptivo como aquel que rompe con los hábitos, sale de los esquemas para generar nuevas ideas. (Meneses, 2015)

Según el estudio de Deloitte “Tendencias Globales en Capital Humano 2017” las organizaciones de hoy en día necesitan lideres diferentes, es decir, formar una generación de líderes más jóvenes, agiles y digitalmente listos. A medida que los antiguos modelos de negocios ya no son eficientes, es necesario realizar un cambio; sin embargo, la gran parte de compañías son inmigrantes tecnológicos. Las cuales están basados en modelos antiguos de control y rendimiento financiero, por tal motivo las grandes organizaciones se están planteando nuevos objetivos, como la innovación y el movimiento a gran escala.

Se están rediseñando para ser empresas más dinámicas, centradas en trabajo en equipo y conectadas, dichos cambios no solo son necesario para cambiar el modelo operativo, si no es esencial para tener un líder que dinamice y ejecute el nuevo modelo. Los futuros líderes necesitan habilidades interdisciplinarias, con las cuales puedan liderar equipos, entender cómo construirlos, mantener a las personas conectadas, comprometidas, fomentar cultura de innovación, aprendizaje y mejora continua. En resumen, los futuros líderes del mundo digital 
necesitan pensar, actuar y reaccionar de manera distinta para que su organización tenga éxito. (Deloitte, 2017)

\subsubsection{El cambio demográfico}

El cambio demográfico es uno de los factores que va a influir en quienes serán los futuros líderes de la transformación digital. Por lo cual, los Millennials, futura generación en establecerse como la mayor fuerza laboral del mercado, esperan desarrollar sus habilidades mediante oportunidades, tutorías y tareas retadoras. Asimismo, las empresas más competentes están desarrollando el liderazgo combinando diseño organizacional, diseño del trabajo, mentoría y programas de desarrollo para obtener los líderes que requieren. Sin embargo, en el común de las compañías buscan dar esta mentoría a los ejecutivos con los rangos más altos, por tal motivo los Millennials se sienten excluidos por el poco interese en su desarrollo. (Deloitte, 2017)

\subsubsection{2. $\quad$ El líder Digital}

La mayoría de compañías están preocupados en tener líderes digitales, pero solo un 5\% de las compañías creen que tienen líderes digitales sólidos. El 72\% de los encuestados, por el estudio de Tendencias Globales en Capital Humano 2017, están comenzando a diseñar programas de liderazgo digital. La investigación de Deloitte basada en estudios con MIT, muestra el cambio de las capacidades de liderazgo en tres tipos de transformación:

- Transformación cognitiva: Necesitan pensar diferente

- Transformación conductual: Necesitan actuar diferente

- Transformación emocional: Necesitan reaccionar diferente

- Adicionalmente, existen tres tipos de líderes que necesitaran ser combinadas en las organizaciones para alcanzar sus objetivos:

- Inversionistas digitales: Son capitalistas con habilidades para descubrir oportunidades, invertir en talento, forjan alianzas y buscan crear un ecosistema adecuado para el desarrollo y ejecutar las ideas innovadoras. Su misión es educar a los ejecutivos y a otros líderes que no comprendan aún la naturaleza del cambio. 
- Pioneros digitales: Son los visionaros, encargados de formar nuevos modelos de negocio y liderar una estrategia que los definirá e impulsará a la transformación digital de las organizaciones.

- Transformadores digitales: Encargados de gestionar los cambios radicales y transformar los modelos de negocios.

Figura 1. Capacidades de liderazgo necesarias para tener éxito en un mundo digital

\begin{tabular}{|c|c|c|}
\hline $\begin{array}{l}\text { Transformación Cognitiva } \\
\text { (PIENSA diferente) }\end{array}$ & $\begin{array}{l}\text { Transformación Conductual } \\
\text { (ACTUA diferente) }\end{array}$ & $\begin{array}{l}\text { Transformación Emocional } \\
\text { (REACCIONA diferente) }\end{array}$ \\
\hline $\begin{array}{l}\text { Conceptualizar las posibilidades en un mundo } \\
\text { virtual }\end{array}$ & $\begin{array}{l}\text { Adaptación a un constante cambio de poder e } \\
\text { influencia }\end{array}$ & Tolerar un entorno de riesgo y ambigüedad \\
\hline Manejo de la creciente complejidad cognitiva & $\begin{array}{c}\text { Colaborar con facilidad en muchos equipos } \\
\text { diferentes }\end{array}$ & Mostrar resiliencia ante el constante cambio \\
\hline $\begin{array}{l}\text { Pensar divergentemente sobre nuevas maneras } \\
\text { de hacer las cosas }\end{array}$ & $\begin{array}{l}\text { Valorar la contribución de los nuevos socios } \\
\text { de trabajo y los diferentes grupos de interés }\end{array}$ & $\begin{array}{c}\text { Ser valiente en desafiar cómo se están } \\
\text { haciendo las cosas }\end{array}$ \\
\hline $\begin{array}{l}\text { Tomar decisiones rápidamente sin tener toda la } \\
\text { información }\end{array}$ & $\begin{array}{c}\text { Invertir grandes cantidades de energía para } \\
\text { hacer las cosas bien; intentar, fallar e intentar } \\
\text { de nuevo }\end{array}$ & $\begin{array}{l}\text { Tener la confianza necesaria para tomar el } \\
\text { liderazgo y dirigir el cambio }\end{array}$ \\
\hline
\end{tabular}

Fuente: Deloitte, Elaboración propia

A medida que la transformación digital va a avanzando es necesario que este nuevo líder disruptivo sea identificado en las organizaciones dentro de los mandos medios y más jóvenes para que puedan ser formados y capacitados. Para lo cual Deloitte plantea los siguientes puntos de inicio:

- Rediseñar el modelo de liderazgo de la organización: Incluir la innovación, crecimiento, inclusión, trabajo en equipo y colaboración.

- Identificar a los posibles líderes digitales de la organización: Identificar a los futuros inversionistas, pioneros y transformadores, luego capacitarlos.

- Asegurar la entrega de cuentas: Tener al equipo responsable ante el consejo y sean parte de la estrategia del negocio.

- Promueve a gente joven hacia el liderazgo más rápido: Dar oportunidad de liderar a gente joven con el apoyo de sus líderes senior y de la misma forma buscar que la gente joven enseñe a los líderes senior sobre tecnología, trabajo y cultura actual. 
- Fomentar la toma de riesgos y la experimentación mediante estrategias de liderazgo: las organizaciones deben crear programas interdisciplinarios enfocados en innovar, toma de riesgos y experimentación, en medida que desarrollen nuevas habilidades.

- Ve más allá del entrenamiento tradicional del liderazgo: Integrar liderazgo, nuevas formas de cultura organizacional, empoderamiento, toma de riesgos, intercambio de conocimientos, exposición, gestión matricial y formación de talento. Asimismo, buscar líderes externos para cambiar los viejos enfoques tradicionalistas de liderazgo.

\subsection{Transformación digital}

Para entender sobre la transformación digital, se expondrá en detalle como ha venido desarrollándose, en qué medida afecta a las compañías en los distintos sectores y las claves del éxito para la transformación digital.

La era de la transformación digital o como algunos la llamarían la cuarta revolución industrial, está tomando cada vez más relevancia. No solo se trata de tener un mejor hardware o software para la empresa, implica todo un proceso de cambio que debe iniciar por las cabezas de las compañías y con ello una conversión mental del equipo humano que tienen a cargo. Para realizar la transformación digital las empresas están enfocándose en dos objetivos, mientras las que se dedican al sector Retail, Banca y Seguros tienen un enfoque impulsado por el cliente (interno y externo) o usuario de sus servicios y/o productos. Por otro lado, las industrias de Minería y Petróleo se enfocan en la transformación digital para reducir sus procesos. Cabe resaltar que mientras más se demoren en darse o comprender estos cambios las empresas estarían destinadas a desaparecer.

Según Deloitte el 42\% de los CEO de las empresas más importantes del mundo, consideran que la parte digital y la transformación es relevante. En el Perú solo el 52\% de las empresas buscan la transformación digital. Sin embargo, menos del 50\% tienen estrategias claras para ponerlo en marcha. Alejandra D' Angostino, socia de Capital Humano en Deloitte Perú, menciona que en la práctica las empresas peruanas adquieren herramientas tecnológicas, pero no saben aún aprovecharlas para incrementar la productividad del negocio. (Gestión, Applying Consulting: Una empresa sin transformación digital está condenada a morir. 
Gestión, 2017) El estudio de Deloitte menciona que el 52\% considera contar con líderes digitales dentro de la organización; sin embargo, solo el 7\% está desarrollando nuevos programas de liderazgo enfocados en gestión digital.

\subsubsection{Claves para la transformación digital}

Según Harvard Business Review (HBR) en su artículo "Las seis claves para que la transformación digital sea un éxito" precisa que las compañías necesitan una ruta de crecimiento más rentable. Asimismo, expone que a pesar de lo necesario que son estos cambios para el beneficio de las empresas, son pocas las que optado por realizarlas. Es así que la investigación realizada en el 2016, se descubrió que solo el 16\% de las empresas había tomado medidas para la transformación digital y en su investigación más reciente, a mediados del 2017, en base a empresas de todo el mundo, solo el $20 \%$ invirtió en la "reinvención digital". (Harvard Business Review, 2017) Por tal motivo, la investigación proporcionada por HBR nos permitirá entender las claves para que el cambio sea exitoso.

- Observe la turbulencia en el horizonte: Es primordial que las empresas puedan entender el impacto que genera en sus ganancias el no implementar medidas para poder competentes en un futuro no lejano. Si bien el sector tecnológico está 2.5 veces más ofensivas de estrategias digitales, los otros sectores entienden poco a poco el impacto que les causaría.

- Comprendan todos los riesgos, no solo las start ups: Las compañías tienen que ver a todos sus competidores como pares y no confiarse solo de los avances que da una start up si no de las que están optando por la reinvención digital, las cuales pueden tomar delantera.

- Haga un ataque doble en núcleo y diversificación: Dedicar la misma cantidad de tiempo y recursos al modelo actual del negocio como a sus otras opciones de negocios.

- Establezca un liderazgo para la transformación digital: Es básico que los líderes que estén a cargo de la transformación digital tengan claro las medidas que van a tomar para conducir las compañías a sus objetivos de transformación digital. 
- Priorice las jugadas comerciales centradas en la demanda: Los operadores tradicionales tienen mayor retorno cuando cambian su modelo de negocio a un modelo de plataforma. La encuesta realizada por HBR confirma el descubrimiento, puesto que si toman el modelo de plataforma como la principal prioridad 2,5 veces más.

- Experimentar con las últimas tecnologías: Es importante que las empresas entiendan las facetas del uso de tecnologías para poder emplear la correcta en su industria y por ende deben dominar cada generación tecnológica. Por lo cual no es posible pasar a ver inteligencia artificial si es que en un inicio no trataron lo básico como las redes sociales.

\subsection{Sector Seguros}

La Cámara Hondureña de Aseguradores (CAHDA) informa que el sector asegurador global cayó debido a la crisis mundial entre 2008 y 2009, con la crisis existente el sector, se contrajo en tamaño y en sofisticación. Mientras esto sucedía en los diversos continentes, solo Latinoamérica creció en penetración. Los principales mercados latinoamericanos son Brasil y México. (Cámara Homdureña de Aseuradores-CAHDA, 2016) PWC España, en Insurance 2020: El futuro de las transacciones en el sector seguros, denomina al sector asegurador como un mercado en plena revolución silenciosa. El estudio señala tres desafíos que debe afrontar en los próximos años para lograr rentabilidad y eficiencia: uso de tecnología, pricing inteligente y los cambios demográficos. (PWC, 2016)

Según Ratings PCR, en su último informe anual del Sector Seguros, Perú es uno de los Países con menor cobertura en la región. Tiene un nivel de penetración de 1.8\%, menor al promedio de $2.86 \%$. Las cifras son preocupantes, pero también significa que hay poca expansión en los nichos de mercado no explotados y oportunidades de crecimiento. Al cierre del 2017, el sector de seguros peruano está conformado por 21 empresas, de las cuales 5 se dedican a ramos generales y de vida, 8 a ramos generales y 8 a ramos de vida. (PWC, 2016)

Según APESEG en la actualidad las empresas con mayor participación de mercado en la Industria de Seguros son Rimac, Pacifico, Mapfre y La Positiva quienes actualmente están implementado el área de transformación digital antes las necesidades que estarán afrontando a un corto plazo. Son las que presentan mayor potencial para el desarrollo de estrategias 
digitales en beneficio de sus clientes, los cuales buscan una relación más cercana y eficiente con sus compañías de seguro.

En los siguientes gráficos se podrá observar los rankings acumulados de los ramos generales y vida de las cuatro compañías de seguros con mayor participación del mercado. La información proporcionada por APESEG fue recopilada y proyectada desde el 2012 hasta el acumulado de octubre del 2017. En cuanto al ramo Generales no se ve cambios en las tendencias de participación, mientras que el ramo Vida es el que ha tenido variaciones y una fuerte competencia por parte de Mpafre y La Positiva.

Figura 2. Primas acumuladas de seguros netas - Ramos generales

\section{Ranking de Primas Acumuladas de Seguros Netas de Ramos} Generales (Al 31 de Oct. 2017)

\begin{tabular}{|c|c|c|c|c|c|}
\hline $40 \%$ & $40 \%$ & $39 \%$ & $39 \%$ & $37 \%$ & \\
\hline $27 \%$ & $27 \%$ & $26 \%$ & $23 \%$ & $25 \%$ & $25 \%$ \\
\hline $15 \%$ & $15 \%$ & $15 \%$ & $17 \%$ & $18 \%$ & $18 \%$ \\
\hline $14 \%$ & $12 \%$ & $14 \%$ & $14 \%$ & $13 \%$ & $15 \%$ \\
\hline 2012 & 2013 & 2014 & 2015 & 2016 & oct-17 \\
\hline
\end{tabular}

Fuentes: Apeseg

Elaboración propia 
Figura 3. Primas acumuladas de seguros netas - Ramos de vida
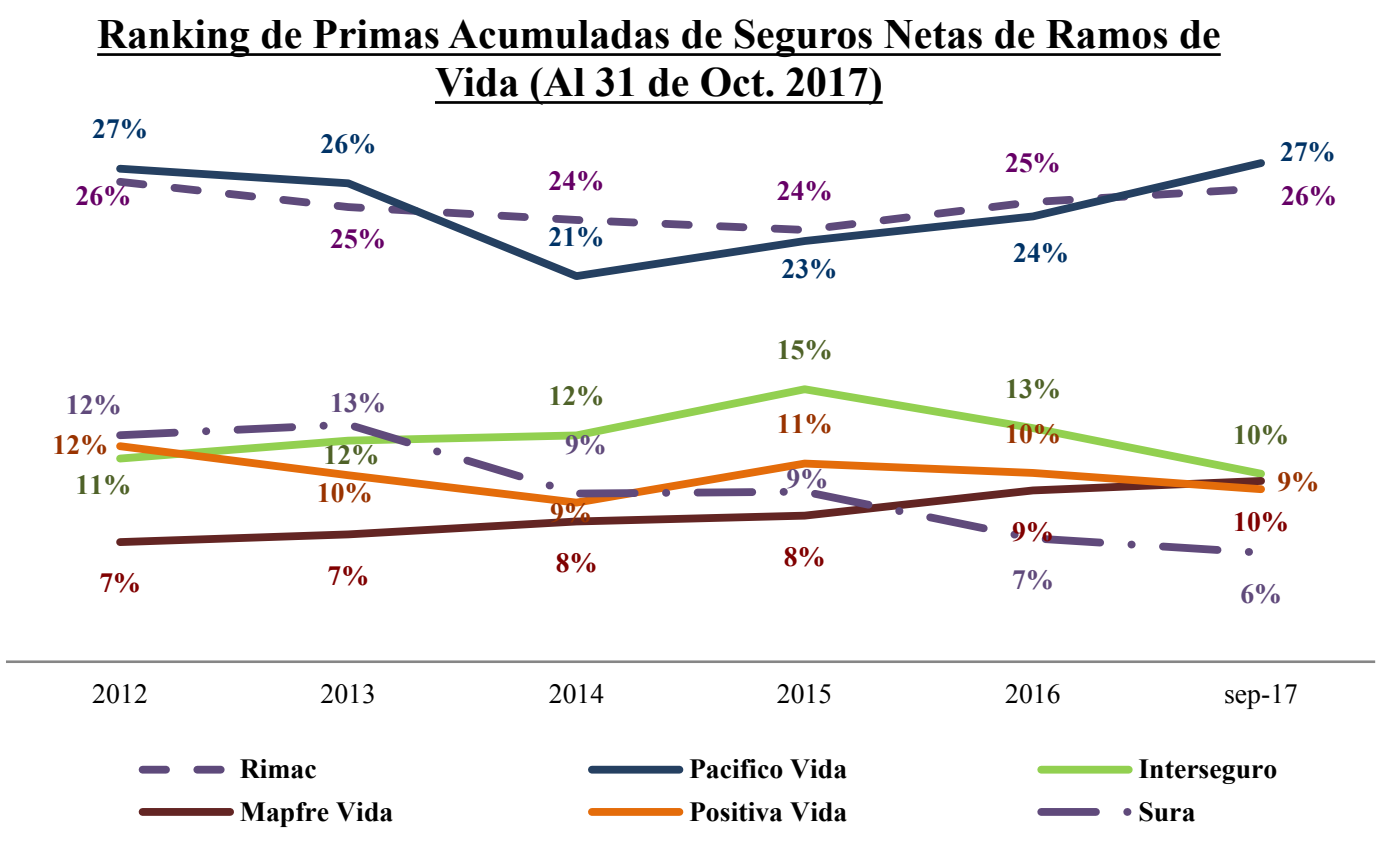

Fuente: Apeseg

Elaboración propia

\subsubsection{La transformación digital en el sector seguro}

(Falcon, 2015)La industria de seguros es uno de los sectores que está invirtiendo recursos en Transformación digital, impulsada por los clientes que cada vez se encuentran con mayores expectativas sobre los servicios que contratan y el alcance de información a la que tienen acceso. Sin embargo, según Gestión, el uso de información sobre los usuarios no está siendo muy bien desarrollada por parte de las empresas de Seguros, dejando una gran oportunidad de desarrollo. Everis Perú, presenta qué oportunidades tienen las empresas de seguros para poder desarrollarse en el tema de transformación digital:

- Social Media: La transformación de la experiencia del cliente, la conversación social para el diseño de nuevos productos y crear diferenciación con atributos emotivos.

- Omnicanalidad: Alcance de la información completa que es necesaria por los usuarios a la palma de sus manos como la compañía, productos, servicios, costos, prestadores del servicio, etc. 
- Analytics: Las compañías deben ser capaces de realizar análisis avanzados de las bases de datos que manejan, lo que les dará una ventaja competitiva de donde saldrán estrategias de fidelización, retención y crecimiento.

Para todo lo antes mencionado es necesario que se tenga un capital humano que empuje estás ideas y lideren equipos de gran impacto para las organizaciones. Además, de la información justificada en el sector de seguros, hemos considerado elegir a la industria de seguros debido a los siguientes puntos:

- A nivel mundial es una industria líder, mientras que en América es una industria en crecimiento y que está invirtiendo en Transformación digital para una mejor relación con sus clientes.

- Es la segunda industria luego del Sector Banca que está realizando innovaciones tecnológicas en el Perú enfocado a tener mejor relaciones y experiencia con sus clientes.

- El factor contactos de información también es un punto relevante para la selección de esta industria y poder obtener información estratégica por parte de las empresas que lideran el mercado.

- Finalmente, tener la mayor parte del mercado en 4 empresas líderes fue importante para tener un mejor alcance y una muestra más compacta en la investigación. 


\section{Capítulo 2. Plan de investigación}

\subsection{Problema}

Planteamiento del problema: ¿Existen en el mercado Millennials con las competencias requeridas para el futuro líder disruptivo que logre la transformación digital en las compañías de seguro en Lima metropolitana?

La transformación digital ha traído consigo una serie de cambios que no están siendo tratados con la relevancia debida por parte de las empresas. Según estadísticas presentadas en Gestión, un 50\% de las empresas están conscientes del cambio, pero solo el $7 \%$ de las empresas en el Perú están realizando una transformación digital eficiente. Algunas de las causas que podrían estar generando este mínimo porcentaje de éxito es que las cabezas de las compañías no lo ven como uno los principales objetivos a cumplir dentro de su organización o visualizan como un gasto y no como una inversión, estas empresas están destinadas al fracaso o a desaparecer. En el Perú, la industria de seguros es una de las que posee mayor avance en temas de transformación digital, impulsada por la necesidad de sus clientes o por decisiones internas. Además de ser una de las industrias con mayor información de sus clientes para poder ser usada como beneficio para el desarrollo de la compañía. (Falcon, 2015) En el capítulo I en el punto 1.5 se justificó la elección del sector de seguros basados en los siguientes puntos:

- A nivel mundial es una industria líder, mientras que en América es una industria en crecimiento y que está invirtiendo en Transformación digital para una mejor relación con sus clientes.

- Es la segunda industria luego del Sector Banca que está realizando innovaciones tecnológicas en el Perú enfocado a tener mejor relaciones y experiencia con sus clientes.

- El factor contactos de información también es un punto relevante para la selección de esta industria y poder obtener información estratégica por parte de las empresas que lideran el mercado. 
- Finalmente, tener la mayor parte del mercado en 4 empresas líderes fue importante para tener un mejor alcance y una muestra más compacta en la investigación.

Es por ello, que encontramos importante realizar el estudio acerca de la transformación digital en las compañías de seguros de Lima Metropolitana.

El problema principal que se presentan en nuestra investigación es que no se ha identificado si en el mercado laboral existen Millennials con las competencias necesarias para que sean formados y capacitados como los futuros líderes disruptivos de la transformación digital en las compañías de seguro de Lima metropolitana y logren los objetivos de las organizaciones ante los cambios tan acelerado que atraviesa la industria. Por lo cual, hemos identificado el estudio elaborado por Institute for the future, el cual plantea en su informe Future Work Skills 2020, 10 competencias claves para el futuro colaborador. Así como el estudio "Trabajo 3.0"de la revista "Semana Económica" donde mencionan el cambio de las competencias requeridas para que los futuros profesionales afronten la transformación digital en el entorno peruano. Ambos estudios mencionan las competencias requeridas, el primero basado en un contexto global y el segundo en el contexto peruano, por tal motivo la presente investigación tendrá como referencia el estudio de Semana Económica.

El problema está compuesto por dos etapas, el primero es identificar si se tienen millennials con las competencias necesarias para afrontar la transformación digital en las compañías de seguro de Lima metropolitana, lo cual será validado con una encuesta que valida el cumplimiento de cada una de las nueve competencias expuestas por el estudio de Semana Económica. En una segunda etapa se usará el estudio de Deloitte "Reescribiendo las reglas para la era digital" - Tendencias del Capital Humano 2017 para validar la formación de un futuro líder disruptivo en trasformación digital, debido a que lo resaltante de este estudio es que para afrontar la transformación digital se requiere formar 3 tipo de líderes disruptivos para afrontar los cambios a largo plazo en las compañías, pioneros digitales, transformadores digitales e inversionistas digitales. Para nuestro estudio será importante validar que las competencias que se tienen en semana económica son válidas con las características expuestas por Deloitte para formar a un futuro líder disruptivo. En adición se busca validar 
que las compañías de seguro encuentren futuros líderes en el mercado para poder afrontar la transformación digital de una manera exitosa.

\subsection{Objetivos}

\subsubsection{Objetivo principal}

Analizar si en el mercado laboral existe Millennials con las competencias requeridas para convertirse en el futuro líder disruptivo que permita la transformación digital y cubra las necesidades de las compañías de seguros de Lima Metropolitana.

\subsubsection{Objetivos Específicos}

- Analizar si las compañías de Seguro de Lima metropolitana solicitan perfiles con las competencias identificadas como el futuro ideal Millennials laboral, según el estudio realizado por Semana económica.

- Identificar si en el mercado laboral de Lima se cuenta con Millennials que cumplan con el perfil para contribuir con la transformación digital. 


\section{Capítulo 3. Metodología de trabajo}

El capítulo tres tiene como objetivo presentar las herramientas que se han usado para el desarrollo de la investigación de la presente tesis, en donde se presentara el diseño de investigación, diseño de muestra y la metodología de prueba de hipótesis.

\subsection{Diseño de Investigación:}

La Tesis se dividió en dos etapas: Investigación Exploratoria para validar las necesidades de personal que tienen las empresas del sector de seguros en Lima Metropolitana y la Investigación Descriptiva para validar si los Millennials cumplen con las competencias que las empresas están buscando.

Figura 4. Diseño de investigación

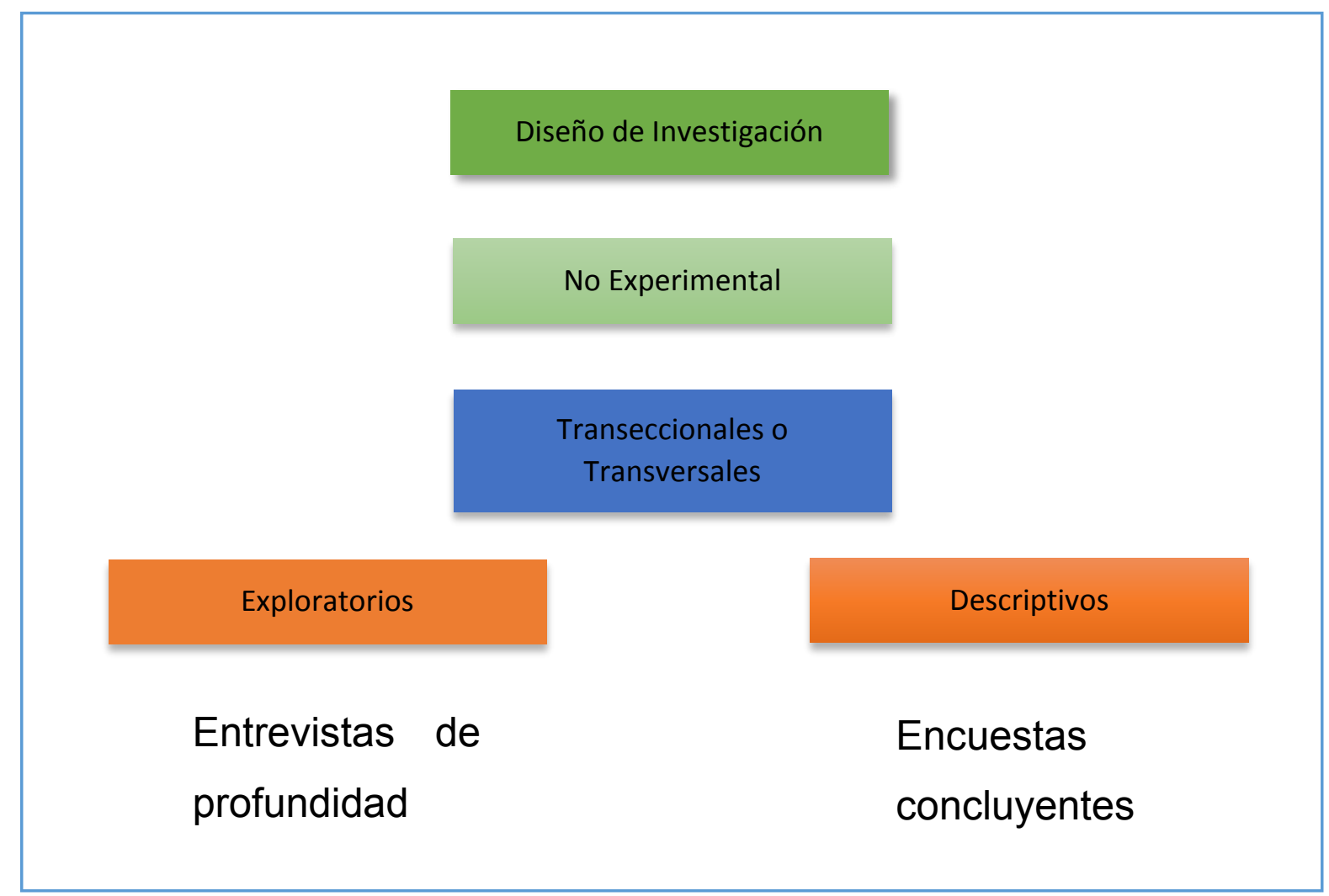

Elaboración propia 


\subsubsection{Investigación Exploratoria}

La investigación exploratoria es la primera parte de nuestro diseño de Investigación, este tipo de investigación nos permite revisar temas con poca investigación y tiene como objetivo proporcionar ideas y comprensión. Además, se caracteriza por la flexibilidad y versatilidad de sus métodos, porque no se emplean protocolos y procedimientos de la investigación formal, posee muestra pequeña y no representativa y la información se define en forma muy aproximada. (Malhorta, 2008)

\subsubsection{Entrevistas de Profundidad}

Para poder validar nuestra hipótesis se realizó entrevistas de profundidad a las áreas de Recursos Humanos de las 4 empresas de seguro con mayor porcentaje de participación de mercado en el Perú (Pacífico, Rimac, Mapfre y la Positiva). Basado en preguntas (Ver Anexo 1) que tienen como principal objetivo identificar si las competencias que buscan las empresas en los candidatos, para formar el equipo de Transformación digital, cumplen con las competencias para convertirse en Líderes Disruptivos y afrontar el cambio. Estos resultados serán comparados con el estudio "Competencias Laborales” de la edición Trabajo 3.02016 de la revista "Semana Económica". En complemento se realizaron preguntas que ayudan a identificar como se generó este cambio en sus empresas, identificar el compromiso que tienen las empresas para la Transformación digital, como afrontar el cambio y saber si las estrategias de la empresa son sensibles a este nuevo cambio y forma de trabajo.

\subsubsection{Investigación Descriptiva}

La investigación descriptiva es un tipo de Investigación Transversal que tiene como objetivo principal la descripción de algo, generalmente las características o funciones del mercado. (Malhorta, 2008) Como características principales tiene:

- Describir las características más importantes de los grupos como son los consumidores o áreas de mercado.

- Por lo general se basa en gran cantidad de muestra representativa.

- Diseño previamente planeado y estructurado. 


\subsubsection{Encuesta Concluyente}

Como segunda etapa de nuestra investigación se realizó una investigación descriptiva para validar nuestra hipótesis y verificar si en el mercado laboral los Millennials cumplen con las competencias para convertirse en líderes para la transformación digital (Ver Anexo 2). En el cuestionario, se realizaron preguntas en base a casos y definiciones para identificar si los futuros líderes en transformación digital, tienen conocimiento de las competencias que deberían tener para afrontar los futuros cambios que se presenten en el mercado laboral de las empresas que están realizando el proceso de Transformación digital. Como información complementaria, dentro del formulario se busca identificar cuáles son las industrias preferidas por los Millennials, cuánto tiempo trabajan en una empresa y que es lo que más los motiva en su centro de labores, entre otras cuestiones.

La encuesta aplicada fue una elaboración propia basándonos en los estudios realizados por Semana económica para poder validar las competencias expuestas como objetivo principal de este instrumento. En adición se realizaron preguntas complementarias para poder realizar análisis a profundidad de los resultados basándonos en los siguientes puntos:

- Género

- Nivel de estudios

- Edad

- Tiempo de permanencia en su centro de labores

- Motivos de cambio de centro de labores

- Beneficios que lo motivan en su centro de labores

- Procesos de selección en participación

- Situación laboral

- Motivos de rechazo de ofertas laborales

- Industria de trabajo e Industria deseada 
Para la validación de la encuesta, se realizaron pruebas con 3 personas elegidas aleatoriamente en distintas etapas. Por cada ajuste en la encuesta solicitada por MBA Ana Elena Del Carmen Senmache Sarmiento experta en el tema y la validación, se realizó una prueba externa con un usuario aleatorio para poder obtener retroalimentación sobre la claridad de cada pregunta, se tuvo 3 ajustes y 3 formatos de encuesta de prieba. Realizar la validación de la encuesta con el experto tuvo las siguientes ventajas y desventajas:

- Se definió la manera correcta para poder realizar preguntas adecuadas que sustenten el cumplimiento de cada competencia.

- Se aplicaron mayores variables que permitieron realizar mejor análisis del mercado laboral y poder tener búsquedas más estratificadas.

- Se realizó la manera correcta de tener las respuestas en la escala más adecuada, en un inicio se hizo todo el cuestionario con escala ordinal, lo cual no era lo más apropiado para el análisis.

- Como principal desventaja, se tuvo muy pocas validaciones con usuarios finales y expertos antes de aplicar la encuesta, sujeto al tiempo estipulado en el plan de trabajo.

Para la aplicación de la encuesta, se utilizó medios virtuales como redes sociales en las que se podía encontrar de manera concentrada al público objetivo pues existen grupos de interés común como las redes de Linkedin o Facebook

\subsection{Diseño de la Muestra}

\subsubsection{Población Millennials}

Para la elaboración de la muestra se delimitó la población de Millennials en Lima Metropolitana, la cual se obtuvo del estudio de IPSOS - "Perfil del Adulto Joven" (21 a 35 años) Generación "Y" o Millennials 2016. El estudio cuenta con información de población total de Lima Metropolitana de 9, 893, 245 personas y la población de jóvenes de 21 a 35 años, 26\% de la población de Lima Metropolitana, 2, 576, 688 personas. 


\subsubsection{Muestra resultante}

Para el cálculo de nuestro modelo de muestra, se delimitó que los encuestados deberían cumplir con un nivel de Estudio Superior Universitario Incompleta - Completa, correspondiente al $19 \%$ de la población de jóvenes entre 21 a 35 años de Lima Metropolitana, la cual resulta ser 489570 personas. Se delimita en Universitario incompleta y completa, porque son los que presentan mayor oportunidad para poder tener una línea de carrera y formen parte de los ejecutivos de altos rangos dentro las compañías de Seguros. Adicionalmente, es uno de los focos que tienen establecidos las cuatro empresas entrevistas.

A continuación, realizaremos el cálculo de la muestra representativa:

\begin{tabular}{|l|l|}
\hline Edad & $21-35$ \\
\hline Género & Indistinto \\
\hline Ubicación & Lima Metropolitana \\
\hline $\begin{array}{l}\text { Nivel de } \\
\text { Estudios }\end{array}$ & $\begin{array}{l}\text { Universitario } \\
\text { incompleta y completa }\end{array}$ \\
\hline
\end{tabular}

\section{Fórmula de la Muestra:}

$n=\frac{N \cdot\left(Z^{2}\right) \cdot\left(E^{2}\right)}{(N-1) E^{2}+Z^{\wedge} 2\left(E^{2}\right)}$

\section{$Z=$ Nivel de Confianza, $N=$ Población, $E=$ Margen de error}

\section{Cálculo:}

$\mathrm{Z}=\mathbf{1 . 9 6}$

$\mathrm{N}=489570$

$\mathbf{E}=$

$n=\frac{489570 \cdot\left(1.96^{2}\right) \cdot\left(0.05^{2}\right)}{(489570-1) 0.05^{2}+1.96^{\wedge} 2\left(0.05^{2}\right)}$

$n=383$

Después de delimitar nuestra población, el cálculo de nuestra muestra representativa, con un margen de error del 5\%, es de 383 personas. Número base que tomaremos para realizar 
nuestra encuesta de Millennials, será el mínimo que se deberá obtener para que la prueba de hipótesis sea aprobada o desaprobada.

\subsection{Metodología de prueba de hipótesis}

Para la validación de nuestra hipótesis hemos realizado la prueba de Chi Cuadrado de Pearson ya que permite determinar la relación entre dos variables, o si existe dependencia estadística entre ellas. Para nuestro análisis tenemos las variables de acierto por competencias tanto por la Industria de seguros y por los Millennials encuestados. (Hernández, S. R., \& Fernández, C. C., 2014)

Además, para realizar la prueba de Chi cuadrado hemos identificado el siguiente diagrama:

Figura 5. Datos no paramétricos

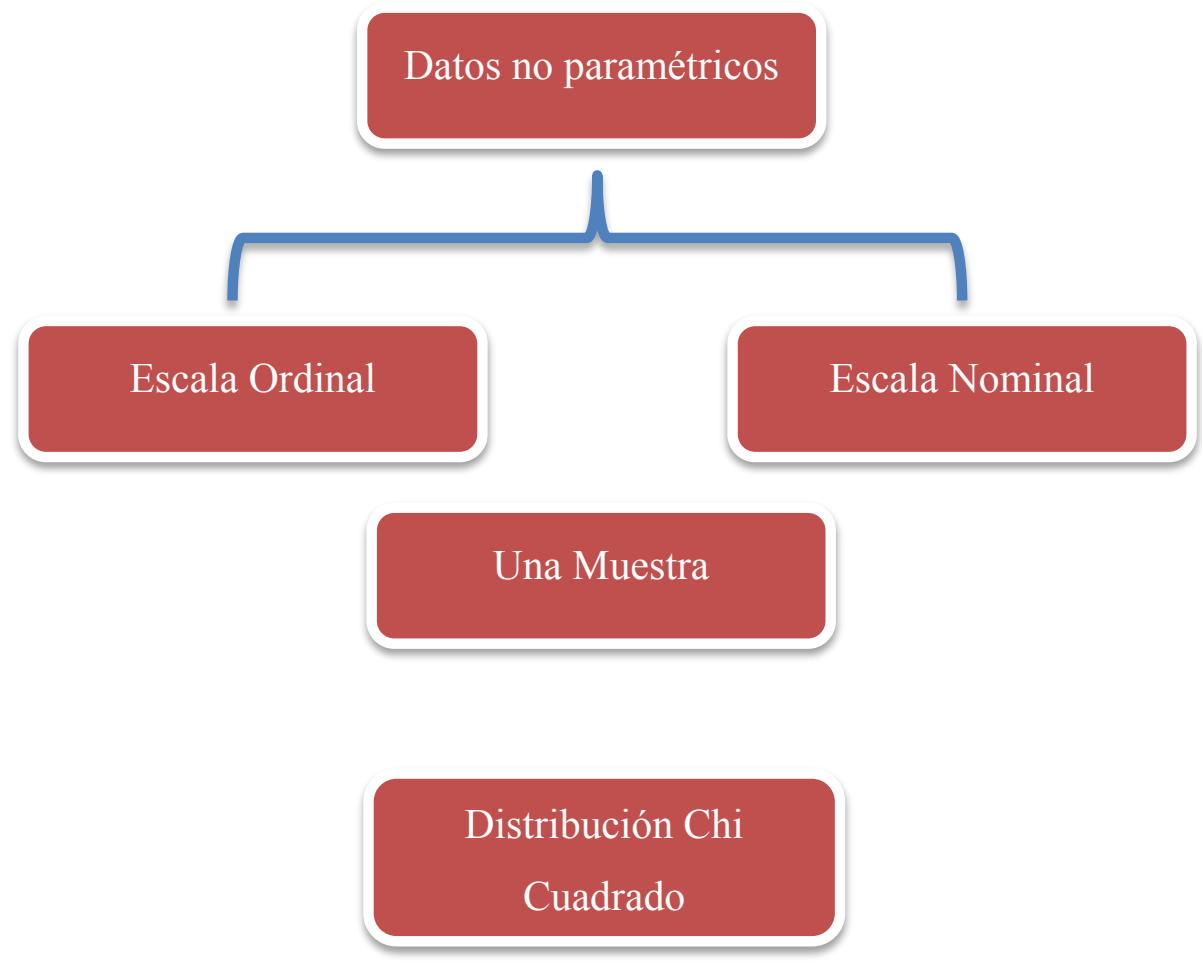

Fuente: Naresh K.M. 2008

Elaboración propia 


\section{Capítulo 4. Desarrollo}

\subsection{Desarrollo de la hipótesis}

\subsubsection{Hipótesis}

En el mercado laboral no existen Millennials con las competencias requeridas para el futuro líder disruptivo que permita alcanzar la transformación digital y cubrir las necesidades de las compañías de seguros en Lima Metropolitana.

Para la evaluación y validación de nuestra hipótesis utilizaremos la Distribución Chi Cuadrado Debido a que esta prueba estadística sirve para comparar frecuencias observadas (frecuencias obtenidas en un experimento o muestreo)

Definición de Variables

X1: Porcentaje de competencias por encuestado de Millennials de Lima Metropolitana.

X2: Porcentaje de competencias por entrevistas a empresas del sector Seguros de Lima Metropolitana.

\subsubsection{Definición de Hipótesis}

H0: En el mercado laboral si existen Millennials con las competencias requeridas para el futuro líder disruptivo que permita alcanzar la transformación digital y cubrir las necesidades de las compañías de seguros en Lima Metropolitana.

H1: En el mercado laboral no existen Millennials con las competencias requeridas para el futuro líder disruptivo para alcanzar la transformación digital y cubrir las necesidades de las compañías de seguros en Lima Metropolitana.

\subsubsection{Desarrollo de entrevista}

\subsubsection{Rimac}

Entrevistado: Guillermo Gates, Coordinador de selección de Rimac

Puntos principales de la entrevista:

- Rimac es una empresa socialmente responsable. 
- La empresa busca dar un equilibrio de vida laboral a sus trabajadores con programas de días libres que no son vacaciones.

- La empresa tiene una visión global de los negocios y la idea de implementar cosas a nivel de tecnología, marketing, recursos humanos.

- Iniciativa de captar talento no solo peruano si no también extranjero y así ser una empresa más competitiva.

- Tener un enfoque con servicio al cliente, tanto externo como interno.

- Tener comunicación frecuente entre los colaboradores, para lo cual se tiene diversos canales de comunicación.

- Buscan la excelencia, ser líderes y mejorar siempre.

- Cuentan con un área que realiza algoritmos para poder predecir el comportamiento y necesidad de sus clientes.

- Cuentan con iniciativas como la Hackaton que busca que los participantes resuelvan problemas de la empresa a través de algoritmos, no tienen restricción de edad y se realiza en toda una noche.

- No se ha tenido un cambio de misión y visión a pesar de la iniciativa de transformación digital. Se han presentado cambios en la Gerencia General y cambio cultura (código de vestimenta)

- Las competencias de Rimac son las siguientes:

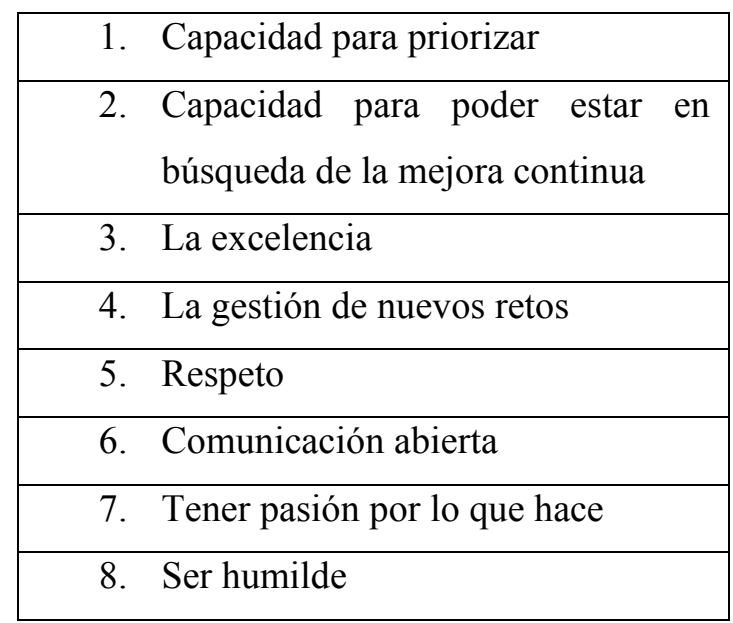


- Se han presentado casos de resistencia al cambio, a pesar de tener cuidado en no generar incertidumbre en los colaboradores.

- El cambio se ha generado de manera lenta; sin embargo, se tuvo salidas de colaboradores, cambios en la Gerencia General y Vicepresidencias.

- Para afrontar el cambio, Rimac fue muy abierto a la comunicación para reducir el miedo en sus colaboradores.

- Se cuenta con un plan de trabajo hasta el 2030, lo que genera estabilidad laboral en sus colaboradores.

- Los cambios fueron impulsados tanto por decisión de los altos directivos como por la necesidad del mercado. Rimac busca adaptarse a las necesidades de sus clientes.

- Actualmente el líder de todo este cambio es Fernando Ríos Sarmiento - VP Ejecutivo de Seguros Personales y Marketing Digital.

- El área de compensaciones ha elaborado una banda salarial diferente o rangos especiales para apostar por este nuevo talento.

\subsubsection{Mapfre}

Entrevistado: Pablo Trelles Valle Riestra, Coordinador de selección

Puntos principales de la entrevista:

- Mapfre posee una misión y visión alineada a los 5 continentes al ser una multinacional con prácticas que se realizan en la casa matriz de España.

- Mapfre vende confianza a sus clientes, pues probablemente el servicio que se vende nunca se use.

- Es la única aseguradora y reaseguradora, pues no pertenece a ningún grupo económico que lo respalde.

- Mapfre posee una cultura bien estructurada y jerárquica, debido al giro del negocio, aunque se busca cambiar la mentalidad de "la empresa extranjera que venden seguros en el país”. Se están tomando acciones de manera interna y se reflejen con sus clientes y generar confianza en ellos. 
- Se trata de tener los flujos de respuesta a sus clientes bien eficientes, que sean de manera rápida y claros

- Se ha implementado un canal de ventas por internet y teléfono que permite colocar 50 seguros en una hora (promedio)

- Se busca mantener las buenas prácticas realizadas en el Perú por todo el mundo donde este Mapfre, mantener una cultura Global.

- Se tienen oficinas virtuales desde donde se pueden visualizar los niveles de siniestralidad de sus trabajadores, usos de EPS y toda la información de cada colaborador.

- En cuanto a un cambio de misión y visión esta todo como proyecto, se realizan campañas internas, aunque sin poder revelarlo. Se están usando los canales virtuales de comunicación de la compañía para llegar a los colaboradores.

- Todo trabajador de Mapfre tiene inducciones y debe estar involucrado al giro del negocio, tienes que sentir tuyo la empresa y los objetivos organizacionales como personales.

- Las competencias para un colaborador de Mapfre son las siguientes:

\begin{tabular}{|rl|}
\hline 1. & Trabajar en equipo \\
\hline 2. & Relaciones Interpersonales \\
\hline 3. & Colaborativo \\
\hline 4. & Receptivo de feedback \\
\hline 5. & Capacidad de mejorar \\
\hline
\end{tabular}

- La persona que entra a Mapfre debe tener la tranquilidad que va aprender y hacer una línea de carrera.

- Ante la creación del canal digital, el perfil que se tenía era más frontal, ahora se busca personas con capacidad de dar unas respuestas más rápidas y que pueda solucionar un problema de manera diferente.

- El cambio es complicado, pero está en camino de lograrse. El cambio se realizó por decisión de los altos mandos gerenciales. 
- Se ha presentado resistencia mínima al cambio, pues existen áreas afectadas que han sido sacadas de su estatus QUO, pues consideran que ya tienen buenos resultados, pero no se percatan que podemos tener muchos mejores.

- La empresa tiene un plan de trabajo para poder evitar la resistencia al cambio, y se están reflejando los resultados, la empresa busca lo mejor para seguir creciendo y mejorar.

- La persona que está promoviendo este cambio es la directora Silvana Orizoli.

- Mapfre ofrece a sus colaboradores un buen ambiente de trabajo, beneficios, descuentos en productos de la empresa, días libres por eventos importantes para el colaborador, capacitaciones, viajes al exterior, personas con las que aprendes, programas de artes y darles vitrina a los jóvenes.

\subsubsection{Pacifico}

Entrevistado Martín Ferradas, Corporative recruitment chief

Puntos principales de la entrevista:

- Poseen un compromiso con sus clientes y es que no se empobrezca ante un caso fortuito.

- Tener un enfoque hacia los clientes, para ello se tiene los procesos y la parte tecnológica como factores clave en la compañía.

- Se trabaja mucho con mantener relaciones con clientes y bróker. Se realiza una segmentación más fina para identificar la demanda de sus negocios y ver el tipo de atención que se debe tener con cada uno y ofrecer una propuesta de valor.

- Se tiene un área que realiza analytics para identificar patrones de comportamiento de los clientes, para saber que necesitan y que soluciones les pueden ofrecer.

- Se tiene el área de digital que se encarga de mejorar los productos ofrecidos a los clientes y busca darles una mejor propuesta que la competencia.

- Para que un trabajador ingrese a Pacífico debe conocer la misión y visión de la empresa, pasar por inducción presencial y virtual. 
- Se realizan mensajes periódicos de la gerencia para mostrar los resultados de la compañía, nuevos retos orientados a la satisfacción del cliente y dar soluciones innovadoras.

- Como iniciativa de proyectos de transformación digital, se realizan concursos de ideas innovadoras donde parte del mismo concurso se comparte la metodología y se involucra a los colaboradores.

- Se buscan colaboradores que estén orientados al cliente, las relaciones interpersonales, trabajo en equipo, ser dinámicos, flexibles eficientes, que busquen resultados, orientados a la comunicación.

- Pacífico tiene 6 competencias las cuales son las siguientes.

\begin{tabular}{|rl|}
\hline 1. & Atención al cliente interno y externo \\
\hline 2. & Planificación y establecimiento de prioridades \\
\hline 3. & Toma de decisiones y solución de problemas \\
\hline 4. & Orientación a resultados \\
\hline 5. & Ética e integridad por la información \\
\hline 6. & Capacidad de equilibrio de la vida laboral \\
\hline
\end{tabular}

- Las competencias presentadas son previas a la transformación digital, a futuro se busca realizar un cambio en las competencias que necesite la empresa.

- Se tiene un área de transformación digital desde hace un año, que tiene como objetivo alinear la estrategia del negocio a la estrategia del área.

- Formar el equipo de transformación digital fue complicado debido a que no solo se buscó gente inteligente, si no que tenga visión distinta y que sea empático para captar clientes.

- En cuanto al cambio no se ha tenido mucha resistencia, debido a que se sigue manteniendo la satisfacción del cliente. No se ha dado un cambio total, pero se encuentra en proceso.

- Los colaboradores deben tener sensibilidad a las personas, resistencia al cambio, adoptar nuevas ideas, ser más disruptivos y receptivos. 


\subsubsection{La Positiva}

Entrevistada María Pía Insausti, Supervisora de selección

Puntos principales de la entrevista:

- Actualmente no se tiene una visión y misión actualizada a nivel corporativo, por lo que no se está valorando dentro de un perfil.

- Se tiene un perfil por competencias que se usa para la evaluación de desempeño y selección.

- Se tiene una cultura de puertas abiertas, comunicación horizontal entre todas las gerencias. Se está construyendo una cultura de innovación, creatividad y mejoras en procesos.

- Se tiene un área de transformación digital dentro de la gerencia de Marketing, cuenta con menos de dos años y ve todos los proyectos de transformación digital de la empresa, para este proceso se buscó gente creativa, innovadora, con alto nivel de pro actividad para hacer cambio y mejoras.

- En cuanto a las competencias que el entrevistado otorgo para la transformación digital son las siguientes:

\begin{tabular}{|rl|}
\hline 1. & Pensamiento analítico \\
\hline 2. & Pasión por las metas y los resultados \\
\hline 3. & Proactividad e iniciativa \\
\hline 4. & Foco en la experiencia del cliente \\
\hline 5. & Disposición a la transformación \\
\hline 6. & Desarrollo del conocimiento \\
\hline 7. & Comunicación efectiva \\
\hline 8. & Contribución en equipo \\
\hline 9. & Agudeza estratégica \\
\hline 10. & Desarrollo de equipos de alto desempeño \\
\hline
\end{tabular}

- Las exigencias de contar con un nuevo perfil vienen de las necesidades del mercado como por la Gerencia. 


\subsubsection{Desarrollo de encuesta}

La encuesta que se realizó de manera virtual y nos muestra los siguientes resultados:

Figura 6. Nivel de estudio

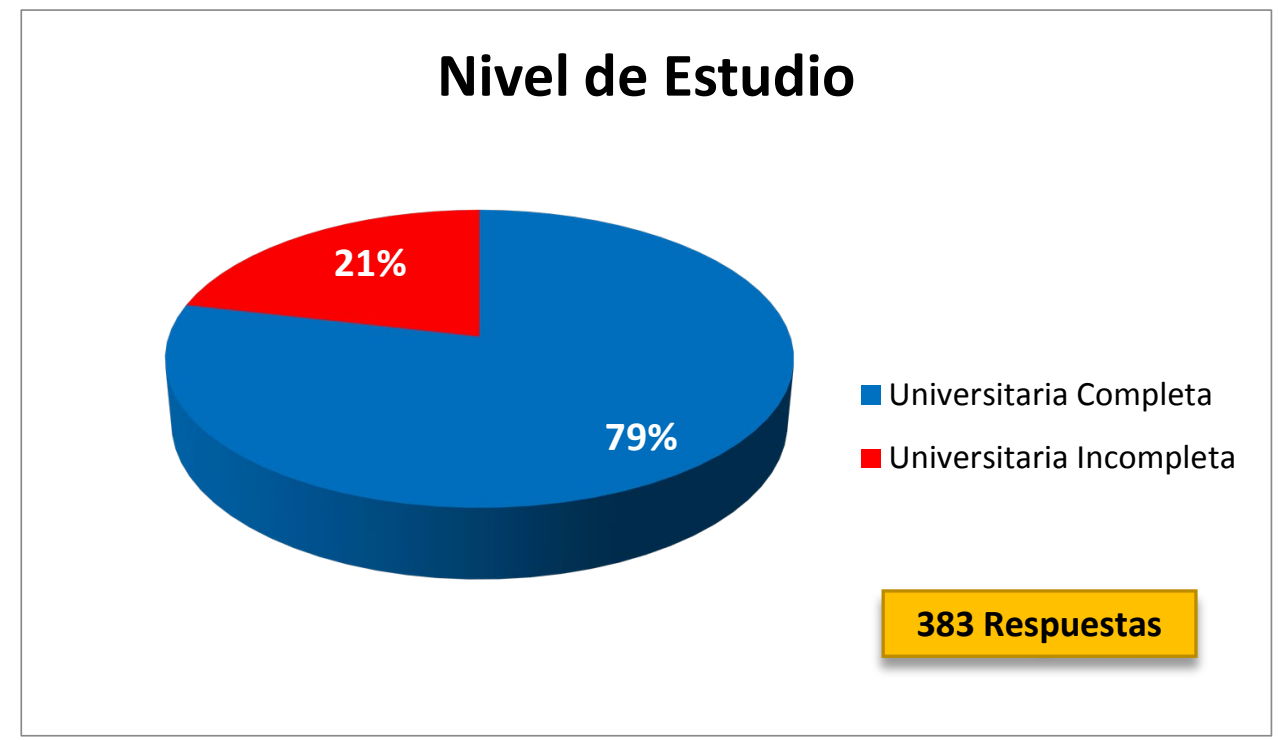

Elaboración propia

Figura 7. Situación laboral

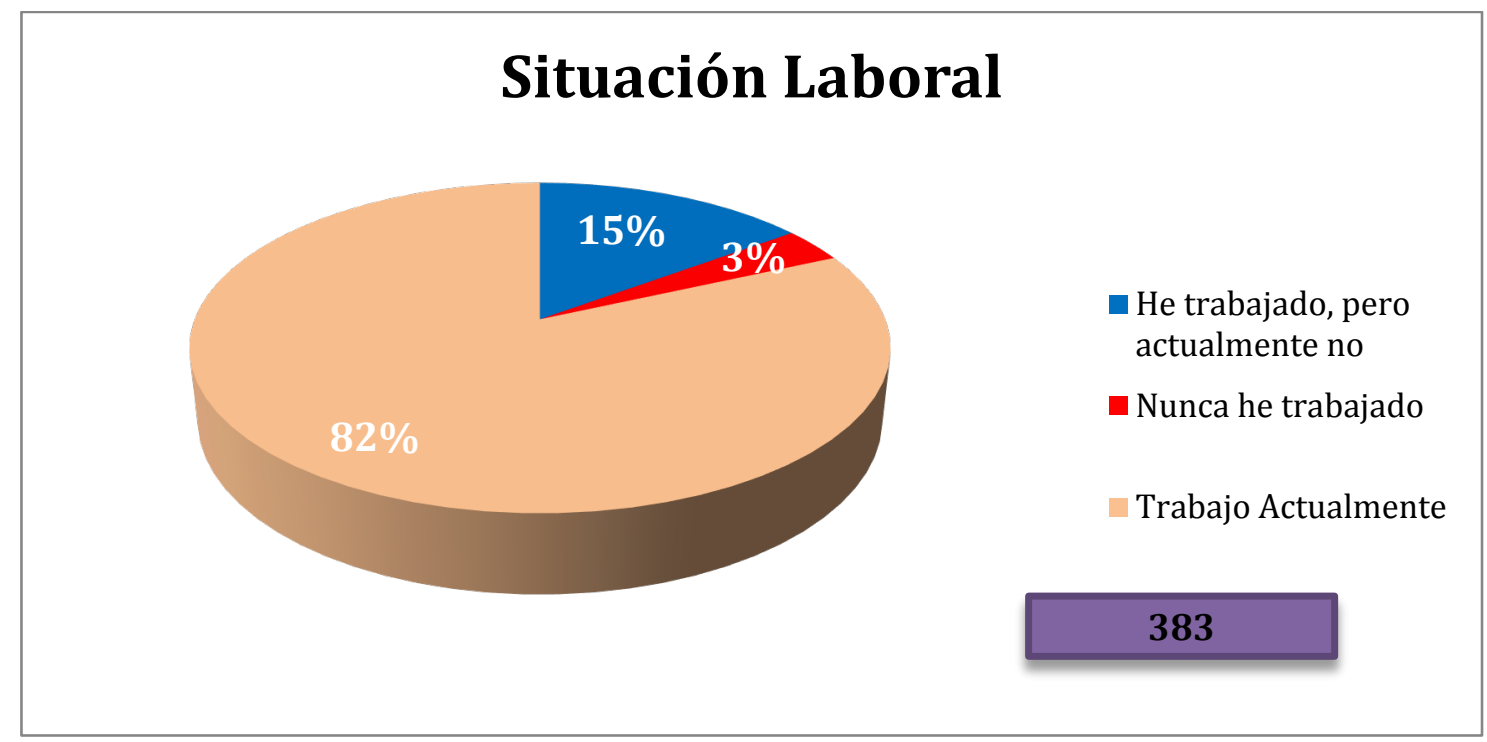

Elaboración Propia 
Figura 8. Principales industrias donde laboran los Millennials

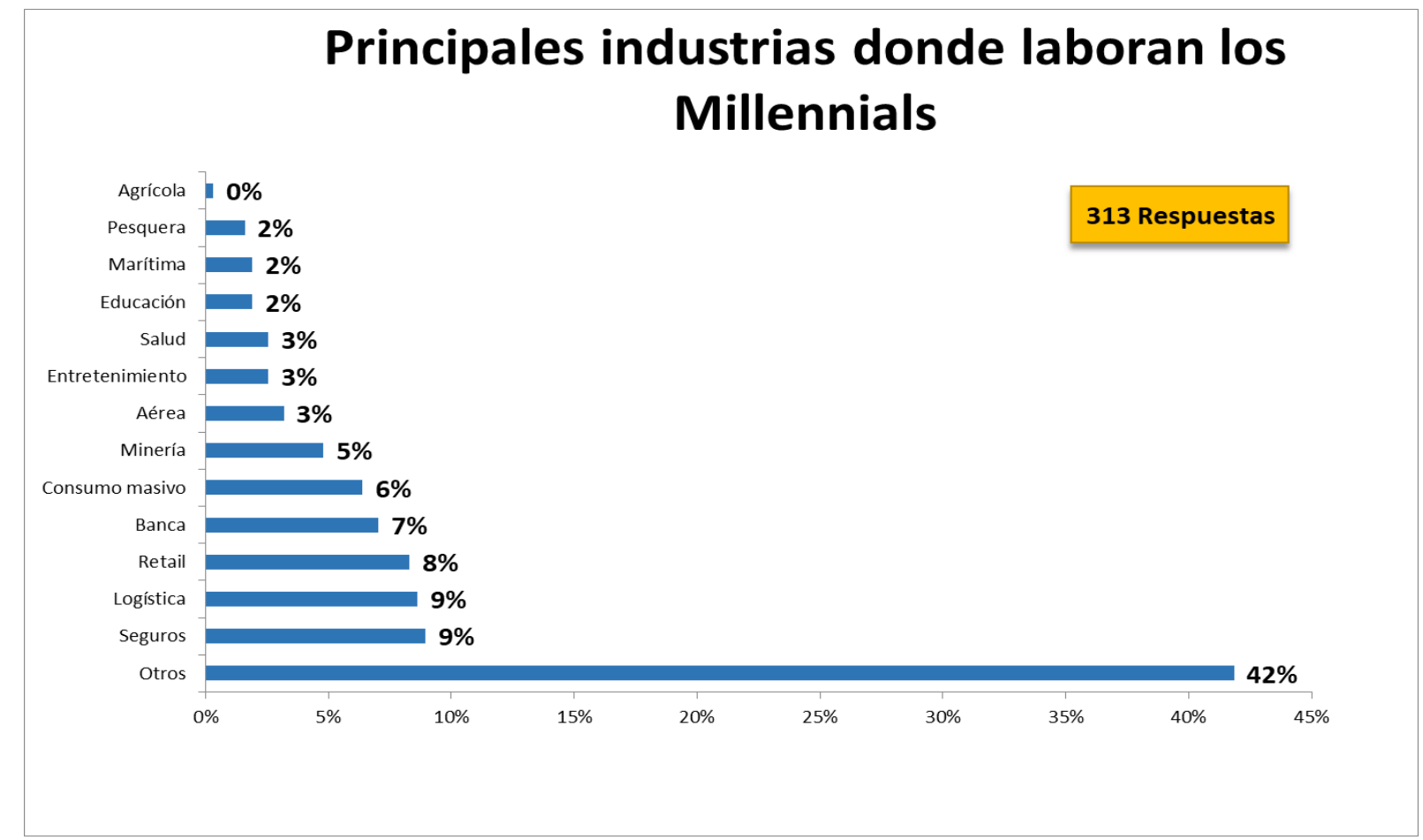

Elaboración propia

Considerar que el $42 \%$ de otros respondieron industrias muy variables

Figura 9. Millennials que se presentaron a un proceso de selección

\section{¿En el último año te has presentado en algún proceso de selección?}

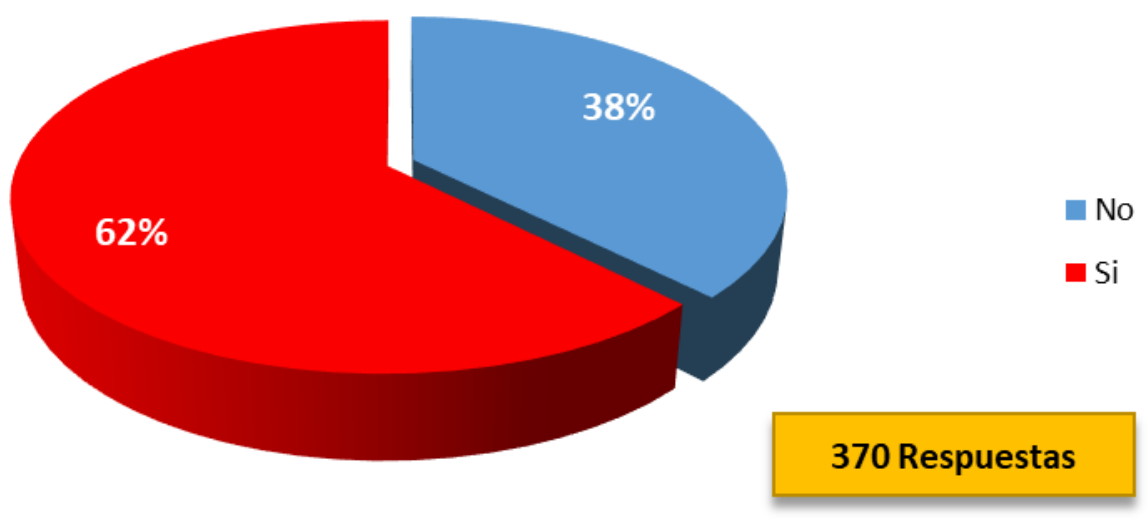

Elaboración Propia 
Figura 10. Rechazo de ofertas laborales de Millennials

\section{¿Has rechazado alguna oferta laboral en los últimos 6 meses?}

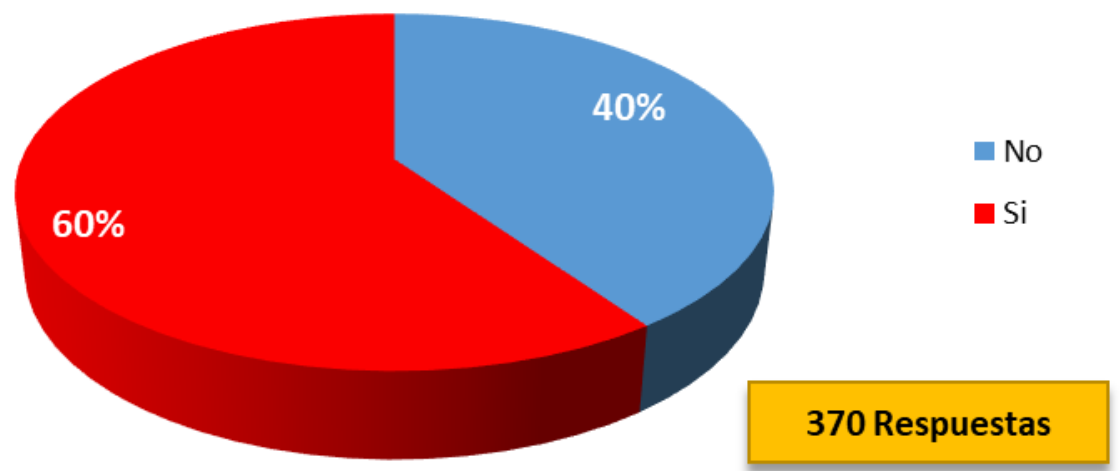

Elaboración propia

Figura 11. Razón de rechazo de la propuesta laboral

\section{¿Por qué rechazaste la propuesta laboral?}

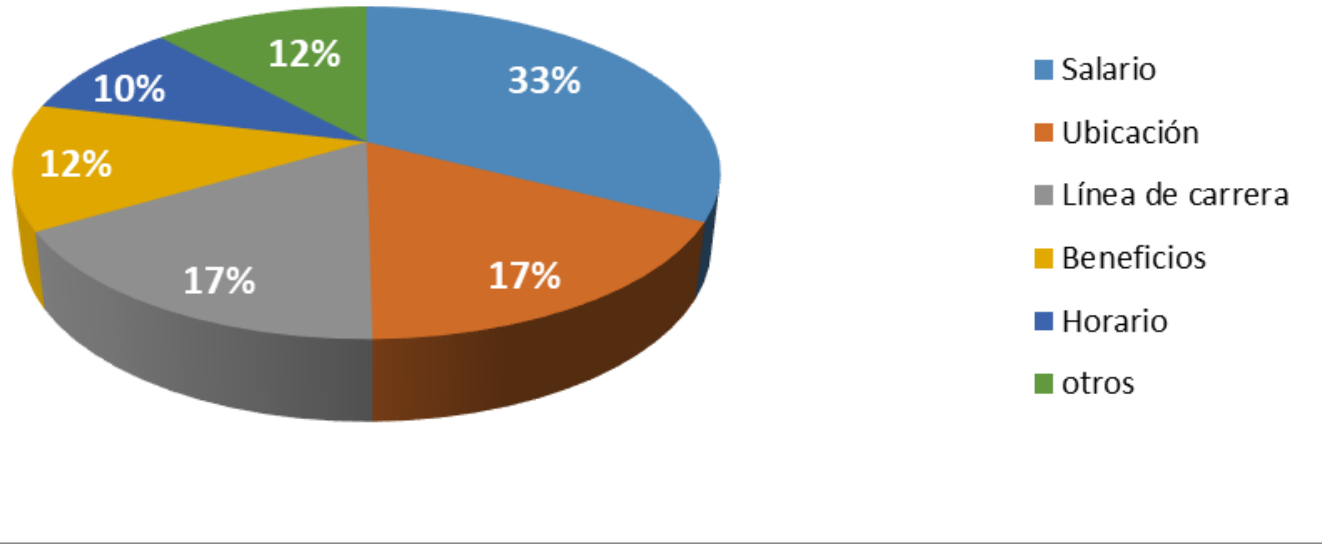

Elaboración propia

Considerar que de los 370 que laboraron o están laborando, 221 han rechazado una oferta laboral. 
Figura 12. Tiempo de permanencia de los Millennials en una empresa

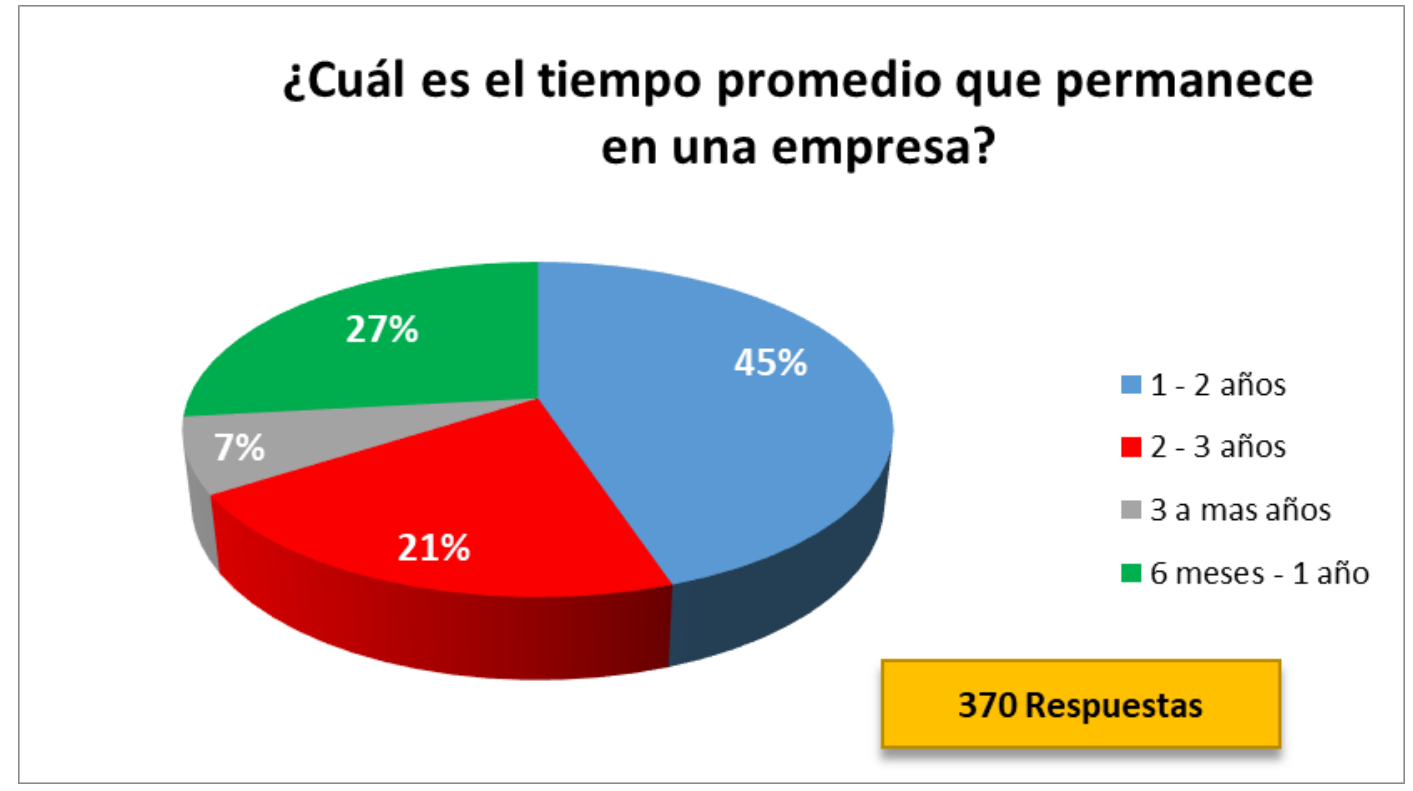

Elaboración propia

Figura 13. Motivo de cambio laboral

\section{¿Qué te motivó a realizar tu último cambio laboral?}

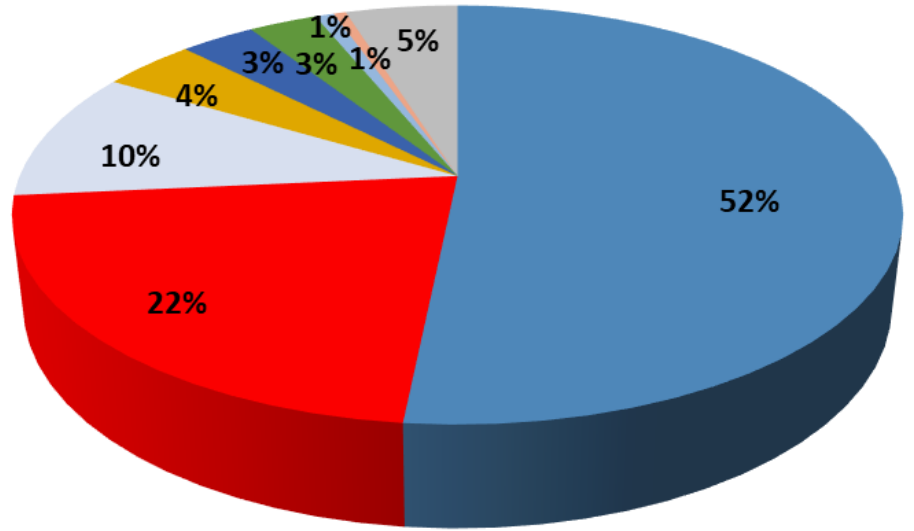

- Oportunidad de crecimiento

- Sueldo y beneficios

Falta de desafíos / proyectos

Falta de reconocimiento

- Reestructuración

- Conflicto con tu jefe

Estudios

Estudios en el extranjero

Otros

Elaboración propia 
Figura 14. Beneficios que motivan a un Millennials

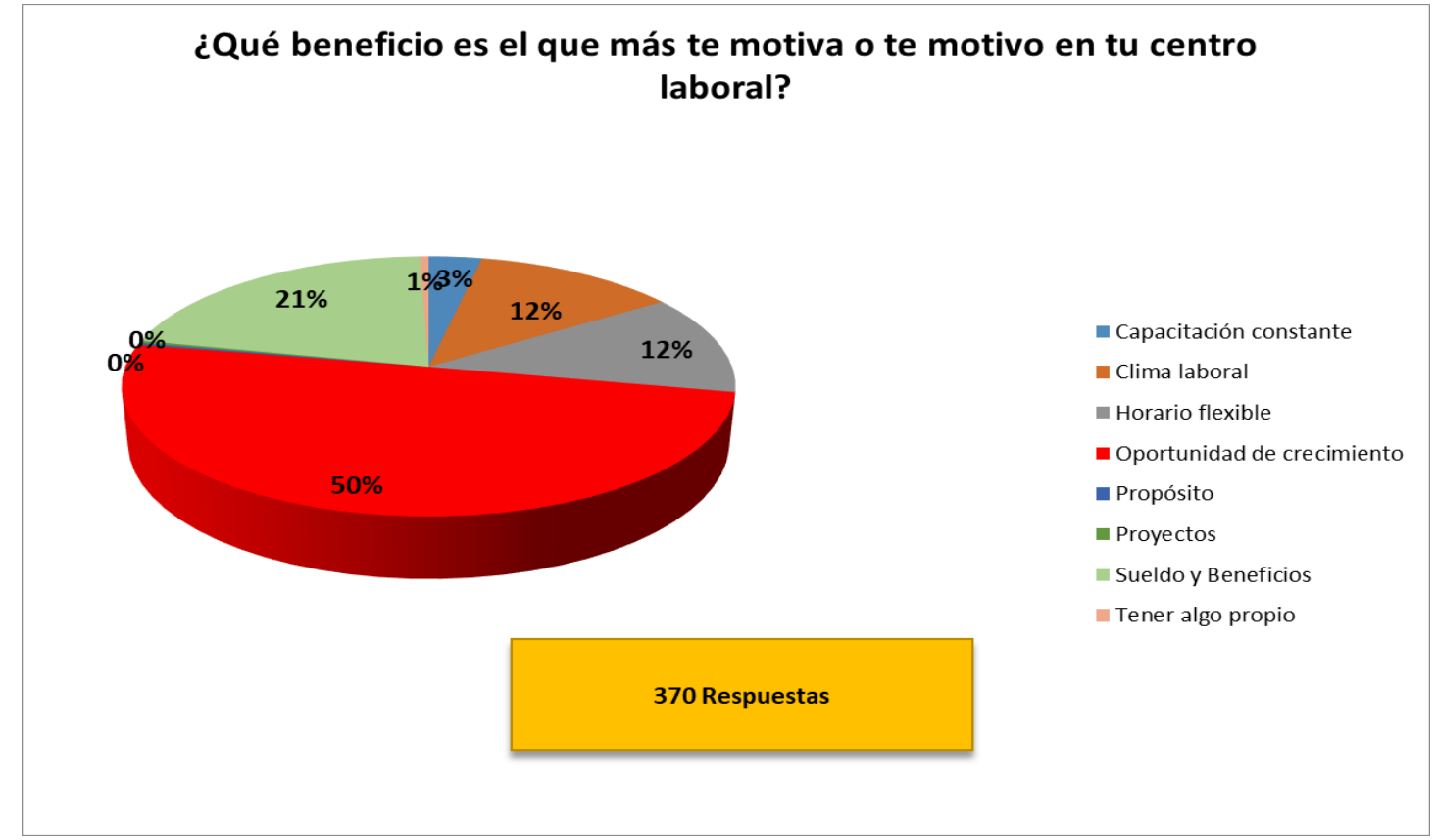

Elaboración propia

Figura 15. Industria que atrae a los Millennials

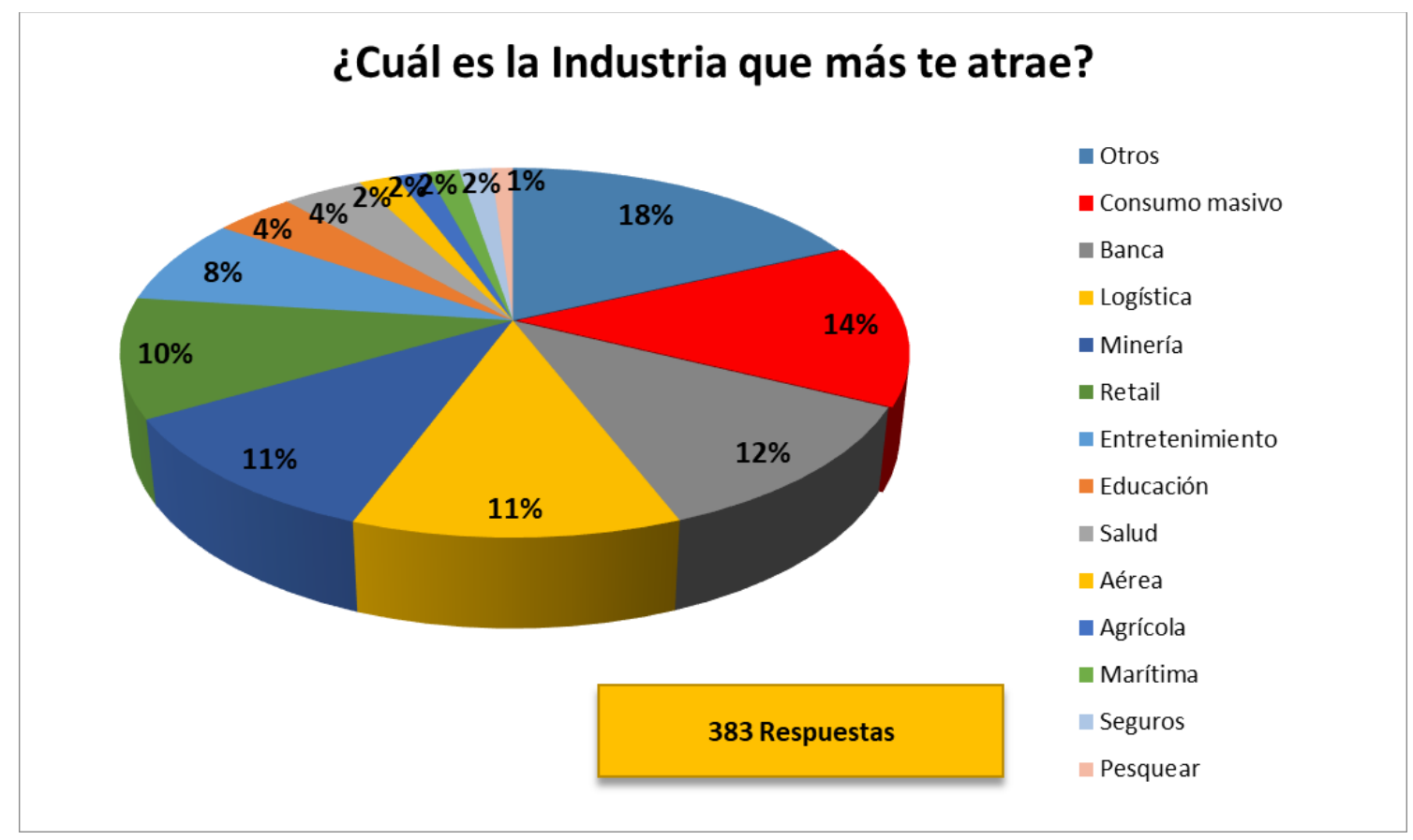

Elaboración propia 
Figura 16. Gestión de diversidad

Estas conversando con tu compañero de trabajo y ves que pone sus manos en los bolsillos ¿Cuál de las siguientes alternativas consideras es la que mejor describe la postura adoptada por tu compañero?

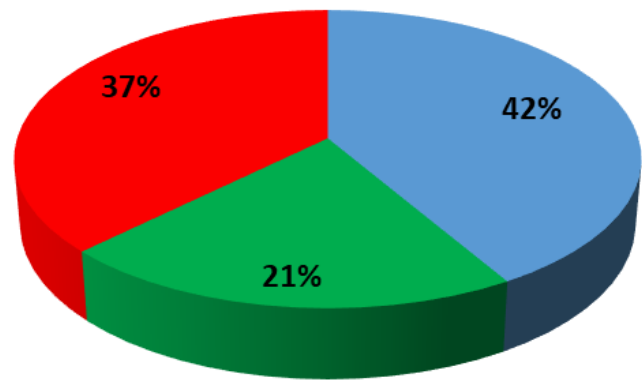

Muestra desinterés en la conversación

- Muestra Interés en la conversación

- Transmite una actitud reprimida, ansiosa o reprimida

383 Respuestas

Elaboración Propia

Figura 17. Conocimiento de otras culturas

¿Con qué frecuencias tienes contacto con personas de otros Países? Ya sea virtual o presencial.

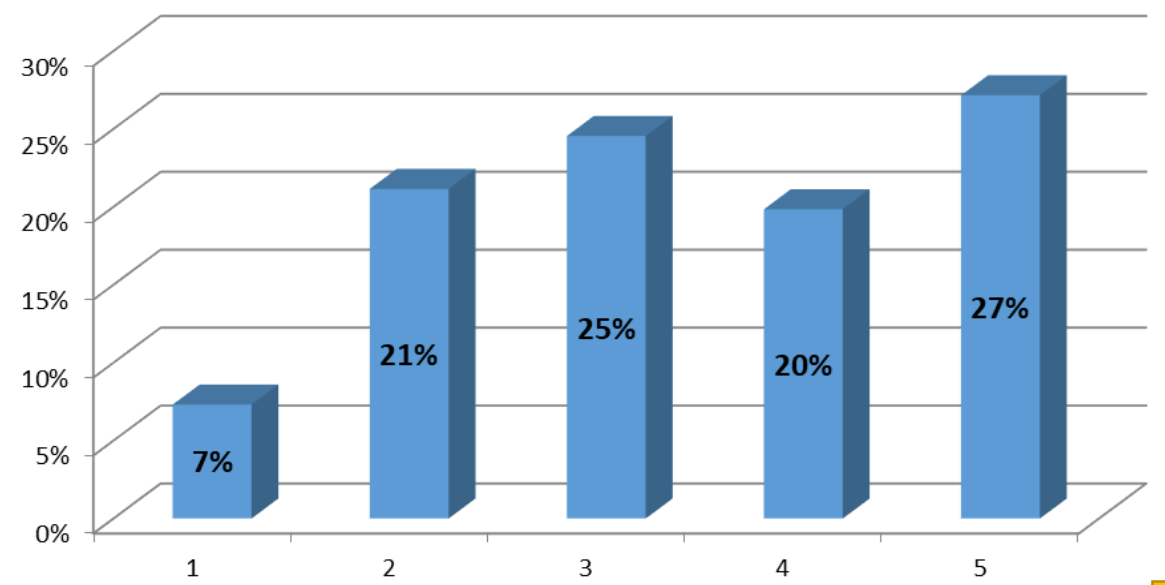

Donde 1 es nada y 5 siempre

Elaboración propia 
Figura 18. Comprensión profunda del significado

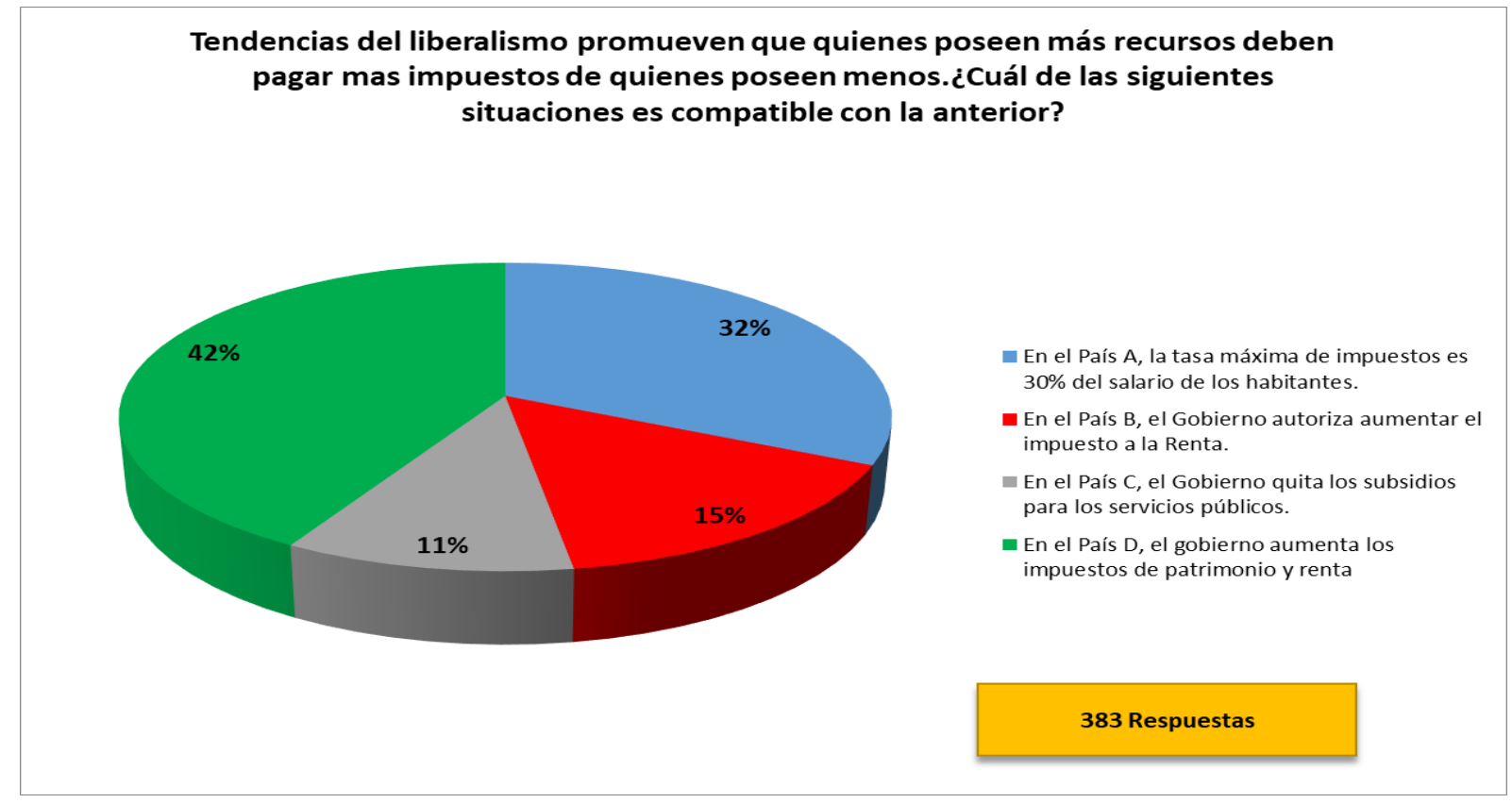

Elaboración propia

Figura 19. Resolución efectiva de conflictos

\section{Cuando se te presenta un problema ¿Cómo lo resuelves?}

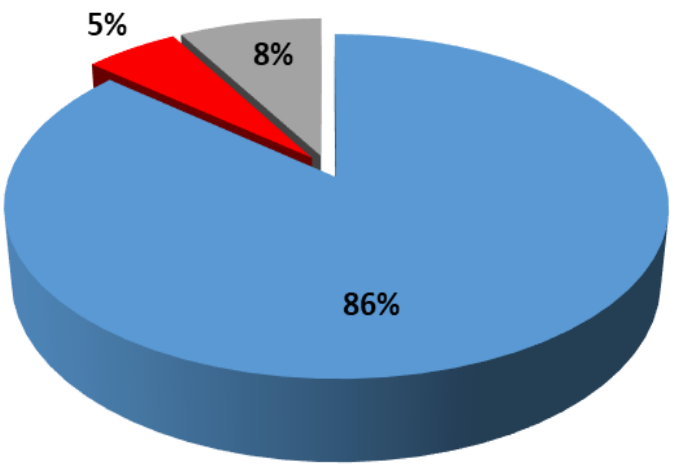

- Buscas caminos alternativos y múltiples soluciones con tu equipo de trabajo, realizando una evaluación profunda de los problemas

- Buscas soluciones inmediatas sin consultar a tu equipo de trabajo

- Evalúas a detalle la causa del problema y realizas focus group para encontrar la solución

383 Respuestas

Elaboración propia 
Figura 20. Disposición para aprender

\section{¿Con qué frecuencia participas en capacitaciones o cursos de actualización?}

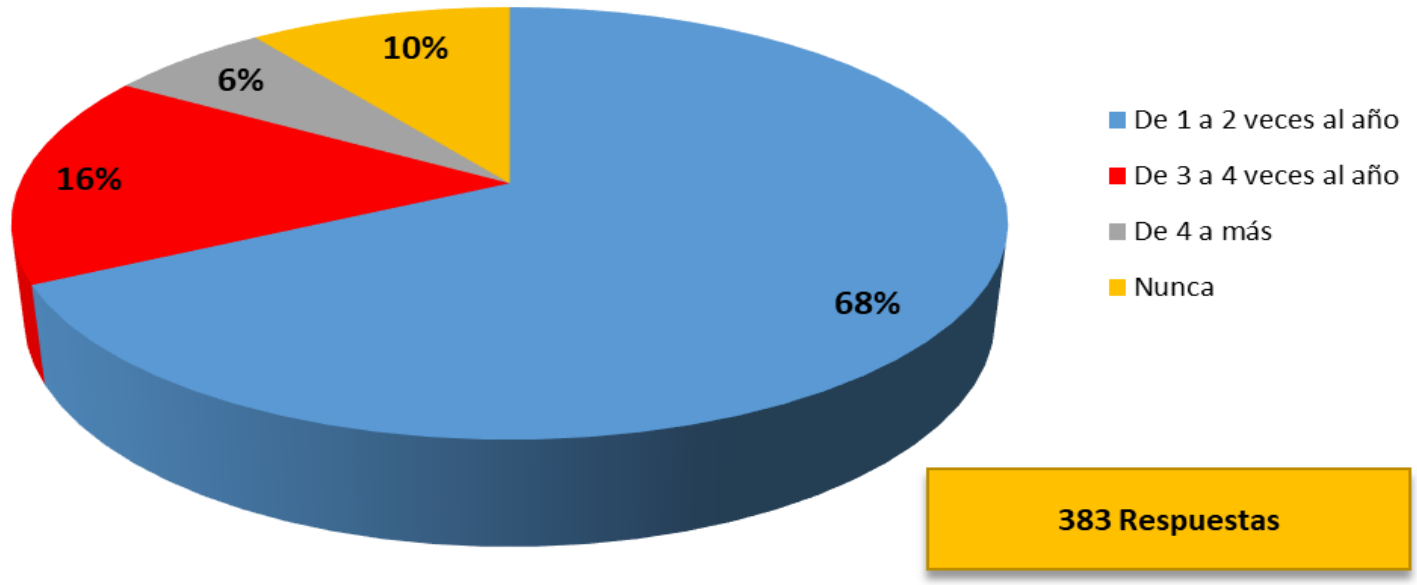

Elaboración propia

Figura 21. Gestión exitosa de outsourcing

Considerando que la tecnología te puede dar facilidades para trabajar desde casa ¿Qué tipo de jornada laboral consideras que es mas efectiva para cumplir con tus objetivos profesionales y organizacionales?

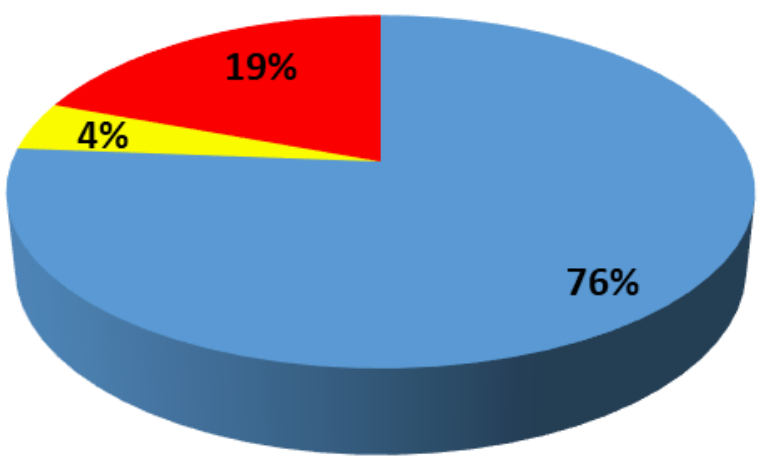

- Trabajar 3 días en la oficina y 2 en casa

Trabajar en casa los 5 días de la semana

- Trabajar los 5 días en la oficina

383 Respuestas

Elaboración propia 
Figura 22. Gran capacidad de comunicación

\section{¿Qué tan importante consideras la comunicación dentro de las organizaciones?}

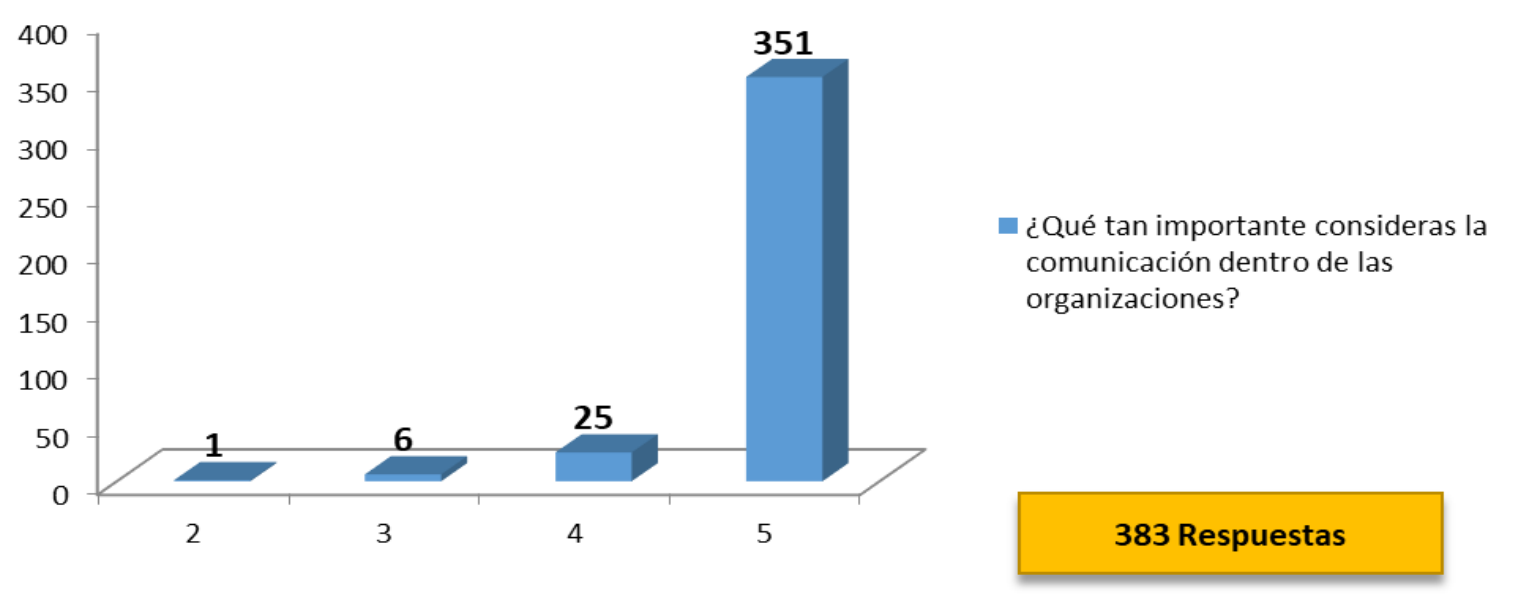

Elaboración propia

Figura 23. Comprensión de análisis de datos

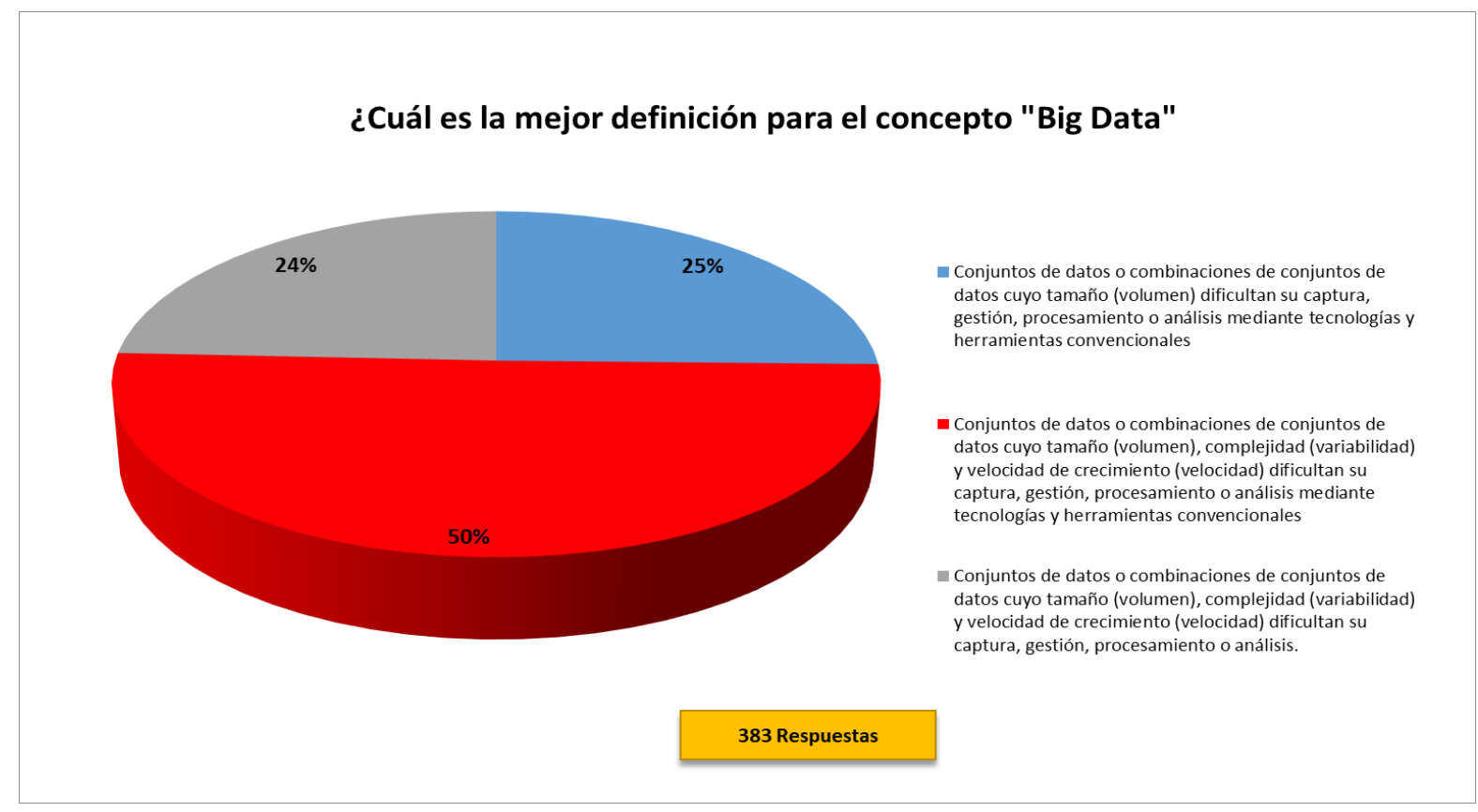

Elaboración propia 
Figura 24. Mentalidad orientada al diseño

\section{Cuando afrontas un problema, te guías:}

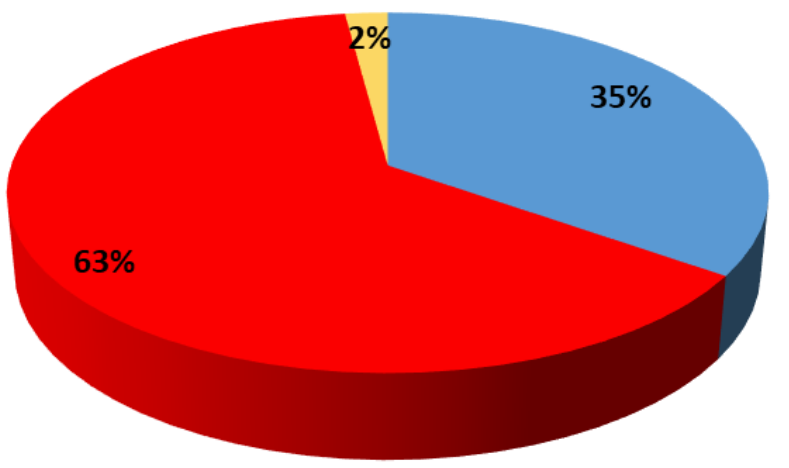

- Por experiencias pasadas

- Razonando que es lo mas justo para

afrontar el problema

Solo por tu intuición

383 Respuestas

Elaboración propia

Figura 25. Edad de Millennials encuestados

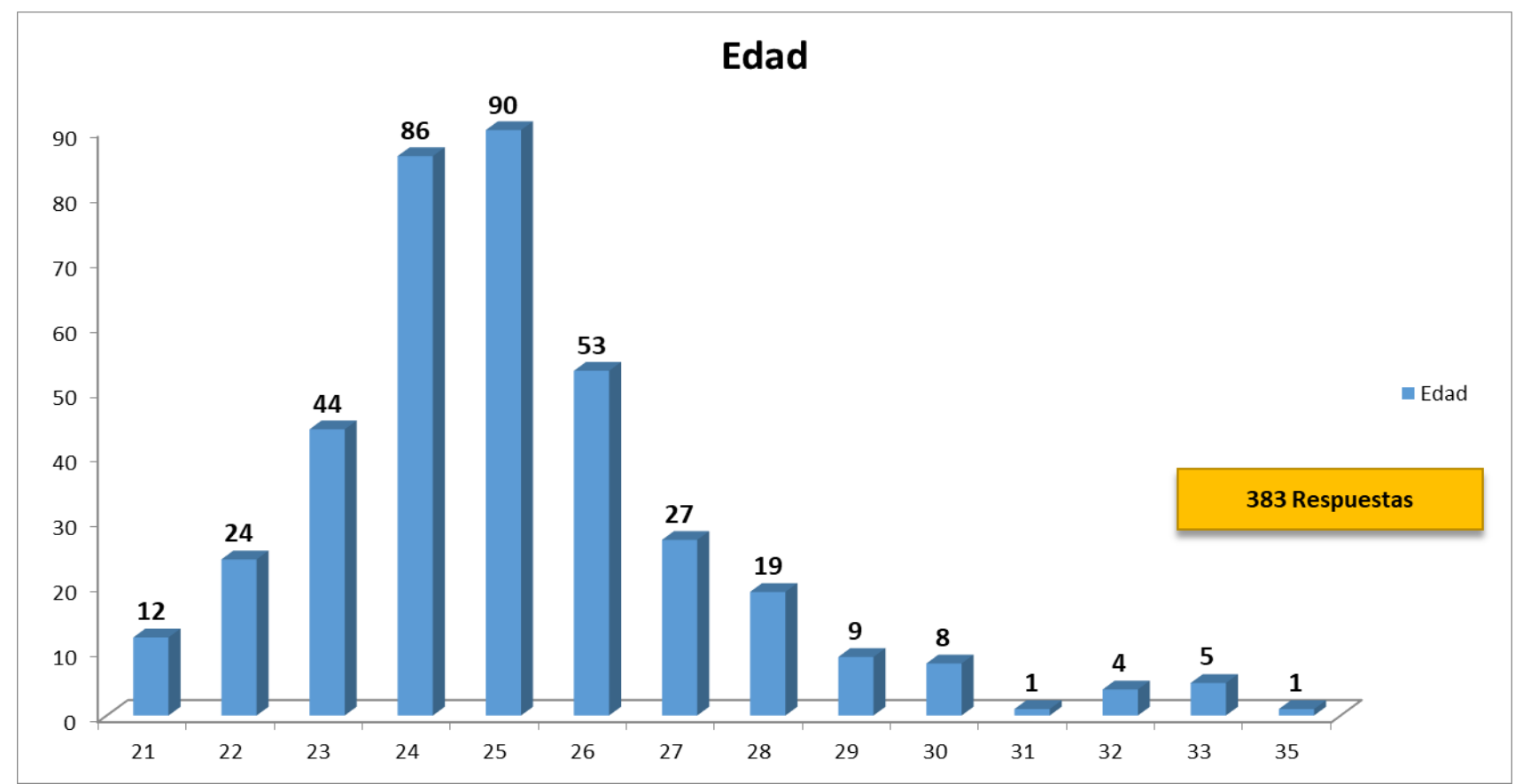

Elaboración propia 
Figura 26. Genero de Millennials encuestado

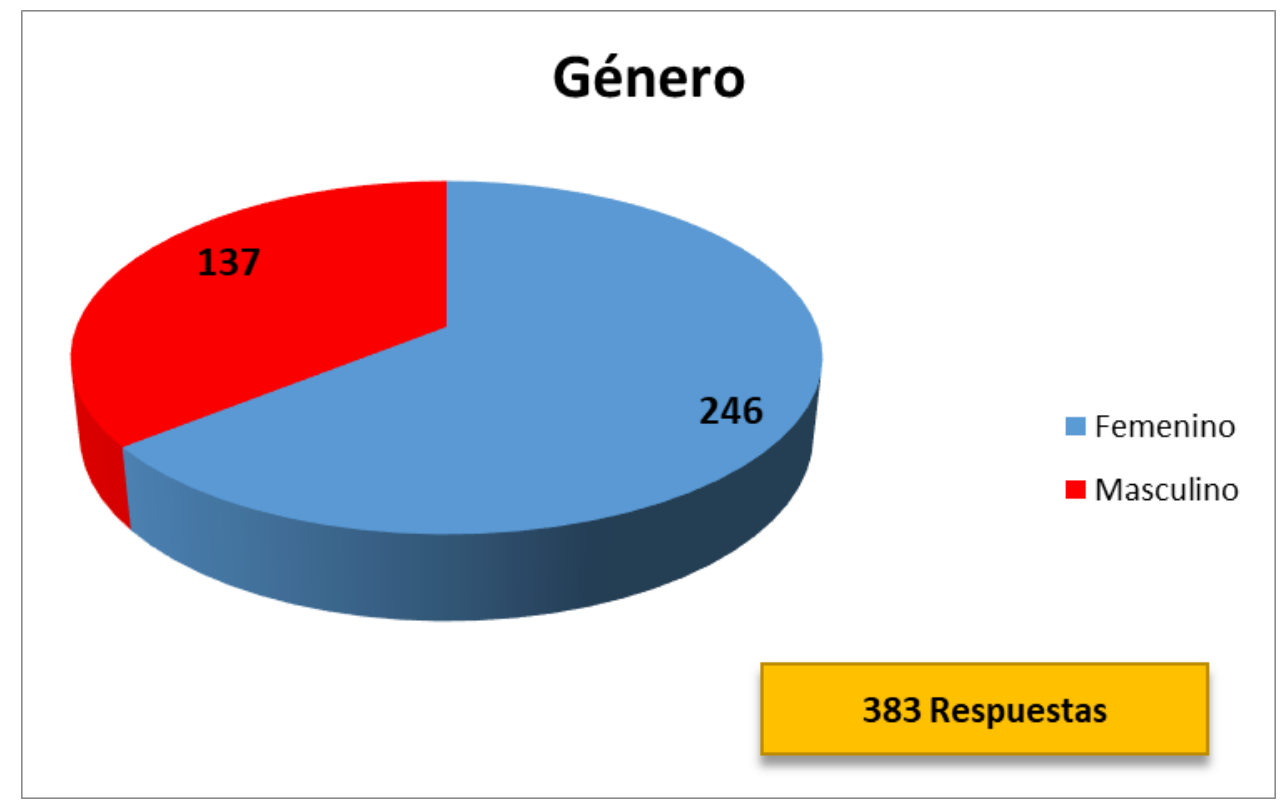

Elaboración propia

\subsubsection{Prueba de hipótesis}

El cuadro representa los índices de aceptación por competencias en los dos análisis que se realizaron, encuestas y entrevistas.

\begin{tabular}{|l|ccccccccc|c|}
\cline { 2 - 10 } \multicolumn{1}{c|}{} & A & B & C & D & E & F & G & H & | & Total \\
\hline Encuestas & 0.42 & 0.72 & 0.42 & 0.86 & 0.90 & 0.76 & 0.92 & 0.50 & 0.63 & 6.13 \\
Entrevistas & 0.50 & 1.00 & 0.25 & 1.00 & 1.00 & 0.50 & 0.75 & 0.50 & 1.00 & $\mathbf{6 . 5 0}$ \\
\hline Total & $\mathbf{0 . 9 2}$ & $\mathbf{1 . 7 2}$ & $\mathbf{0 . 6 7}$ & $\mathbf{1 . 8 6}$ & $\mathbf{1 . 9 0}$ & $\mathbf{1 . 2 6}$ & $\mathbf{1 . 6 7}$ & $\mathbf{1 . 0 0}$ & $\mathbf{1 . 6 3}$ & \\
\hline
\end{tabular}

\section{Fórmula de la Chi Cuadrado}

$$
\chi^{2}=\sum\left[\frac{\left(f_{0}-f_{e}\right)^{2}}{f_{e}}\right]
$$

Fo: Frecuencias de valor observado

Fe: Frecuencias de valor esperado 
Frecuencias teóricas esperadas:

\begin{tabular}{|c|c|c|c|}
\hline & Gestión de la Diversidad & Total & Fre cuencia \\
\hline Encue stas & $\begin{array}{r}0.42 \\
\end{array}$ & 6.13 & 0.45 \\
\hline Entrevistas & 0.50 & 6.5 & 0.47 \\
\hline \multirow[t]{2}{*}{ Total } & \begin{tabular}{|c|}
0.92 \\
\end{tabular} & 12.63 & \\
\hline & Conocimiento de Otras Culturas & Total & Fre cuencia \\
\hline Encue stas & $\begin{array}{r}0.72 \\
\end{array}$ & 6.13 & 0.83 \\
\hline Entrevistas & 1.00 & 6.5 & 0.89 \\
\hline \multirow[t]{2}{*}{ Total } & $\begin{array}{r}1.72 \\
\end{array}$ & 12.63 & \\
\hline & Comprensión profunda del significado & Total & Frecuencia \\
\hline Encue stas & 0.42 & 6.13 & 0.33 \\
\hline Entrevistas & 0.25 & 6.5 & 0.34 \\
\hline \multirow{2}{*}{\begin{tabular}{|l|l|} 
Total \\
\end{tabular}} & 0.67 & 12.63 & \\
\hline & Re solución efe ctiva de conflictos & Total & Frecuencia \\
\hline Encue stas & \begin{tabular}{|c|}
0.86 \\
\end{tabular} & 6.13 & 0.90 \\
\hline Entrevistas & 1.00 & 6.5 & 0.96 \\
\hline \multirow[t]{2}{*}{ Total } & 1.86 & 12.63 & \\
\hline & Disposición para aprender & Total & Frecuencia \\
\hline Encue stas & 0.90 & 6.13 & 0.92 \\
\hline Entrevistas & 1.00 & 6.5 & 0.98 \\
\hline \multirow[t]{2}{*}{ Total } & 1.90 & 12.63 & \\
\hline & Gestión exitosa del outsourcing & Total & Frecuencia \\
\hline Encue stas & 0.76 & 6.13 & 0.61 \\
\hline Entrevistas & 0.50 & 6.5 & 0.65 \\
\hline \multirow[t]{2}{*}{ Total } & $\begin{array}{r}1.26 \\
\end{array}$ & 12.63 & \\
\hline & Gran capacidad de comunicación & Total & Frecuencia \\
\hline Encue stas & $\begin{array}{c} \\
\end{array}$ & 6.13 & 0.81 \\
\hline Entrevistas & 0.75 & 6.5 & 0.86 \\
\hline \multirow[t]{2}{*}{ Total } & $\begin{array}{r}1.67 \\
\end{array}$ & 12.63 & \\
\hline & Comprensión del análisis de datos & Total & Frecuencia \\
\hline Encue stas & 0.50 & 6.13 & 0.49 \\
\hline Entrevistas & 0.50 & 6.5 & 0.51 \\
\hline \multirow[t]{2}{*}{ Total } & 1.00 & 12.63 & \\
\hline & Mentalidad Orienta da al diseño & Total & Frecuencia \\
\hline Encue stas & 0.63 & 6.13 & 0.79 \\
\hline Entrevistas & 1.00 & 6.5 & 0.84 \\
\hline Total & 1.63 & 12.63 & \\
\hline
\end{tabular}

\section{Grados de Libertad}

$$
G l=(r-1)(k-1)
$$

r=Número de Filas

$\mathrm{K}=$ Número de columnas

Solución de Grados de Libertad: 
$\mathrm{Gl}=(2-1)(9-1)$

$\mathrm{Gl}=8$

Distribución Chi Cuadrado

$$
\chi^{2}=\sum\left[\frac{\left(f_{0}-f_{e}\right)^{2}}{f_{e}}\right]
$$

\begin{tabular}{|c|c|c|c|c|}
\hline & Gestión de la Diversidad & Total & Frecuencia & Chi Cuadrado \\
\hline Encuestas & 0.42 & 6.13 & 0.45 & 0.0016 \\
\hline Entrevistas & 0.50 & 6.5 & 0.47 & 0.0015 \\
\hline \multirow{2}{*}{ Total } & $\begin{array}{r}0.92 \\
\end{array}$ & 12.63 & & \\
\hline & Conocimiento de Otras Culturas & Total & Frecuencia & \\
\hline Encuestas & 0.72 & 6.13 & 0.83 & 0.0158 \\
\hline Entrevistas & 1.00 & 6.5 & 0.89 & 0.0149 \\
\hline \multirow[t]{2}{*}{ Total } & $\begin{array}{r}1.72 \\
\end{array}$ & 12.63 & & \\
\hline & Comprensión profunda del significado & Total & Frecuencia & \\
\hline Encuestas & 0.42 & 6.13 & 0.33 & 0.0276 \\
\hline Entrevistas & 0.25 & 6.5 & 0.34 & 0.0261 \\
\hline \multirow{2}{*}{ Total } & \begin{tabular}{|c|}
0.67 \\
\end{tabular} & 12.63 & & \\
\hline & Resolución efectiva de conflictos & Total & Frecuencia & \\
\hline Encuestas & 0.86 & 6.13 & 0.90 & 0.0020 \\
\hline Entrevistas & 1.00 & 6.5 & 0.96 & 0.0019 \\
\hline \multirow[t]{2}{*}{ Total } & 1.86 & 12.63 & & \\
\hline & Disposición para aprender & Total & Frecuencia & \\
\hline Encuestas & 0.90 & 6.13 & 0.92 & 0.0005 \\
\hline Entrevistas & 1.00 & 6.5 & 0.98 & 0.0005 \\
\hline \multirow[t]{2}{*}{ Total } & 1.90 & 12.63 & & \\
\hline & Gestión exitosa del outsourcing & Total & Frecuencia & \\
\hline Encuestas & 0.76 & 6.13 & 0.61 & 0.0360 \\
\hline Entrevistas & 0.50 & 6.5 & 0.65 & 0.0340 \\
\hline \multirow[t]{2}{*}{ Total } & 1.26 & 12.63 & & \\
\hline & Gran capacidad de comunicación & Total & Frecuencia & \\
\hline Encuestas & 0.92 & 6.13 & 0.81 & 0.0148 \\
\hline Entrevistas & 0.75 & 6.5 & 0.86 & 0.0139 \\
\hline \multirow[t]{2}{*}{ Total } & 1.67 & 12.63 & & \\
\hline & Comprensión del análisis de datos & Total & Frecuencia & \\
\hline Encuestas & 0.50 & 6.13 & 0.49 & 0.0004 \\
\hline Entrevistas & 0.50 & 6.5 & 0.51 & 0.0004 \\
\hline \multirow[t]{2}{*}{ Total } & \begin{tabular}{|c|}
1.00 \\
\end{tabular} & 12.63 & & \\
\hline & Mentalidad Orientada al diseño & Total & Frecuencia & \\
\hline Encuestas & 0.63 & 6.13 & 0.79 & 0.0328 \\
\hline Entrevistas & 1.00 & 6.5 & 0.84 & 0.0309 \\
\hline Total & 1.63 & 12.63 & & \\
\hline \multicolumn{4}{|c|}{ TOTAL } & 0.2558 \\
\hline
\end{tabular}




\section{Chi Cuadrado Tabla}

Para el cálculo del Chi cuadrado tabla cruzaremos el grado de libertad con el margen de error

\begin{tabular}{|l|r|}
\hline Grado de Libertad & 8 \\
\hline Margen de error & 0.05 \\
\hline Resultado del Chi cuadrado tabla & 15.507 \\
\hline
\end{tabular}

Tabla 1. Valores críticos de la distribución Chi cuadrado

\begin{tabular}{|c|c|c|c|c|c|c|c|c|c|}
\hline & 0,001 & 0,005 & 0,01 & 0,02 & 0,025 & 0,03 & 0,04 & 0,05 & 0,10 \\
\hline $\begin{array}{r}\text { g.d.I } \\
1\end{array}$ & 10,828 & 7,879 & 6,635 & 5,412 & 5,024 & 4,709 & 4,218 & 3,841 & 2,706 \\
\hline 2 & 13,816 & 10,597 & 9,210 & 7,824 & 7,378 & 7,013 & 6,438 & 5,991 & 4,605 \\
\hline 3 & 16,266 & 12,838 & 11,345 & 9,837 & 9,348 & 8,947 & 8,311 & 7,815 & 6,251 \\
\hline 4 & 18,467 & 14,860 & 13,277 & 11,668 & 11,143 & 10,712 & 10,026 & 9,488 & 7,779 \\
\hline 5 & 20,515 & 16,750 & 15,086 & 13,388 & 12,833 & 12,375 & 11,644 & 11,070 & 9,236 \\
\hline 6 & 22,458 & 18,548 & 16,812 & 15,033 & 14,449 & 13,968 & 13,198 & 12,592 & 10,645 \\
\hline 7 & 24,322 & 20,278 & 18,475 & 16,622 & 16,013 & 15,509 & 14,703 & 14,067 & 12,017 \\
\hline 8 & 26,124 & 21,955 & 20,090 & 18,168 & 17,535 & 17,010 & 16,171 & 15,507 & 13,362 \\
\hline 9 & 27,877 & 23,589 & 21,666 & 19,679 & 19,023 & 18,480 & 17,608 & 16,919 & 14,684 \\
\hline 10 & 29,588 & 25,188 & 23,209 & 21,161 & 20,483 & 19,922 & 19,021 & 18,307 & 15,987 \\
\hline
\end{tabular}

Fuente: (http://www.mat.uda.cl/hsalinas/cursos/2010/eyp2/Tabla\%20Chi-Cuadrado.pdf) 


\section{Capítulo 5. Análisis de resultados}

\subsection{Millennials con las competencias requeridas para el futuro líder disruptivo}

Objetivo principal: Analizar si en el mercado laboral existe Millennials con las competencias requeridas para convertirse en el futuro líder disruptivo que logre la transformación digital y cubra las necesidades de las compañías de seguros de Lima Metropolitana.

Para poder analizar el objetivo principal se expondrá el análisis de entrevistas y de las encuestas realizadas.

\subsubsection{Análisis del resultado}

H0: En el mercado laboral si existe un perfil adecuado con las competencias requeridas para el futuro líder en transformación digital y cubrir las necesidades de las compañías de seguros en Lima Metropolitana.

H1: En el mercado laboral no existe un perfil adecuado con las competencias requeridas para el futuro líder en transformación digital y cubrir las necesidades de las compañías de seguros en Lima Metropolitana.

\begin{tabular}{|l|l|}
\hline Chi Cuadrado Tabla & 15.507 \\
\hline Chi Cuadrado Calculado & 0.2558 \\
\hline
\end{tabular}

- Chi cuadrado calculado $<$ Chi cuadrado tabla

Bajo el análisis de la Distribución Chi Cuadrado, si la Chi calculado existe evidencia estadística para Aceptar la $\mathrm{H} 0$ debido a que el Chi cuadrado calculado es menor que el chi cuadrado de la tabla. (En el mercado laboral existe un perfil adecuado con las competencias requeridas para el futuro líder en transformación digital y cubrir las necesidades de las compañías de seguros en Lima Metropolitana)

El análisis estadístico realizado se comparó las competencias que necesita un trabajador para afrontar los cambios en transformación digital. Se ha validado que los Millenials en el mercado cumplen con el perfil que las empresas solicitan. Sin embargo, las 9 competencias 
planteadas son para la transformación digital. Según Zemsania Global Group para la transformación digital se requiere la característica de la disrupción para un futuro líder como fue mencionado en el Capítulo I.

Como punto adicional debemos recalcar en la Industria de seguros, ninguna de las empresas en el sector de seguros tiene definido un perfil especial para un líder en transformación digital ni un líder disruptivo en transformación digital, las 4 empresas tienen menos de 2 años en promedio desde que empezaron a formar sus áreas en transformación digital y realizar los cambios organizacionales que la transformación requiera. En los 4 casos, se está implementando recién transformación digital.

Debido a lo expuesto, analizaremos que competencias están alineadas a lo expuesto por el estudio de Deloitte Reescribiendo las reglas para la era digital - Tendencias del Capital Humano 2017 expuesto en el capítulo I, para un futuro líder disruptivo en transformación digital.

Figura 27. Capacidades del liderazgo necesarias para tener éxito en un mundo digital

\begin{tabular}{|c|c|c|}
\hline $\begin{array}{l}\text { Transformación Cognitiva } \\
\text { (PIENSA diferente) }\end{array}$ & $\begin{array}{l}\text { Transformación Conductual } \\
\text { (ACTUA diferente) }\end{array}$ & $\begin{array}{l}\text { Transformación Emocional } \\
\text { (REACCIONA diferente) }\end{array}$ \\
\hline $\begin{array}{c}\text { Conceptualizar las posibilidades en un mundo } \\
\text { virtual }\end{array}$ & $\begin{array}{l}\text { Adaptación a un constante cambio de poder e } \\
\text { influencia }\end{array}$ & Tolerar un entorno de riesgo y ambigüedad \\
\hline Manejo de la creciente complejidad cognitiva & $\begin{array}{c}\text { Colaborar con facilidad en muchos equipos } \\
\text { diferentes }\end{array}$ & Mostrar resiliencia ante el constante cambio \\
\hline $\begin{array}{c}\text { Pensar divergentemente sobre nuevas maneras } \\
\text { de hacer las cosas }\end{array}$ & $\begin{array}{l}\text { Valorar la contribución de los nuevos socios } \\
\text { de trabajo y los diferentes grupos de interés }\end{array}$ & $\begin{array}{c}\text { Ser valiente en desafiar cómo se están } \\
\text { haciendo las cosas }\end{array}$ \\
\hline $\begin{array}{l}\text { Tomar decisiones rápidamente sin tener toda la } \\
\text { información }\end{array}$ & $\begin{array}{l}\text { Invertir grandes cantidades de energía para } \\
\text { hacer las cosas bien; intentar, fallar e intentar } \\
\text { de nuevo }\end{array}$ & $\begin{array}{l}\text { Tener la confianza necesaria para tomar el } \\
\text { liderazgo y dirigir el cambio }\end{array}$ \\
\hline
\end{tabular}

Fuente: Deloitte, Elaboración propia

El estudio divide en 3 transformaciones las 12 características que debe tener un futuro líder disruptivo.

- Transformación Cognitiva: Los líderes necesitan pensar diferente

- Conceptualizar las posibilidades de un mundo virtual: Esta característica se alinea a la Gestión exitosa del outsorurcing, entendida por el estudio de semana económica como 
dar facilidades a sus colaboradores para el trabajo y ellos estén de acuerdo a este tipo de trato o forma de trabajo. Hace referencia a gestionar talento a distancia a través de la tecnología.

- Manejo de la creciente complejidad cognitiva: Esta característica está alineada a la Comprensión de análisis de datos, ya que utiliza de tecnologías cognitivas como la inteligencia de artificial, Big data, automatización robótica de procesos, algoritmos predictivos, auto aprendizaje y entre otros.

- Pensar divergentemente sobre las nuevas maneras de hacer las cosas: Esta característica está alineada a la competencia de Comprensión profunda del significado y Mentalidad orientada al diseño, tener una visión diferente de la que el común de los usuarios realiza.

- Tomar decisiones rápidamente sin tener toda la información: Esta característica está alineada a la Resolución efectiva de conflictos, la cual menciona que hay que detectar errores con mayor rapidez y encontrar mejores soluciones de manera rápida.

- Transformación conductual: Los líderes necesitan actuar diferente

- Adaptación a un constante cambio de poder e influencia; Colaborar con facilidad muchos equipos diferentes; Valorar la contribución de los nuevos socios de trabajo y los diferentes grupos de interés: Estas características están alineadas a la Gran capacidad de la comunicación, conocimiento de otras culturas y gestión de la diversidad, estas competencias están alineadas al comportamiento que se tiene al contacto con otras personas.

- Invertir grandes cantidades de energía para hacer las cosas bien, intentar, fallar e intentar de nuevo: Esta característica está alienada a la Disposición para aprender, la cual indica que debemos estar dispuestos a aprender y aceptar tener nuevas habilidades. 
Tabla 2. Características del liderazgo disruptivo

\begin{tabular}{|c|c|c|}
\hline Tipo & Caracteristicas & Cumple \\
\hline \multirow{4}{*}{$\begin{array}{l}\text { Transformación } \\
\text { Cognitiva } \\
\text { (PIENSA } \\
\text { diferente) }\end{array}$} & Conceptualizar las posibilidades en un mundo virtual & 1 \\
\hline & Manejo de la creciente complejidad cognitiva & 1 \\
\hline & Pensar divergentemente sobre nuevas maneras de hacer las cosas & 1 \\
\hline & Tomar decisiones rápidamente sin tener toda la información & 1 \\
\hline \multirow{4}{*}{$\begin{array}{l}\text { Transformación } \\
\text { Conductual } \\
\text { (ACTUA } \\
\text { diferente) }\end{array}$} & Adaptación a un constante cambio de poder e influencia & 1 \\
\hline & Colaborar con facilidad en muchos equipos diferentes & 1 \\
\hline & Valorar la contribución de los nuevos socios de trabajo y los diferentes grupos de interés & 1 \\
\hline & Invertir grandes cantidades de energía para hacer las cosas bien; intentar, fallar e intentar de nuevo & 1 \\
\hline \multirow{4}{*}{$\begin{array}{l}\text { Transformación } \\
\text { Emocional } \\
\text { (REAccloNA } \\
\text { difierente) }\end{array}$} & Tolerar un entorno de riesgo y ambigüedad & 0 \\
\hline & Mostrar resiliencia ante el constante cambio & 0 \\
\hline & Ser valiente en desafiar cómo se están haciendo las cosas & 0 \\
\hline & Tener la confianza necesaria para tomar el liderazgo y dirigir el cambio & 0 \\
\hline Total & Cumplimiento Caracaterísticas Lider Disruptivo - Competencias Semana económica & $67 \%$ \\
\hline
\end{tabular}

Como resumen de las 12 características, que el estudio de Deloitte propone para un futuro líder disruptivo en transformación digital, se han dividido en tres tipos: Transformación cognitiva, la Transformación conductual y transformación emocional. Las dos primeras tienen características que están alineadas a las competencias para un trabajador exitoso en transformación digital según el estudio de Semana Económica. En cuanto a la competencia Comprensión profunda de significado es la única competencia del estudio de semana económica que no tiene relación con las características propuestas por el estudio de Deloitte. Por otro lado, las 4 características dentro de la transformación emocional no coinciden con alguna de las competencias propuestas por el estudio de semana económica, es decir hay una brecha para ser un líder disruptivo. Como resultado final se tiene el siguiente índice, de las 9 competencias solo 8 están alineadas a las 12 características para un líder disruptivo, lo que corresponde a un $67 \%$ de alineación entre características y competencias.

\subsection{Competencias requeridas por las compañías de seguros}

Objetivo específico 1: Analizar si las compañías de Seguro de Lima metropolitana solicitan perfiles con las competencias identificadas como el futuro ideal Millennials laboral, según el estudio realizado por Semana económica.

\subsubsection{Análisis de entrevistas}

Para el análisis de las competencias que tienen las compañías de seguro se realizaron entrevistas de profundidad para poder identificar que buscan las empresas de seguro en el 
mercado laboral, específicamente la pregunta 8 de la entrevista (Ver Anexo 1) hace referencia a las competencias requeridas para cumplir con el perfil de la compañía. Sin embargo, las 4 empresas entrevistadas comentaron que los perfiles para la transformación digital no están totalmente definidos, ya que están adaptándose a los cambios y circunstancias que se presenten durante el proceso. Debido a esto, los entrevistados expusieron características que buscan en sus colaboradores, las cuales cumplen con las competencias que el artículo de Semana económica propone para un Trabajador en Transformación digital.

\subsubsection{Rimac}

El entrevistado Guillermo Gates, Coordinador de selección de Rimac mencionó 8 competencias que la empresa busca al momento de contratar a sus colaboradores (Ver Anexo 1)

\begin{tabular}{|rl|}
\hline 1. & Capacidad para priorizar \\
\hline 2. & Capacidad para poder estar en \\
& búsqueda de la mejora continua \\
\hline 3. & La excelencia \\
\hline 4. & La gestión de nuevos retos \\
\hline 5. & Respeto \\
\hline 6. & Comunicación abierta \\
\hline 7. & Tener pasión por lo que hace \\
\hline 8. & Ser humilde \\
\hline
\end{tabular}

Las siguientes competencias son las que tuvieron relación con las presentadas por el estudio de semana económica

- Capacidad para poder estar en búsqueda de la mejora continua: Realizar actividades como la "Hackaton" que tuvo como objetivo encontrar personas que tengan capacidad de razonamiento e innovar más rápidamente y como menciona el entrevistado con la capacidad de encontrar soluciones de manera diferente. Esta característica del trabajador de Rimac encaja con las características de Mentalidad orientada al diseño. 
- La gestión de nuevos retos: Esta competencia se alinea a la competencia de Disposición para aprender, que nos menciona que debemos estar dispuestos a aprender y aceptar que siempre se va a añadir nuevas habilidades. Para gestionar nuevos retos debes estar dispuesto a aprender tanto de tus éxitos como de tus errores.

- Comunicación abierta: Esta competencia se alinea a la competencia de Gran capacidad de comunicación que hace referencia a que las habilidades técnicas pierden valor si la capacidad de comunicación de una persona es pobre.

Existen otras características que el entrevistado mencionó durante la entrevista (Ver Anexo 1) que debería tener los colaboradores de Rimac que cumplen con las siguientes competencias del estudio de Semana económica.

- Gestión de la Diversidad

- Conocimiento de otras culturas

- Comprensión del análisis de datos

- Resolución efectiva de conflictos

Algunas de las características que debe poseer un trabajador de Rimac es que debe conocer diferentes culturas y comportamientos. En la actualidad, no solo se está reclutando gente de Perú, sino también de otros países. En adición el trabajador de Rimac debe saber interpretar la comunicación no verbal de sus Stakeholder, por lo que estarían cumpliendo con la competencia de Gestión de la Diversidad y Conocimiento de otras culturas.

Además, la “Hackaton” solicita que los colaboradores de Rimac tengan un alto nivel de análisis de datos, ya que deben estar alineados a predecir respuesta de clientes, por lo que trabajan mucho con los datos que la empresa brinda, este concepto está alineado a la competencia de Comprensión del análisis de datos.

El entrevistado menciona que para afrontar los cambios que se han presentado en la organización, han tenido estrategias de comunicación en las que los vicepresidentes hacían reuniones con los colaboradores para evitar malas reacciones en la compañía, estas características van alineadas a las competencias de Resolución efectiva de conflictos. 
Para finalizar Rimac cumple con 7 competencias de las 9 propuestas por el estudio de semana económica.

\subsubsection{Mapfre}

El entrevistado Pablo Trelles Valle Riestra, Coordinador de selección mencionó 5 competencias para un colaborador de Mapfre (Ver Anexo 1) Se realizará la comparación con las competencias expuestas por semana económica para un trabajador que deba afrontar la transformación digital.

\begin{tabular}{|rl|}
\hline 1. & Trabajar en equipo \\
\hline 2. & Relaciones Interpersonales \\
\hline 3. & Colaborativo \\
\hline 4. & Receptivo de feedback \\
\hline 5. & Capacidad de mejorar \\
\hline
\end{tabular}

A continuación, se realizará el análisis de cada caso y la manera en que están alineadas a las competencias definidas en el estudio.

- Relaciones interpersonales: Esta competencia va alienada a Conocimiento de otras culturas. Mapfre es una empresa con presencia en los 5 continentes, por lo que sus trabajadores deben tener la competencia de estar en contacto con diferentes culturas a las establecidas en su país de residencia.

- Receptivo de feedback: Esta competencia va alineada a Disposición para aprender, ya que es parte de recibir feedback aprender de las cosas buenas que realizamos y en que podemos mejorar.

- Capacidad de mejorar: Esta competencia va alineada a la de Disposición para aprender que dice, debemos estar dispuestos a aprender y aceptar que siempre se va a añadir nuevas habilidades. 
Existen otras características que el entrevistado mencionó durante la entrevista (Ver Anexo 1) que debería tener los colaboradores de Mapfre que cumplen con las siguientes competencias del estudio de Semana económica.

- Gestión exitosa del outsorcing

- Resolución efectiva de conflictos

- Gestión de la diversidad

El entrevistado menciona que se están tomando medidas para que el colaborador de Mapfre sienta que no está en un trabajo y se le está otorgando facilidades para sus horarios de trabajo, así como el formato de vestimenta que deben usar en la oficina, ante estas medidas es que el colaborador de Mapfre está cumpliendo con la competencia de Gestión exitosa del outsourcing, entendida por el estudio de semana económica como dar facilidades a sus colaboradores para el trabajo y ellos estén de acuerdo a este tipo de trato o forma de trabajo.

Mapfre cuenta con un área de solución de problemas para el cliente como se menciona en la entrevista, todos los trabajadores están enfocados a dar soluciones inmediatas a sus clientes externos e internos. Por lo que están alineados a la competencia de Resolución efectiva de conflictos, pues detectan errores y encuentran mejores soluciones a los problemas con mayor rapidez.

El entrevistado hace mención que si bien es cierto la venta de seguros se está dando a través del formato digital que conforma el área de Transformación digital, muchos de los seguros siguen vendiéndose bajo la modalidad face to face, por lo que deben cumplir con la competencia de Gestión de la diversidad, que hace referencia a interpretar palabras tonos y gestos.

\subsubsection{Pacifico}

El entrevistado Martín Ferradas, Corporative recruitment chief menciona 6 competencias que debe poseer el actual trabajador de Pacífico (Ver anexo 1). 


\begin{tabular}{|rl|}
\hline 1. & Atención al cliente interno y externo \\
\hline 2. & Planificación y establecimiento de prioridades \\
\hline 3. & Toma de decisiones y solución de problemas \\
\hline 4. & Orientación a resultados \\
\hline 5. & Ética e integridad por la información \\
\hline 6. & Capacidad de equilibrio de la vida laboral \\
\hline
\end{tabular}

A continuación, se realizará el análisis de cada caso y la manera en que están alineadas a las competencias definidas en el estudio.

- Atención al cliente interno y externo: Durante la entrevista se recalcó que Pacifico está enfocada netamente al cliente sea interno o externo. Debido a esto es que el colaborador de Pacifico debe estar acostumbrado a trabajar con diferentes culturas y comportamientos de las personas. Debido a esto, están alineados a la competencia de

\section{Conocimiento de otras culturas.}

- Toma de decisiones y solución de problemas: La competencia con la que se alinea es la Resolución efectiva de conflictos, buscar la manera eficaz de resolver conflictos.

- Capacidad de equilibrio de la vida laboral: Esta competencia hace referencia a la Gestión exitosa del outsourcing (entendida por el estudio de semana económica como dar facilidades a sus colaboradores para el trabajo y ellos estén de acuerdo a este tipo de trato o forma de trabajo) pues esta competencia hace referencia a mantener un equilibrio en la vida personal y la vida laboral, así como mantener al colaborador con libertades y tiempos para que puedan realizar actividades extra laborales.

Existen otras características que el entrevistado mencionó durante la entrevista (Ver Anexo 1) que debería tener los colaboradores de Pacifico que cumplen con las siguientes competencias del estudio de Semana económica.

- Gran capacidad de comunicación

- Disposición para aprender

- Comprensión de análisis de datos

- Mentalidad orientada al diseño 
Pacífico realiza mensajes periódicos de la alta gerencia hacia los colaboradores, además menciona que en un proceso de selección, buscan que sus futuros trabajadores deben estar alineados a la comunicación, relaciones horizontales, dinámicos y siempre buscando la eficiencia. Estas características van alineadas a las competencias de Gran capacidad de comunicación y Disposición para aprender.

Pacífico cuenta con un área de Analitics el cual trabaja para identificar los patrones de comportamiento sus clientes y poder identificar qué soluciones se les puede dar a sus requerimientos. Por lo que necesitan que sus colaboradores cumplan con la competencia de Comprensión de análisis de datos.

Finalmente, el entrevistado menciona que la empresa cuenta con proyectos transversales para tener accesos más rápidos de la información y conocer mejor a nuestros clientes, con el objetivo de conocerlos mejor y así ofrecer mejor servicio. Para ello trabajan una segmentación más fina para identificar la demanda de sus negocios y ver el tipo de atención que debemos tener con ellos. Es decir, de una forma transversal para ofrecer una buena propuesta de valor. Estas características van alineadas a la Mentalidad orientada al diseño, pues idean productos o crear prototipos o modelos para el negocio.

\subsubsection{La Positiva}

La entrevistada María Pía Insausti, Supervisora de selección menciona las 10 competencias para los trabajadores de la Positiva deben tener.

\begin{tabular}{|rl|}
\hline 1. & Pensamiento analítico \\
\hline 2. & Pasión por las metas y los resultados \\
\hline 3. & Proactividad e iniciativa \\
\hline 4. & Foco en la experiencia del cliente \\
\hline 5. & Disposición a la transformación \\
\hline 6. & Desarrollo del conocimiento \\
\hline 7. & Comunicación efectiva \\
\hline 8. & Contribución en equipo \\
\hline
\end{tabular}


9. Agudeza estratégica

10. Desarrollo de equipos de alto desempeño

A continuación, se realizará el análisis de cada caso y la manera en que están alineadas a las competencias definidas en el estudio.

- Pensamiento Analítico: Capacidad para examinar, entender y cuestionar el origen, componentes y alcance de diversas situaciones, se alinea a la competencia de Comprensión profunda del significado, que es la capacidad de comprender a mayor énfasis las cosas.

- Foco en la experiencia del cliente: Al estar enfocados al cliente y querer mantener relaciones sostenibles y producidas con ellos, deben conocer diferentes culturas y comportamiento de sus clientes por lo que va alineado a la competencia de Conocimiento de otras culturas.

- Desarrollo del conocimiento: Habilidad para reconocer la calidad del propio conocimiento y desarrollar constantemente acciones que contribuyen al enriquecimiento del mismo. Esta competencia va alineada a la competencia de Disposición para aprender.

- Comunicación efectiva: Capacidad para escuchar con atención y en forma activa, logrando establecer comunicación positiva de doble vía. Esta competencia va alineada a Gran capacidad de comunicación.

- Contribución en equipo: Disposición para integrar equipos de trabajo, contribuir de manera productiva y positiva desde el propio rol y colaborar con la gestión de otros para la consecución de objetos comunes. La competencia de Resolución efectiva de conflictos, nos habla de formas grupos y/o equipos para innovar y encontrar mejores soluciones a los problemas que se presentan y encontramos relación en ambas competencias pues tienen un objetivo común.

En base a las entrevistas realizadas a las 4 empresas de seguros con mayor posicionamiento en el mercado se realizó un análisis de las competencias que cada una de ellas propone para 
sus trabajadores, se colocó un valor de 1 para poder identificar con que competencias cumple cada una y así ponderar e identificar el porcentaje de cumplimiento de competencias que tiene la Industria, el siguiente cuadro muestra los resultados de cumplimiento por empresa e industria.

Figura 28. Consolidado de entrevistas

\begin{tabular}{|c|c|c|c|c|c|c|}
\hline \multicolumn{2}{|l|}{ Competencias } & RIMAC & MAPFRE & PACIFICO & LA POSITIVA & INDUSTRIA \\
\hline Gestión de la Diversidad & A & 1 & 1 & 0 & 0 & 2 \\
\hline Conocimiento de Otras Culturas & B & 1 & 1 & 1 & 1 & 4 \\
\hline Comprensión profunda del significado & C & 0 & 0 & 0 & 1 & 1 \\
\hline Resolución efectiva de conflictos & D & 1 & 1 & 1 & 1 & 4 \\
\hline Disposición para aprender & E & 1 & 1 & 1 & 1 & 4 \\
\hline Gestión exitosa del outsourcing & $\mathrm{F}$ & 0 & 1 & 1 & 0 & 2 \\
\hline Gran capacidad de comunicación & G & 1 & 0 & 1 & 1 & 3 \\
\hline Comprensión del análisis de datos & $\mathrm{H}$ & 1 & 0 & 1 & 0 & 2 \\
\hline Mentalidad Orientada al diseño & I & 1 & 0 & 1 & 0 & 4 \\
\hline Total de competencias por em & & 7 & 5 & 7 & 5 & 6 \\
\hline Cumplimiento & & $78 \%$ & $56 \%$ & $78 \%$ & $56 \%$ & $67 \%$ \\
\hline
\end{tabular}

Elaboración propia

Las principales competencias que más se pide en el sector de seguros son las siguientes:

- Conocimiento de Otras Culturas, debido al enfoque tienen en sus clientes y también a los trabajadores de diversas nacionalidades.

- Resolución efectiva de conflictos, alineado a la solución de problemas que se presentan para la atención a sus clientes, así como el enfoque deben tener ante los cambios organizativos que se están presentado en el proceso de Transformación digital.

- Disposición para aprender, debido a que las 4 empresas están atravesando un proceso de transformación digital y necesitan que sus trabajadores estén con la disposición de capacitarte constantemente para estar adaptados a los nuevos cambios que se presenten en la forma de trabajo.

- Mentalidad orientada al diseño las 4 empresas apuestan por el pensamiento lógico y la imaginación, un pensamiento sistémico debido a las innovaciones que realizan para sus proyectos de transformación digital.

Como punto resaltante, La Positiva es la única empresa que tiene una competencia alienada a la competencia de Comprensión profunda del significado, que es la capacidad de comprender a mayor énfasis las cosas. 
En adición, debemos recalcar que el artículo de semana económica resalta que para que un trabajador pueda cumplir con los mínimos requeridos de competencias para la Transformación digital que afronta el mercado son las siguientes

- Conocimiento de otras culturas, solicitada por las 4 empresas de seguros.

- Comprensión profunda del significado, solicitada solo por 1 empresa, La positiva.

- Resolución efectiva de conflictos, solicitada por las 4 empresas de seguros.

- Mentalidad orientada al diseño. Solicitada por 2 empresas Rimac y Pacífico.

Finalmente, el porcentaje de cumplimiento de las competencias individualmente por empresas es el siguiente.

- Rimac cumplió con el $78 \%$ de las competencias que propone es estudio de Semana económica

- Mapfre cumplió con el $56 \%$ de las competencias que propone es estudio de Semana económica

- Pacifico cumplió con el $78 \%$ de las competencias que propone es estudio de Semana económica

- La Positiva cumplió con el $56 \%$ de las competencias que propone es estudio de Semana económica

En resumen, se realizó un promedio con los resultados de las competencias por empresa para poder tener un resultado como Industria de Seguros, ya que no existe un estándar de competencias definidas ideales para un futuro líder en transformación digital. Como resultado final se está cumpliendo con el $67 \%$ de las competencias que propone el estudio de Semana Económica “Trabajo 3.0” para un futuro trabajador en Transformación digital. 


\subsection{Mercado laboral del Millennials peruanos}

Objetivo específico 2: Identificar si en el mercado laboral de Lima se cuenta con Millennials que cumplan con el perfil para contribuir con la transformación digital.

\subsubsection{Análisis de las encuestas}

El presente cuadro muestra los resultados sobre la encuesta aplicada a los Millennials con un rango de edad de 22 a 35 años ubicados en Lima Metropolitana. El objetivo de realizar esta encuesta fue identificar si los Millennials actuales cumplían con el perfil para afrontar el nuevo cambio tecnológico que están cambiando el mercado laboral. La encuesta se realizó a 383 personas y se basó en las 9 competencias del estudio de Semana económica para un trabajador que quiere adaptarse al nuevo orden laboral. A continuación, se realizará la explicación de los resultados de la encuesta.

Tabla 3. Encuesta de Millennials

\begin{tabular}{|c|c|c|c|c|c|c|c|c|c|c|c|}
\hline $\begin{array}{l}\text { ENCUESTA A } \\
\text { MILLENNIALS }\end{array}$ & A & B & C & D & $E$ & $\mathbf{F}$ & G & $\mathbf{H}$ & I & $\begin{array}{l}\text { Cantidad de } \\
\text { encuestados }\end{array}$ & $\%$ \\
\hline $\begin{array}{c}\text { Q. de respuestas } \\
\text { correctas }\end{array}$ & 159 & 274 & 160 & 330 & 344 & 292 & 351 & 193 & 242 & 383 & $100 \%$ \\
\hline 2 & 0 & 1 & 0 & 0 & 3 & 2 & 3 & 1 & 0 & 5 & $1 \%$ \\
\hline 3 & 0 & 1 & 1 & 4 & 6 & 2 & 6 & 2 & 2 & 8 & $2 \%$ \\
\hline 4 & 6 & 17 & 5 & 22 & 34 & 20 & 33 & 10 & 17 & 41 & $11 \%$ \\
\hline 5 & 15 & 28 & 15 & 52 & 55 & 40 & 52 & 18 & 25 & 60 & $16 \%$ \\
\hline 6 & 44 & 82 & 34 & 93 & 90 & 75 & 94 & 47 & 65 & 104 & $27 \%$ \\
\hline 7 & 45 & 90 & 58 & 101 & 99 & 99 & 105 & 62 & 83 & 106 & $28 \%$ \\
\hline 8 & 40 & 46 & 38 & 49 & 48 & 45 & 49 & 44 & 41 & 50 & $13 \%$ \\
\hline 9 & 9 & 9 & 9 & 9 & 9 & 9 & 9 & 9 & 9 & 9 & $2 \%$ \\
\hline$\%$ & $42 \%$ & $72 \%$ & $42 \%$ & $86 \%$ & $90 \%$ & $76 \%$ & $92 \%$ & $50 \%$ & $63 \%$ & & \\
\hline
\end{tabular}

Elaboración propia
A Gestión de la Diversidad
B Conocimiento de Otras Culturas
C Comprensión profunda del significado
D Resolución efectiva de conflictos
E Disposición para aprender
F Gestión exitosa del outsourcing
G Gran capacidad de comunicación
H Comprensión del análisis de datos
I Mentalidad Orientada al diseño 
Primero analizaremos las cantidades de competencias que cumplieron los encuestados:

- De los 383 encuestados, solo 5 personas cumplieron con al menos dos competencias laborales, de las cuales Disposición para aprender y Gran capacidad de comunicación fueron las que mayor respuesta tuvieron. Además 8 personas respondieron al menos 3 respuestas correctas, de las cuales Disposición para aprender y Gran capacidad de comunicación fueron las que tuvieron mayor frecuencia.

- 41 y 60 encuestados cumplieron con al menos 4 y 5 competencias correctas respectivamente, de las cuales Disposición para aprender y Gran capacidad de comunicación siguen siendo las competencias que más cumplen los Millennials actuales. En este rango se puede evidenciar que la Resolución de conflictos y la Gestión Exitosa del outsorcing empiezan a tomar un mayor protagonismo y el cumplimiento de competencias se vuelve más disperso. Debemos destacar que la Comprensión profunda del significado y la Gestión de la diversidad son competencias que menor cantidad de personas cumplieron.

- 104 y 106 encuestados respondieron 6 y 7 competencias correctamente, en este grueso se encuentran la mayor parte de encuestados. En estos rangos, las competencias Resolución de efectiva de conflictos, Disposición para aprender, Gestión exitosa del outsorcing y Gran capacidad de comunicación fueron las competencias que mayores frecuencias tuvieron. Asimismo, la Gestión profunda del significado y la Gestión de la diversidad fueron las competencias con menor respuesta acertada.

- Para el caso de 8 competencias correctas 50 personas respondieron correctamente, en este caso las respuestas fueron más estandarizadas y en promedio 44 veces fueron respondidas cada competencia.

- Para el caso de 9 competencias, solo 9 personas cumplieron con todas las competencias, potenciales líderes en transformación digital.

- En resumen, las competencias que tuvieron más de $80 \%$ de acierto fueron Gran capacidad de comunicación, Disposición para aprender y Resolución efectiva de conflictos. Por otro lado, las competencias con menor resultado de aceptación fueron 
Gestión de la diversidad y Comprensión profunda del significado y Mentalidad orientada al diseño.

De las competencias que el estudio de semana económica sugiere como mínimo para un futuro colaborador tenemos los siguientes resultados respecto a los resultados de los encuestados.

Tabla 4. Competencias mínimas requeridas

\begin{tabular}{|l|c|}
\hline \multicolumn{1}{|c|}{$\begin{array}{c}\text { Competencias mínimas } \\
\text { requeridas }\end{array}$} & $\begin{array}{c}\% \text { de cumplimiento } \\
\text { de encuestados }\end{array}$ \\
\hline Resolución efectiva de conflictos & $86 \%$ \\
Conocimiento de otras culturas & $72 \%$ \\
Mentalidad orientada al diseño & $63 \%$ \\
Comprensión profunda del significado & $42 \%$ \\
\hline Promedio & $\mathbf{6 6 \%}$ \\
\hline
\end{tabular}

Elaboración propia

Como resumen, se tiene un $66 \%$ de promedio de acierto en las competencias requeridas para poder competir en el futuro mercado laboral. Cabe resaltar que del total de la muestra y en todos los casos por cantidad de respuestas correctas, la comprensión profunda del significado es una competencia que esta poco desarrollada por parte de los Millennials. Por otro lado, la resolución efectiva de conflictos es la tercera competencia que más presencia tiene en los encuestados y la principal dentro de las requeridas por parte del estudio de Semana Económica.

\section{Cuadros de Análisis de Resultados:}

Cantidad de encuestados por género y edad de respuestas correctas, los rangos de edad son de 21 a 35 años, mientras que los datos del centro son las cantidades de personas que cumplieron un número determinado de competencias. 
Tabla 5. Cantidad de encuestados por género y edad

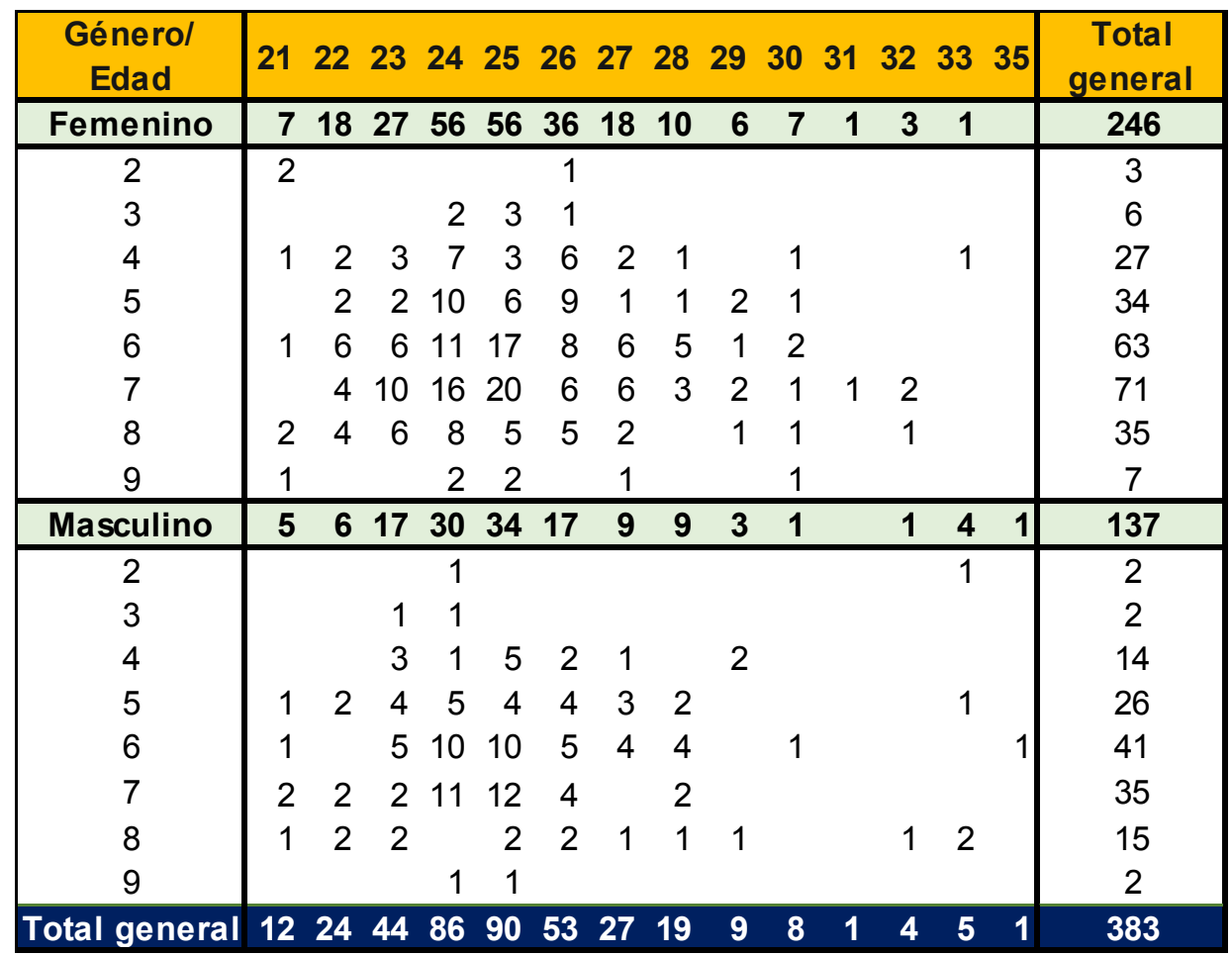

Elaboración propia

- De las 9 personas que cumplieron con las 9 competencias y son posibles líderes en transformación digital, 7 fueron mujeres de las cuales 4 tienen 24 y 25 años y 2 hombres en edades de 24 y 25 años.

- 148 mujeres tuvieron edad entre 24,25 y 26 años de las cuales 56 cumplieron con 7 competencias como mínimo.

- 54 hombres tuvieron edad entre 24 y 25 años de las cuales 22 cumplieron con 7 competencias como mínimo.

Cantidad de encuestados por género y situación laboral

- De las 7 mujeres que cumplieron con 9 competencias 5 trabajan actualmente, 1 nunca ha trabajado y 1 ha trabajado, pero actualmente no labora.

- De los 2 hombres que cumplieron con 9 competencias, ambos trabajan actualmente 
- 60 mujeres trabajan actualmente y cumplen con al menos 7 competencias, mientras que para el caso de los hombres 34 trabajan actualmente y cumplen con al menos 6 competencias.

- 313 personas trabajan actualmente ,13 nunca trabajaron y 57 trabajaron, pero actualmente no laboran.

Tabla 6. Cantidad de encuestados por género y situación laboral

\begin{tabular}{|c|ccc|c|}
\hline $\begin{array}{c}\text { Génerol } \\
\text { Situación } \\
\text { Laboral }\end{array}$ & $\begin{array}{c}\text { He trabajado, } \\
\text { pero } \\
\text { actualmente no }\end{array}$ & $\begin{array}{c}\text { Nunca he } \\
\text { trabajado }\end{array}$ & $\begin{array}{c}\text { Trabajo } \\
\text { Actualmente }\end{array}$ & Total general \\
\hline Femenino & $\mathbf{3 8}$ & $\mathbf{8}$ & $\mathbf{2 0 0}$ & $\mathbf{2 4 6}$ \\
\hline 2 & & 1 & 2 & 3 \\
3 & 5 & 1 & 6 & 6 \\
4 & 7 & 1 & 21 & 27 \\
5 & 10 & 1 & 26 & 34 \\
6 & 9 & 2 & 60 & 63 \\
7 & 6 & 1 & 28 & 71 \\
8 & 1 & 1 & 5 & 35 \\
9 & $\mathbf{1 9}$ & $\mathbf{5}$ & $\mathbf{1 1 3}$ & $\mathbf{1 3 7}$ \\
\hline Masculino & & & 2 & 2 \\
\hline 2 & 3 & & 2 & 2 \\
3 & 5 & 2 & 11 & 14 \\
4 & 5 & 2 & 34 & 26 \\
5 & 5 & 1 & 30 & 41 \\
6 & 1 & & 13 & 15 \\
7 & & $\mathbf{1 3}$ & $\mathbf{3 1 3}$ & $\mathbf{3 8 3}$ \\
\hline 8 & $\mathbf{5 7}$ & & & \\
9 & & & & 2 \\
\hline Total general & & & & \\
\hline
\end{tabular}

Elaboración propia

Tabla 7. Situación laboral por nivel de estudios

\begin{tabular}{|l|ccc|c|}
\hline $\begin{array}{c}\text { Nivel de } \\
\text { Estudio/Situ.Laboral }\end{array}$ & $\begin{array}{c}\text { He trabajado, } \\
\text { pero } \\
\text { actualmente no }\end{array}$ & $\begin{array}{c}\text { Nunca he } \\
\text { trabajado }\end{array}$ & $\begin{array}{c}\text { Trabajo } \\
\text { Actualmente }\end{array}$ & Total general \\
Universitaria Completa & 36 & 3 & 262 & 301 \\
Universitaria Incompleta & 21 & 10 & 51 & 82 \\
\hline Total general & $\mathbf{5 7}$ & $\mathbf{1 3}$ & $\mathbf{3 1 3}$ & $\mathbf{3 8 3}$ \\
\hline
\end{tabular}

Elaboración propia 
- 282 personas trabajan actualmente y tienen estudios universitarios completos.

- 51 personas trabajan y tienen universidad incompleta.

- 301 encuestados cuentan con Universidad completa.

- 36 y 21 mujeres y hombres nunca han trabajado.

Tabla 8. Encuestados por nivel de estudio, género y situación laboral

\begin{tabular}{|c|ccc|c|}
\hline $\begin{array}{c}\text { Nivel de estudios } \mathbf{y} \\
\text { Género / Situación } \\
\text { lab }\end{array}$ & $\begin{array}{c}\text { He trabajado, } \\
\text { pero actualmente } \\
\text { no }\end{array}$ & $\begin{array}{c}\text { Nunca he } \\
\text { trabajado }\end{array}$ & $\begin{array}{c}\text { Trabajo } \\
\text { Actualmente }\end{array}$ & Total general \\
\hline $\begin{array}{c}\text { Universitaria } \\
\text { Completa }\end{array}$ & 36 & 3 & 262 & 301 \\
$\begin{array}{c}\text { Femenino } \\
\text { Masculino } \\
\text { Universitaria } \\
\text { Incompleta }\end{array}$ & 24 & & 175 & 199 \\
Femenino & 12 & 3 & 87 & 102 \\
\hline Masculino & 21 & 10 & 51 & 82 \\
\hline \hline Total general & 14 & 8 & 25 & 47 \\
\hline
\end{tabular}

Elaboración propia

- 175 y 87 mujeres y hombres respectivamente cuentan con universitaria completa y trabajan actualmente.

- 25 y 26 mujeres y hombres respectivamente cuentan con Universidad incompleta y trabajan.

Industrias por competencias logradas

- De los 7 encuestados que cumplieron con las 9 competencias y laboran actualmente 2 pertenecen a la industria de seguros, mientras que otros 2 a la industria aérea.

Participación en procesos de selección y Rechazos de Oferta Laboral 
Tabla 9. Cantidad de competencias correctas vs presentación a procesos de selección

\begin{tabular}{|c|cc|c|}
\hline \multicolumn{4}{|c|}{$\begin{array}{c}\text { ¿En el último año te has presentado en algún proceso } \\
\text { de selección? }\end{array}$} \\
\hline $\begin{array}{c}\text { Cantidad de } \\
\text { competencias } \\
\text { correctas }\end{array}$ & No & Si & Total general \\
\hline 2 & 3 & 1 & 4 \\
3 & 2 & 6 & 8 \\
\hline 4 & 19 & 21 & 40 \\
\hline 5 & 20 & 37 & 57 \\
6 & 41 & 60 & 101 \\
7 & 34 & 70 & 104 \\
\hline 8 & 4 & 32 & 48 \\
9 & $\mathbf{1 3 9}$ & $\mathbf{2 3 1}$ & $\mathbf{3 7 0}$ \\
\hline
\end{tabular}

Elaboración propia

Tabla 10. Cantidad de competencias correctas vs rechazos de ofertas laborales

\begin{tabular}{|c|cc|c|}
\hline \multicolumn{3}{|c}{ ¿Has rechazado alguna oferta laboral en los últimos 6} \\
meses?
\end{tabular}

Elaboración propia

- De las 9 personas que cumplieron con las 9 competencias 1 nunca ha trabajado, por lo que nunca ha participado en procesos de selección.

- Las personas con 6 y 7 competencias fueron las que a más procesos de selección se presentaron.

- Las personas con 6 y 7 competencias que han rechazado la oferta laboral en los últimos 6 meses son 64 y 66 personas respectivamente. 


\section{Motivo de rechazo de oferta}

- Las principales razones por las que se rechazó las ofertas laborales fueron las siguientes, salario $33 \%$, ubicación $17 \%$, línea de carrera $17 \%$, beneficios $12 \%$, horario $10 \%$.

- Las 3 personas que cumplieron con las 9 competencias y rechazaron la oferta laboral fueron debido a Beneficios, Línea de carrera y Salario.

Tabla 11. Tiempo de Permanencia

\begin{tabular}{|c|ccccc|c|}
\hline $\begin{array}{c}\text { Competencias/ } \\
\text { permanencia }\end{array}$ & $\mathbf{1}$ - $\mathbf{2}$ años & $\mathbf{2}-\mathbf{3}$ años & $\begin{array}{c}\mathbf{3} \text { a mas } \\
\text { años }\end{array}$ & $\begin{array}{c}\mathbf{6} \text { meses }-\mathbf{1} \\
\text { año }\end{array}$ & $\begin{array}{c}\text { (en } \\
\text { blanco) }\end{array}$ & Total general \\
\hline 2 & & & 2 & 2 & 1 & 5 \\
\hline 3 & 4 & 2 & & 2 & & 8 \\
4 & 19 & 5 & 1 & 15 & 1 & 41 \\
\hline 5 & 27 & 15 & 5 & 10 & 3 & 60 \\
\hline 6 & 46 & 22 & 10 & 23 & 3 & 104 \\
\hline 7 & 42 & 21 & 6 & 35 & 2 & 106 \\
\hline 8 & 24 & 11 & 2 & 11 & 2 & 50 \\
\hline 9 & 4 & 2 & 1 & 1 & 1 & 9 \\
\hline \hline Total general & 166 & $\mathbf{7 8}$ & $\mathbf{2 7}$ & $\mathbf{9 9}$ & $\mathbf{1 3}$ & $\mathbf{3 8 3}$ \\
\hline
\end{tabular}

Elaboración propia

- De las 9 personas que cumplieron con las 9 competencias, 4 tienen de 1 a 2 años de permanencia.

- El mayor porcentaje de Millennials permanecen entre 1 a 2 años en una empresa, es decir el $43 \%$ de los encuestados.

- 46 personas permanecen de 1-2 años cumplieron con 6 competencias, esta es la mayor cantidad de personas por caso de competencias / permanencia.

Beneficios que motivan al encuestado-Por cantidad de competencias correctas y tiempo de permanencia 
Tabla 12. Cruce de competencias, beneficios y tiempo de permanencia en una empresa

\begin{tabular}{|c|c|c|c|c|c|c|}
\hline Competencias/ Beneficios & 1 - 2 años & 2 - 3 años & $\begin{array}{c}3 \text { a mas } \\
\text { años }\end{array}$ & $\begin{array}{c}6 \text { meses - } \\
1 \text { año }\end{array}$ & $\begin{array}{c}\text { (en } \\
\text { blanco) }\end{array}$ & Total general \\
\hline 2 & & & 2 & 2 & 1 & 5 \\
\hline Oportunidad de crecimiento & & & & 1 & & 1 \\
\hline Sueldo y Beneficios & & & 2 & 1 & & 3 \\
\hline (en blanco) & & & & & 1 & 1 \\
\hline 3 & 4 & 2 & & 2 & & 8 \\
\hline Capacitación constante & & & & 1 & & 1 \\
\hline Clima laboral & & & & 1 & & 1 \\
\hline Horario flexible & 1 & & & & & 1 \\
\hline Oportunidad de crecimiento & 2 & 2 & & & & 4 \\
\hline Sueldo y Beneficios & $\overline{1}$ & & & & & 1 \\
\hline 4 & 19 & 5 & 1 & 15 & 1 & 41 \\
\hline Capacitación constante & & & & 1 & & 1 \\
\hline Clima laboral & 1 & & & 2 & & 3 \\
\hline Horario flexible & 2 & 1 & 1 & 2 & & 6 \\
\hline Oportunidad de crecimiento & 11 & 3 & & 3 & & 17 \\
\hline Sueldo y Beneficios & 5 & 1 & & 6 & & 12 \\
\hline Tener algo propio & & & & 1 & & 1 \\
\hline (en blanco) & & & & & 1 & 1 \\
\hline 5 & 27 & 15 & 5 & 10 & 3 & 60 \\
\hline Capacitación constante & & 1 & & 1 & & 2 \\
\hline Clima laboral & 4 & 2 & 1 & 1 & & 8 \\
\hline Horario flexible & 6 & 1 & 2 & 1 & & 10 \\
\hline Oportunidad de crecimiento & 12 & 7 & 1 & 6 & & 26 \\
\hline Proyectos & & 1 & & & & 1 \\
\hline Sueldo y Beneficios & 5 & 3 & 1 & 1 & & 10 \\
\hline (en blanco) & & & & & 3 & 3 \\
\hline 6 & 46 & 22 & 10 & 23 & 3 & 104 \\
\hline Capacitación constante & 1 & 2 & & & & 3 \\
\hline Clima laboral & 5 & 1 & 4 & 3 & & 13 \\
\hline Horario flexible & 4 & 3 & & 5 & & 12 \\
\hline Oportunidad de crecimiento & 27 & 11 & 6 & 8 & & 52 \\
\hline Sueldo y Beneficios & 9 & 5 & & 6 & & 20 \\
\hline Tener algo propio & & & & 1 & & 1 \\
\hline (en blanco) & & & & & 3 & 3 \\
\hline 7 & 42 & 21 & 6 & 35 & 2 & 106 \\
\hline Capacitación constante & 2 & 1 & & 1 & & 4 \\
\hline Clima laboral & 7 & 2 & 1 & 7 & & 17 \\
\hline Horario flexible & 4 & 4 & & 6 & & 14 \\
\hline Oportunidad de crecimiento & 17 & 10 & 3 & 17 & & 47 \\
\hline Propósito & 1 & & & & & 1 \\
\hline Sueldo y Beneficios & 11 & 4 & 2 & 4 & & 21 \\
\hline (en blanco) & & & & & 2 & 2 \\
\hline 8 & 24 & 11 & 2 & 11 & 2 & 50 \\
\hline Capacitación constante & & 1 & & & & 1 \\
\hline Clima laboral & 3 & 1 & & & & 4 \\
\hline Horario flexible & 1 & & & 2 & & 3 \\
\hline Oportunidad de crecimiento & 16 & 8 & 2 & 4 & & 30 \\
\hline Sueldo y Beneficios & 4 & 1 & & 5 & & 10 \\
\hline (en blanco) & & & & & 2 & 2 \\
\hline 9 & 4 & 2 & 1 & 1 & 1 & 9 \\
\hline Oportunidad de crecimiento & 3 & 2 & 1 & 1 & & 7 \\
\hline Sueldo y Beneficios & 1 & & & & & 1 \\
\hline (en blanco) & & & & & 1 & 1 \\
\hline Total general & 166 & 78 & 27 & 99 & 13 & 383 \\
\hline
\end{tabular}

\section{Elaboración propia}

- De las 9 personas que cumplieron con las 9 competencias 7 se motivan más por Oportunidades de crecimiento. De las 7 personas, 3 personas se quedan de 1 a 2 años. 
Tabla 13. Nivel de estudios y situación laboral

\begin{tabular}{|c|c|c|c|c|}
\hline Nivel de Estudio/Situ.Laboral & $\begin{array}{l}\text { He trabajado, pero } \\
\text { actualmente no }\end{array}$ & $\begin{array}{l}\text { Nunca he } \\
\text { trabajado }\end{array}$ & $\begin{array}{c}\text { Trabajo } \\
\text { Actualmente }\end{array}$ & Total general \\
\hline 2 & & 1 & 4 & 5 \\
\hline $\begin{array}{c}\text { Universitaria Completa } \\
\text { Universitaria Incompleta }\end{array}$ & & 1 & $\begin{array}{l}3 \\
1\end{array}$ & $\begin{array}{l}3 \\
2\end{array}$ \\
\hline 3 & & & 8 & 8 \\
\hline $\begin{array}{l}\text { Universitaria Completa } \\
\text { Universitaria Incompleta }\end{array}$ & & & $\begin{array}{l}7 \\
1\end{array}$ & $\begin{array}{l}7 \\
1\end{array}$ \\
\hline 4 & 8 & 1 & 32 & 41 \\
\hline $\begin{array}{l}\text { Universitaria Completa } \\
\text { Universitaria Incompleta }\end{array}$ & $\begin{array}{l}3 \\
5\end{array}$ & 1 & $\begin{array}{c}26 \\
6\end{array}$ & $\begin{array}{l}29 \\
12\end{array}$ \\
\hline 5 & 12 & 3 & 45 & 60 \\
\hline $\begin{array}{l}\text { Universitaria Completa } \\
\text { Universitaria Incompleta }\end{array}$ & $\begin{array}{l}9 \\
3\end{array}$ & $\begin{array}{l}2 \\
1\end{array}$ & $\begin{array}{c}37 \\
8\end{array}$ & $\begin{array}{l}48 \\
12\end{array}$ \\
\hline 6 & 15 & 3 & 86 & 104 \\
\hline $\begin{array}{l}\text { Universitaria Completa } \\
\text { Universitaria Incompleta }\end{array}$ & $\begin{array}{c}12 \\
3\end{array}$ & $\begin{array}{l}1 \\
2\end{array}$ & $\begin{array}{l}69 \\
17\end{array}$ & $\begin{array}{l}82 \\
22\end{array}$ \\
\hline 7 & 14 & 2 & 90 & 106 \\
\hline $\begin{array}{l}\text { Universitaria Completa } \\
\text { Universitaria Incompleta }\end{array}$ & $\begin{array}{l}8 \\
6 \\
\end{array}$ & 2 & $\begin{array}{l}79 \\
11 \\
\end{array}$ & $\begin{array}{l}87 \\
19 \\
\end{array}$ \\
\hline 8 & 7 & 2 & 41 & 50 \\
\hline $\begin{array}{l}\text { Universitaria Completa } \\
\text { Universitaria Incompleta }\end{array}$ & $\begin{array}{l}3 \\
4\end{array}$ & 2 & $\begin{array}{c}34 \\
7\end{array}$ & $\begin{array}{l}37 \\
13\end{array}$ \\
\hline 9 & 1 & 1 & 7 & 9 \\
\hline $\begin{array}{l}\text { Universitaria Completa } \\
\text { Universitaria Incompleta }\end{array}$ & 1 & 1 & 7 & $\begin{array}{l}8 \\
1\end{array}$ \\
\hline Total general & 57 & 13 & 313 & 383 \\
\hline
\end{tabular}

Elaboración propia

De las personas que cumplieron 6 y 7 competencias representan $54 \%$ del total de encuestados de las cuales el 38\% poseen Universitaria completa y actualmente se encuentran trabajando. El 4\% del 54\% se encuentra sin trabajo y están entre universitario completos e incompletos.

Tabla 14. Nivel de estudio, género y competencias cumplidas

\begin{tabular}{|c|ccccccccc|c|}
\hline Nivel de estudio / Género & A & B & C & D & E & F & G & H & I & Resultado \\
\hline Universitaria Completa & 115 & 219 & 128 & 263 & 283 & 234 & 274 & 151 & 185 & 301 \\
Femenino & 80 & 146 & 82 & 180 & 188 & 152 & 185 & 99 & 125 & 199 \\
Masculino & 35 & 73 & 46 & 83 & 95 & 82 & 89 & 52 & 60 & 102 \\
Universitaria Incompleta & 44 & 55 & 32 & 67 & 61 & 58 & 77 & 42 & 57 & 82 \\
Femenino & 22 & 31 & 17 & 38 & 32 & 38 & 44 & 28 & 33 & 47 \\
Masculino & 22 & 24 & 15 & 29 & 29 & 20 & 33 & 14 & 24 & 35 \\
\hline Total general & 159 & 274 & 160 & 330 & 344 & 292 & 351 & 193 & 242 & 383 \\
\hline
\end{tabular}

Elaboración propia 
Las competencias que tuvieron mayor cumplimiento por parte de los encuestados son las siguientes:

- G (Gran capacidad de comunicación) 351 personas cumplieron con esta competencias de las cuales $78 \%$ poseen Universidad completa, el 65\% fueron mujeres.

- E (Disposición para aprender) 344 personas cumplieron con esta competencias de las cuales $82 \%$ poseen Universidad completa y el $54 \%$ son mujeres con universidad completa. Para el caso de los hombres, 102 hombres validaron esta competencia, es la competencia que más hombres cumplieron.

- D (Resolución efectiva de conflictos) 330 personas cumplieron con esta competencia y es la competencia que más Universitarios incompletos cumplieron de las cuales 18 fueron mujeres y 29 hombres.

Tabla 15. Situación laboral, género y competencias cumplidas

\begin{tabular}{|c|ccccccccc|c|}
\hline Situación Laboral/Género & A & B & C & D & E & F & G & H & I & Resultado \\
\hline Femenino & 102 & 177 & 99 & 218 & 220 & 190 & 229 & 127 & 158 & 246 \\
He trabajado, pero actualmente no & 18 & 28 & 16 & 33 & 30 & 27 & 36 & 19 & 28 & 38 \\
Nunca he trabajado & 5 & 6 & 4 & 6 & 3 & 8 & 8 & 4 & 4 & 8 \\
Trabajo Actualmente & 79 & 143 & 79 & 179 & 187 & 155 & 185 & 104 & 126 & 200 \\
\hline Masculino & 57 & 97 & 61 & 112 & 124 & 102 & 122 & 66 & 84 & 137 \\
He trabajado, pero actualmente no & 5 & 9 & 5 & 15 & 17 & 17 & 18 & 7 & 17 & 19 \\
Nunca he trabajado & 3 & 4 & 3 & 5 & 4 & 4 & 2 & 2 & 3 & 5 \\
Trabajo Actualmente & 49 & 84 & 53 & 92 & 103 & 81 & 102 & 57 & 64 & 113 \\
\hline Total general & 159 & 274 & 160 & 330 & 344 & 292 & 351 & 193 & 242 & 383 \\
\hline
\end{tabular}

Elaboración propia

Las competencias:

- G (Gran capacidad de la comunicación) 351 personas que cumplieron con esta competencia están actualmente trabajando, 10 nunca han trabajado.

- E (Disposición para aprender) 344 personas cumplieron con esta competencia, esta competencia es la que más personas cumplieron y se encuentran trabajando tanto en hombres como mujeres.

- D (Resolución efectiva de conflictos) 330 personas cumplieron con esta competencia, 271 se encuentran trabajando de las cuales $80 \%$ fueron mujeres. 
Tabla 16. Tiempo de permanencia y competencias cumplidas

\begin{tabular}{|c|ccccccccc|c|}
\hline Tiempo de permanencia & A & B & C & D & E & F & G & H & I & Resultado \\
\hline 1 - 2 años & 71 & 124 & 77 & 144 & 150 & 125 & 152 & 80 & 98 & 166 \\
2 - 3 años & 33 & 56 & 32 & 69 & 76 & 66 & 70 & 38 & 46 & 78 \\
3 a mas años & 10 & 20 & 7 & 25 & 27 & 17 & 25 & 13 & 16 & 27 \\
6 meses - 1 año & 37 & 64 & 37 & 81 & 84 & 72 & 94 & 56 & 75 & 99 \\
(en blanco) & 8 & 10 & 7 & 11 & 7 & 12 & 10 & 6 & 7 & 13 \\
\hline Total general & 159 & 274 & 160 & 330 & 344 & 292 & 351 & 193 & 242 & 383 \\
\hline
\end{tabular}

Las competencias que más veces fueron cumplidas son las siguientes:

- G (Gran capacidad de comunicación) 351 personas cumplieron con esta competencias, el $43 \%$ permanece de 1 a 2 años en sus empresas. Por otro lado, el 26\% solo permanece de 6 meses a 1 año.

- E (Disposición para aprender) 344 personas cumplieron con esta competencias, el 43\% permanece entre 1 a 2 años mientras que el $23 \%$ entre 6 meses a 1 año.

- Solo el $20 \%$ del total de encuestados permanece más de 3 años en sus empresas.

- Las 13 respuestas en blanco representan a las personas que nunca han laborado. 
Tabla 17. Tiempo de permanencia, motivación y competencias cumplidas

\begin{tabular}{|c|c|c|c|c|c|c|c|c|c|c|}
\hline \multicolumn{11}{|c|}{ Motivaciónes en Centros de Labor } \\
\hline Tiempo de permanencia & A & B & $\mathbf{C}$ & D & $\mathbf{E}$ & $\mathbf{F}$ & $\mathbf{G}$ & 1 & $\mathbf{I}$ & Resultado \\
\hline 6 meses - 1 año & 37 & 64 & 37 & 81 & 84 & 72 & 94 & 56 & 75 & 99 \\
\hline Capacitación constante & 1 & 2 & & 3 & 4 & 1 & 4 & 2 & 2 & 4 \\
\hline Clima laboral & 4 & 9 & 4 & 11 & 12 & 11 & 14 & 7 & 11 & 14 \\
\hline Horario flexible & 5 & 9 & 10 & 11 & 14 & 15 & 14 & 8 & 15 & 16 \\
\hline Oportunidad de crecimiento & 15 & 28 & 15 & 34 & 37 & 29 & 37 & 24 & 33 & 40 \\
\hline Sueldo y Beneficios & 10 & 16 & 8 & 20 & 15 & 15 & 23 & 15 & 13 & 23 \\
\hline Tener algo propio & 2 & & & 2 & 2 & 1 & 2 & & 1 & 2 \\
\hline $1-2$ años & 71 & 124 & 77 & 144 & 150 & 125 & 152 & 80 & 98 & 166 \\
\hline Capacitación constante & 1 & 1 & 2 & 3 & 3 & 3 & 3 & 1 & 3 & 3 \\
\hline Clima laboral & 9 & 13 & 8 & 19 & 19 & 14 & 18 & 12 & 15 & 20 \\
\hline Horario flexible & 9 & 12 & 8 & 14 & 15 & 13 & 14 & 7 & 9 & 18 \\
\hline Oportunidad de crecimiento & 37 & 69 & 40 & 79 & 82 & 66 & 84 & 41 & 48 & 88 \\
\hline Propósito & & 1 & 1 & & 1 & 1 & 1 & 1 & 1 & 1 \\
\hline Sueldo y Beneficios & 15 & 28 & 18 & 29 & 30 & 28 & 32 & 18 & 22 & 36 \\
\hline $2-3$ años & 33 & 56 & 32 & 69 & 76 & 66 & 70 & 38 & 46 & 78 \\
\hline Capacitación constante & 3 & 4 & 3 & 5 & 4 & 4 & 3 & 2 & 4 & 5 \\
\hline Clima laboral & 3 & 4 & 1 & 5 & 6 & 5 & 5 & 5 & 4 & 6 \\
\hline Horario flexible & 3 & 7 & 2 & 8 & 9 & 8 & 8 & 3 & 7 & 9 \\
\hline Oportunidad de crecimiento & 16 & 29 & 22 & 39 & 43 & 35 & 41 & 22 & 24 & 43 \\
\hline Proyectos & & & 1 & & 1 & 1 & 1 & & 1 & 1 \\
\hline Sueldo y Beneficios & 8 & 12 & 3 & 12 & 13 & 13 & 12 & 6 & 6 & 14 \\
\hline 3 a mas años & 10 & 20 & 7 & 25 & 27 & 17 & 25 & 13 & 16 & 27 \\
\hline Clima laboral & 4 & 5 & & 6 & 6 & 3 & 6 & 3 & 3 & 6 \\
\hline Horario flexible & & & & 3 & 3 & 2 & 3 & 1 & 2 & 3 \\
\hline Oportunidad de crecimiento & 6 & 12 & 6 & 13 & 13 & 8 & 13 & 7 & 9 & 13 \\
\hline Sueldo y Beneficios & & 3 & 1 & 3 & 5 & 4 & 3 & 2 & 2 & 5 \\
\hline (en blanco) & 8 & 10 & 7 & 11 & 7 & 12 & 10 & 6 & 7 & 13 \\
\hline (en blanco) & 8 & 10 & 7 & 11 & 7 & 12 & 10 & 6 & 7 & 13 \\
\hline Total general & 159 & 274 & 160 & 330 & 344 & 292 & 351 & 193 & 242 & 383 \\
\hline
\end{tabular}

- Las personas con mayores competencias cumplidas que fueron gran capacidad de comunicación y disposición para aprender se quedan entre 1 y 2 año y se sienten motivadas en sus centros de trabajo por las Oportunidades de crecimiento seguidos por el sueldo y beneficio otorgado.

- Para todos los casos proyectos y el horario flexible fue el beneficio que menos motivó a los colaboradores.

- Para las personas con más de 3 años en una compañía no les es relevante el clima laboral, como para los que se quedan por poco tiempo en una empresa como los de 1 a 2 años. 


\section{Conclusiones y recomendaciones}

\section{Conclusiones}

- La transformación digital está generando que las empresas tengan que adaptarse a un nuevo modelo de negocio, nuevas formas de trabajo y sobre todo nuevos perfiles para sus colaboradores, debido a que se están creando áreas, nuevos puestos de trabajo y todos enfocados a dar un mejor servicio a sus clientes tanto internos como externos.

- Las empresas de seguro en Lima metropolitana no son la excepción, pues en las 4 empresas entrevistadas coincidieron que el proceso de transformación digital recién se está llevando a cabo con un promedio de antigüedad de 1 año y medio por lo cual los perfiles, la misión y visión no se encuentran totalmente definidas debido a que están observando el comportamiento de este nuevo cambio para poder realizar un planeamiento estratégico bien definido.

- En la actualidad no se tiene un perfil definido como un líder disruptivo para la transformación digital en Perú, lo que se tiene en estudios realizados por consultoras como el Estudio de Deloitte "Reescribiendo las reglas para la era digital" Tendencias en Capital Humano 2017, son características que debe tener un Líder disruptivo. Cabe resaltar que todos los estudios que se analizaron al momento de investigar el tema, sugieren la disrupción y tener un líder disruptivo a futuro para poder realizar una transformación digital eficiente.

- Las 4 empresas de seguros con las que se tuvo entrevistas no cumplieron con las 9 competencias propuestas por el estudio de semana económica para un trabajador para afrontar la transformación digital. Sin embargo, juntas y evaluándolas como Industria de seguros las 9 competencias propuestas por el estudio están presentes en lo que solicita industria.

- Para el caso de Millennials, de los 383 encuestados para la muestra, solo 9 personas cumplieron con las 9 competencias para un trabajador la totalidad de encuestados y la competencia con mayor frecuencia de respuesta por parte de los encuestados fue 
Disposición para aprender. Por lo tanto, existen personas en el mercado laboral que cumplen con las competencias para un futuro líder en trasformación digital.

- En conclusión, existen evidencia estadística para aceptar la hipótesis nula H0, en el mercado laboral existe un perfil adecuado con las competencias requeridas para el futuro líder en transformación digital y cubrir las necesidades de las compañías de seguros en Lima Metropolitana.

- Finalmente, para el caso de liderazgo disruptivo, solo 8 de las 9 competencias expuestas por semana económica se encuentran alineadas a las 12 competencias expuestas por el estudio de Deloitte para un líder disruptivo. Lo que corresponde a un 67\% de alineación entre característica y competencias. En conclusión, 8 de las competencias para un trabajador en transformación digital pertenecen a las 12 competencias del líder disruptivo en transformación digital.

- Como punto adicional a las conclusiones, las limitaciones que se presentaron en la investigación fueron las siguientes: Carencia de fuentes bibliográficas referentes a transformación digital y Liderazgo disruptivo, lo que se encontró fueron artículos periodísticos de investigación, papers y estudios de consultoras. El factor tiempo limitó a realizar un estudio más completo, razón que se tuvo para delimitar la ciudad e industria para la investigación. Asimismo, nos enfocamos en un rango de edad debido a las distintas muestras que aplicaban distintos autores al momento de definir el rango de la generación Y. 


\section{Recomendaciones}

- En la etapa de análisis de encuestas a los Millennials, se recomienda hacer búsquedas de futuros trabajadores para la transformación digital en rangos de edad de 24 a 26 años de las cuales las mujeres son la población que cumple con mayor número de competencias expuestas por semana económica.

- Se recomienda identificar al potencial talento y tener planes de retención para los futuros líderes en transformación digital, debido a que el $81 \%$ de nuestros encuestados se encuentra laborando actualmente y solo el $2 \%$ nunca ha laborado. Por lo que es importante tener una buena estrategia para buscar talento dentro de otras empresas y retener a los que ya son parte de nuestro equipo.

- Se recomienda hacer búsqueda de talento que cumpla con el perfil para la transformación digital con estudios Universitarios completos, ya que representaron el $78 \%$ de nuestros encuestados. El 87\% de los que poseen universidad completa se encuentra laborando.

- Se recomienda innovar en los procesos de selección y demostrar lo valioso que otorga la empresa, debido a que el $62 \%$ de los encuestados se ha presentado a procesos de selección en el último año. El 59 \% de los encuestados ha rechazado la oferta laboral propuesta, debido a salario, ubicación, línea de carrera, beneficios y horario.

- Se recomienda tener énfasis en el beneficio de Oportunidad de crecimiento, debido a que los futuros trabajadores en transformación digital buscan este beneficio para poder mantenerse dentro de una empresa, aunque su tiempo de permanencia es de 1 a 2 años.

- La presente investigación será de utilidad para las empresas de Seguros de Lima Metropolitana como base de ayuda en la identificación de uno de los principales motores para lograr la transformación digital, es decir el capital humano, el cual trabajará en el proceso de cambio de la transformación digital de las compañías en mención. Asimismo, permitirá ayudar a otras industrias como referencia de la importancia que implica este proceso de cambio dentro de sus organizaciones y la importancia del rol a cumplir de los millenials en la transformación digital de las empresas peruanas. 


\section{Referencias bibliográficas}

Alles, M. A. (2007). Comportamiento Organizacional. Cómo lograr un cambio organizacional a traves de la gestión por competencias. Buenos Aires: Granica.

Alles, M. A. (2009). Diccionario de competencias: La trilogía: Las 60 competencias más utilizadas. Buenos Aires: Granica.

Blog de la Pontífice Universidad Católica del Perú. (2015). Millennials en el Perú: Una generación con grandes oportunidades laborales. Obtenido de https://btpucp.pucp.edu.pe/archivo-reportajes/millennials-en-el-peru-unageneracion-con-grandes-oportunidades-laborales/ [Consulta: 12 de octubre de 2016]

Cacho-Elizondo, S. (2007). Guía para la transformación digital: Un tema de estrategia, no de tecnología. Revista Istmo, 350 (1) 24-28.

Cámara Homdureña de Aseuradores-CAHDA. (13 de octubre de 2016). Hay mercado potencial de US\$398 millones en primas de seguros en América Latina. CAHDA. Obtenido de http://www.cahda.org/hay-mercado-potencial-de-us398-millones-en-primas-deseguros-en-america-latina/ [Consulta: 10 de octubre de 2016]

Casado, J. M. (05 de setiembre de 2017). El rol del líder en la transformación digital. Harvard Deusto. Obtenido de https://www.harvard-deusto.com/el-rol-del-lider-en-latransformacion-digital [Consulta: 15 de octubre de 2017]

CEPLAN. (04 de marzo de 2015). Ceplan: Los Millennials marcarán la fuerza laboral en el Perú dentro de 10 años. Gestión. Obtenido de https://gestion.pe/economia/ceplanmillennials-marcaran-fuerza-laboral-peru-10-anos-152240 [Consulta: 17 de Ocubre de 2017]

Chirinos, N. (2009). Características generacionales y valores: su impacto en lo laboral. Observatorio Laboral Revista Venezolana, 2 (4), 135-152. Obtenido de http://www.redalyc.org/pdf/2190/219016846007.pdf

Deloitte. (2017). Reescribiendo las reglas para la era digital - Tendencias Globales en Capital Humano. Deloitte University Press.

Dessler G. \& Varela R. (2011). Administración de recursos humanos enfoque latinoamericano (5 $5^{\mathrm{a}}$ ed.). México: Pearson educación.

Falcon, D. (2015). Obtenido de http://blogs.gestion.pe/innovaciondisrupcion/2015/09/transformacion-digitalseguros.html.[Consulta: 25 de octubre de 2017].

Fischman, D., \& Universidad Peruana de Ciencias Aplicadas. (2009). Cuando el liderazgo no es suficiente: Desarrolle su inteligencia cultural en la empresa. Lima: Lima: Punto y Coma: El Comercio: UPC, Fondo Editorial.

Forbes. (22 de diciembre de 2014). 6 rasgos clave de los millennials, los nuevos consumidores. Forbes. Obtenido de https://www.forbes.com.mx/6-rasgos-clave-de-los-millennialslos-nuevos-consumidores/ [Consulta: 20 de octubre de 2017] 
García-Arroyo, A. (2017). ¿Por qué los esfuerzos hacia la transformación digital seguirán fracasando? Capital Humano, 58-59.

Gestión. (22 de setiembre de 2017). Applying Consulting: Una empresa sin transformación digital está condenada a morir. Gestión. Obtenido de https://gestion.pe/tecnologia/applying-consulting-empresa-sin-transformaciondigital-esta-condenada-morir-2200631 [Consulta: 20 de octubre de 2017]

Gestión. (18 de junio de 2017). Deloitte: El 52\% de empresas en Perú buscan la transformación digital, ¿cuántas lo logran? Gestión. Obtenido de https://gestion.pe/tecnologia/deloitte-52-empresas-peru-buscan-transformaciondigital-cuantas-lo-logran-2192858 [Consulta: 20 de octubre de 2017]

Gestión. (29 de agosto de 2017). Generación Z: Cuatro claves para venderles con éxito. Gestión. Obtenido de https://gestion.pe/tendencias/generacion-z-cuatro-claves-venderlesexito-142544 [Consulta: 11 de octubre de 2017]

Gestión. (04 de julio de 2017). Generación Z: El efecto en la productividad laboral de una generación adicta al smartphone. Gestión. Obtenido de https://gestion.pe/tendencias/management-empleo/generacion-z-efectoproductividad-laboral-generacion-adicta-smartphone-138504 [Consulta: $12 \mathrm{de}$ octubre de 2017]

Gestión. (25 de setiembre de 2017). Transformación digital: El 50\% de empresas no tienen una estrategia para implementarla. Gesión. Obtenido de https:/gestion.pe/tecnologia/transformacion-digital-50-empresas-no-tienenestrategia-implementarla-2200771 [Consulta: 20 de octubre de 2017]

Harvard Business Review. (28 de diciembre de 2017). Las seis claves para que la transformación digital sea un éxito. Harvard Business Review. Obtenido de https://www.hbr.es/tecnolog/963/las-seis-claves-para-que-la-transformaci-ndigital-sea-un-xito [Consulta: 28 de diciembre de 2017]

Hernández, S. R., \& Fernández, C. C. (2014). Metodología de la investigación (6 $6^{\underline{a}}$ ed.). México D.F.: McGraw-Hill Interamericana.

Institute for the future. (2011). Future work skills 2020. Institute for the future. Obtenido de http://www.iftf.org/futureworkskills/ [Consulta: 01 de Noviembre de 2017]

IPSOS Apoyo. (2016). Perfil del Adulto Joven (21 a 35 años) Generación "Y" o Millennials Lima Metropolitana 2016. Lima: Ipsos apoyo.

Ipsos apoyo. (27 de marzo de 2017). Lo que debes saber de las Generaciones " $X$ ", " $Y$ " $y$ " $Z$ ". Mercado negro. Obtenido de http://www.mercadonegro.pe/lo-debes-saber-lasgeneraciones-x-z/ [Consulta: 18 de Octubre de 2017]

Karsh, B. \& Templin, C. (2013). Manager 3.0: A Millennial's Guide to Rewriting the Rules of Management. New York: AMACON.

Kotler, P. \& Armstrong, G. (2012). Marketing (14를 ed.). México: Pearson educación. 
La Nación. (12 de junio de 2016). Sin millennials en la oficina, no hay futuro. La Nación. Obtenido de https://www.lanacion.com.ar/1907829-sin-millennials-en-la-oficina-nohay-futuro [Consulta: 20 de Octubre de 2017]

Lévy-Leboyer, C. (2002). Gestión de las competencias : Cómo analizarlas, cómo evaluarlas, cómo desarrollarlas. Barcelona : Gestión 2000.

Lussier, R., \& Achua, C. (2011). Liderazgo : Teoría, aplicación, desarrollo de habilidades. México, D.F.: Cengage Learning.

Malhorta, N. K. (2008). Investigación de mercado . México : Pearson educación.

Meneses, R. (2015). LIDERAZGO DISRUPTIVO ¿Para qué? Revista Istmo, 10-14.

Mercado Negro. (27 de Marzo de 2017). Obtenido de http://www.mercadonegro.pe/lodebes-saber-las-generaciones-X-z/ [Consulta: 25 de setiembre de 2017]

Mitta, D. \& Dávila, C. (2015). Retención del talento humano: políticas y practicas aplicadas sobre jóvenes Millennials en un grupo de organizaciones (Tesis de Licenciatura, Pontificia Universidad Católica del Perú, Facultad de Gestión y Alta Dirección,Lima,Perú). Obtenido de http://tesis.pucp.edu.pe/repositorio/bitstream/handle/123456789/6948/MITTA_D ANIEL_DAVILA_CARMEN_RETENCION.pdf?sequence=1\&isAllowed=y [Consulta: 15 de setiembre de 2017]

Newbold, Carlson, Thorne, Carlson, William L, \& Thorne, B. M. (2008). Estadística para administración y economía (6ª ed.). Madrid: Pearson educación.

PWC. (2016). Insurance 2020: El futuro de las transaciones en el sector seguros. PWC. Obtenido de https://www.pwc.es/es/publicaciones/financiero-seguros/assets/insurance2020-resumen-ejecutivo.pdf [Consulta: 10 de noviembre de 2017]

Semana Ecónomica. (26 de junio de 2014). Generación Y: ¿Cuáles son los riesgos para su empleabilidad?. Semana Ecónomica. Obtenido de http://semanaeconomica.com/article/management/gerencia/139347-generacion-ycuales-son-los-riesgos-para-su-empleabilidad/?ref=especial [Consulta: 10 de octubre de 2017]

Semana económmica. (2016). Trabajo 3.0 El Futuro del Trabajo. Semana económica, 56-63.

Sortino, J. (28 de diciembre de 2017). Las seis claves para que la transformación digital sea un éxito. Harvard Business Review. Obtenido de https://www.hbr.es/tecnolog/963/lasseis-claves-para-que-la-transformaci-n-digital-sea-un-xito [Consulta: 30 de diciembre de 2017].

Spencer, L., \& Spencer, Signe. (1993). Competence at work : Models for superior performance. New York: John Wiley \& Sons.

Yukl, G. (2008). Liderazgo en las organizaciones (6ae ed.). Madrid: Pearson Educación.

zemsania Global Group . (16 de noviembre de 2015). wirtualdb, nuevo concepto de transformación digital que convierte datos en modelos de negocio. Obtenido de http://www.zemsania.com/nace-wirtualdb-nuevo-concepto-de-transformacion- 
digital-que-convierte-datos-en-modelos-de-negocio/ [Consulta: 10 de octubre de 2017 ] 


\section{ANEXOS}

\section{Anexo 1. Entrevista de profundidad}

Preguntas realizadas:

1. Se mencionará la misión, visión y valores de cada compañía para hacer entrar en contexto al entrevistado.

2. ¿Qué acciones realizan para que se cumplan? (referente al contexto del punto 1)

3. ¿Cuál es la cultura de compañía?

4. ¿Existe alguna iniciativa para el proceso de trasformación digital de la compañía?

5. ¿Qué proyectos de transformación digital tiene la compañía?

6. ¿Ha cambiado la misión, visión y valores de la compañía para afrontar el proceso de transformación digital?

7. ¿Qué acciones realizan para alinear a sus colaboradores con la nueva misión y visión enfocada a la transformación digital?

8. ¿Cuáles son las competencias requeridas para el perfil de la compañía?

9. ¿En qué niveles organizacionales ha sido cambiado el perfil de puesto?

10. ¿Cómo la cultura organizacional ha cambiado con la transformación digital?

11. ¿Qué tan complicado fue realizar el cambio de transformación digital? ¿En qué nivel organizacional se reflejó mayor resistencia al cambio?

12. ¿Cómo están afrontando la resistencia al cambio? Solo aplica si la anterior es afirmativa

13. ¿Las exigencias de contar con un nuevo perfil vienen empujados por la necesidad del mercado o por decisión de la alta gerencia? 
14. ¿En qué fuentes se basaron para obtener las competencias de un perfil profesional para la transformación digital?

15. ¿Cuál es el perfil de un colaborador que está comprometido en el proceso de transformación digital?

16. ¿Qué porcentaje de los colaboradores actuales tiene el perfil requerido?

17. Según el nivel organizacional ¿Cuáles son los rangos de edades solicitadas para cada posición? (Asistente, Analista, jefe, Sub Gerente, Gerente) Se busca saber que en que jerarquía se encuentran los Millennials y así identificar que tanto poder de toma de decisiones poseen

18. ¿Hace cuánto tiempo RRHH empezó a reclutar personal con un perfil diferente?

19. ¿Cuál es el proceso de selección del personal?

20. ¿Qué tan complicado es el proceso de selección de un trabajador Millennials? ¿Cuánto tiempo en promedio dura el proceso?

21. ¿Es complicado encontrar en el mercado laboral el perfil requerido por la empresa? Si la respuesta es sí, ¿Por qué es complicado?

22. Los Millennials ¿Han rechazado la oferta laboral propuesta por la empresa? ¿Con qué frecuencias ha sucedido? ¿Por qué consideran que ha sucedido esto?

23. ¿Qué impacto ha generado a la empresa el personal con el nuevo perfil para lograr sus objetivos?

24. ¿Cuál es el tiempo promedio de permanencia de los Millennials en la compañía? (Rangos de edad de 18 a 35 años)

25. ¿Qué es lo que busca la generación Millennials para permanecer por más tiempo en la compañía?

26. ¿La compañía cuenta con un líder de transformación digital? 
27. ¿Cuánto tiempo permanece en promedio el líder de transformación digital?

28. ¿Tienen planes de retención de talento para el personal con perfil de transformación digital? ¿Qué acciones realizan para hacer efectivo este plan?

29. ¿Realizan planes de formación en sus colaboradores para que se alineen al nuevo perfil?

30. ¿Ha cambiado la remuneración de estos trabajadores respecto a los cambios de competencias en los perfiles?

31. ¿Qué mensaje final le dejaría a los Millennials que desea atraer su empresa?

\section{RIMAC:}

Entrevistado: Guillermo Gates

Puesto: Analista de selección

Orientados al reciclaje, programas sociales, hay mucha ayuda por parte de la organización, recaudación de dinero en cantidades grandes. Rimac son 4 mil colaboradores aproximadamente y parte de su cultura es darle equilibrio a su vida laboral (no sobrecargar al trabajador). Por tal motivo, existen programas de días libres aparte de sus vacaciones. En cuanto al tema de ser líderes mundiales, tienen una visión amplia corporativa y estratégica que hace a Rimac la empresa con mayor posicionamiento en el grupo Breca. El gerente general tiene 1 año y medio aproximadamente, tiene una visión global de los negocios y la idea es implementar cosas a nivel de tecnología, marketing, recursos humanos. Para ello, tienen ciertos pilares que se toman para lograr la internacionalización y buscan gente de todos lados que van a estudiar fuera. La idea es atraer ese talento que no solo es peruano, porque hay extranjeros de muchas universidades.

Visión: Dar la seguridad a las personas de que todo va estar bien cuando algo suceda y que Rimac estará para ellos.

Valores: Vocación al servicio, desde selección se busca que la gente esta enfocada al cliente externo e interno, hay mucho trabajo que se realiza desde dentro y utilizan los productos de 
Rimac, de esta forma buscan mejorar. Somos íntegros, todo es claro, directo y abierto, si estas contra el código de conducta serán sancionadas. Existen canales de comunicación para que la gente reporte las cosas que puedan ir encontrando o prácticas no necesariamente adecuadas. Estamos comprometidos, el compromiso de siempre trabajar bien a nivel de valores, es el compromiso que el personal debe tener para estar en Rimac. Todos en todos lados son felices cuando comprenden la trascendencia de su trabajo. Buscamos la excelencia, no se quedan en el estatus QO, somos líderes y buscamos mejoras.

Para empezar la cultura no está escrito, es lo que marca la forma de interactuar de la gente, saber que está bien o mal que nadie lo diga, la cultura en si influye mucho en el sentido de orgullo que puedes tener del lugar donde trabajas. Trabajar en la mejor empresa del país que pertenece al mejor grupo económico del país haciendo cosas buenas por la gente y no solo el orgullo, si no que puedes hablar abiertamente decir lo que opinas y te escucharán para seguir mejorando, hay muchas cosas que conforman la cultura de Rimac.

En el área de MKT Rimac tiene 10 divisiones y una es la de MKT y personas, la cual mide mediante una serie de datos numéricos logaritmos que permiten saber y predecir comportamientos. Por ejemplo, Netflix ves series y mediante esta información ellos pueden saber que te gusta y tener una lista de recomendaciones.

Otra iniciativa fue la organización de la Hackaton para buscar gente que genere estos logaritmos y resolver problemas. El concurso fue abierto y dirigido a los hackers, personas que encuentra una forma novedosa y más rápida para solucionar el problema, de cualquier rango de edad, pero que haya ganado o participado anteriormente en algún concurso similar. El evento se realizó en agosto, desde las 8pm hasta las 7 am, para la comodidad de los participantes. Para el desarrollo del concurso Rimac dejaba un problema matemático complejo con información de clientes y ellos tenían que determinar con un logaritmo el comportamiento del cliente con respecto al pago o no de su seguro para el próximo mes. Rimac tenía un $90 \%$ que realizaba el pago y trabajaban con el $10 \%$ que no pagaba.

En cuanto al cambio de Misión y Visión con el nuevo enfoque de la transformación digital, todavía no se realiza el cambio. Rimac está cambiando, ha tenido cambio de Gerencia General, cambio cultural, lo último que cambió fue el código de vestimenta. 
Las competencias están alineadas a lo mencionado en la Misión, visión y los valores. Estos son: capacidad para priorizar, capacidad para poder estar en búsqueda de la mejora continua, la excelencia, la gestión de nuevos retos, respeto, comunicación abierta, tener pasión por lo que hace y ser humilde.

Para hacer efectivo el cambio de transformación digital, se tuvo resistencia, ya que cuando se realiza un cambio cultura se debe tener en cuenta la sensibilidad que tiene, no se puede llegar y hacer cambios bruscos que generen incertidumbre en los colaboradores. Cambios frontales que lastimosamente hace que el talento se vaya. El cambio está llegando poco a poco, si han tenido salidas de gente, cambios de GG, en cabezas, en el mando medio, direcciones y VPs, el cambio a nivel de tecnología se está dando y Rimac apuesta por ese cambio, Se tiene gente que está a favor y contra.

Para afrontar la resistencia al cambio, Rimac está siendo muy abierto con la comunicación para reducir el miedo del personal. Si hay salidas y cambios se comunican y son los que se harán, el personal debe entender que es un nuevo rumbo de la empresa, aunque haya incertidumbre y eso genere miedo. Otra medida tomada es las reuniones de la VP de RRHH en las que explicaba los cambios que se están realizando y las nuevas estrategias que se están aplicando. Por suerte RRHH está dentro de la plana directiva y considerada como un área estratégica y es parte de toma de decisiones. Además, cuenta con un plan de trabajo hasta el 2030 y eso genera estabilidad laboral, pues los colaboradores saben qué hacemos las cosas bien.

Para contar con un nuevo perfil laboral, la decisión vino por necesidad del mercado y por decisión de la alta dirección. Una organización es afectada por sus clientes y competencias, si no te adaptadas a las exigencias del mercado desapareces. Lo que Rimac hizo es adaptarse a las necesidades del mercado. Se enfocaron en sus clientes y generarles un mejor servicio siendo más competitivos. Rimac siempre está trabajando en mejorar para dar un mejor servicio.

En cuanto al proceso de selección de Rimac es el siguiente: 
Muchas veces se realiza Headhunting, identificamos gente que haya trabajado en cosas de innovación, es difícil porque son gente con perfil escaso. Se buscan por LinkedIn, se hace convocatorias bien específicas, es un proceso de selección especial. Se hacen juegos para que en equipos formen circuitos con los materiales que entregamos, el grupo que hagan que la pelota dure más en el circuito gana, se ven temas de liderazgo, innovación, solución de problemas, comunicación, de escucha, tolerancia. En una evaluación muy particular que se tuvo, participó selección y gerencia para observar a sus futuros colaboradores. Este proceso duró un día. Se realiza un proceso de análisis por cada uno de los candidatos y ver qué cantidad de gente se encuentra apta para el perfil y recién empiezan las entrevistas.

El proceso normal está compuesto por:

- $\quad$ Entrevista RRHH

- Innovación

- $\quad$ Entrevista estratégica

- $\quad$ Entrevista con el VP del área

Respecto al tema de rotación, en el caso de practicantes duran máximo 1 año y luego se marchan a pesar de nuestra cultura flexible con ellos. En otros rangos de edades como el de los Millennials llegan a durar entre 1 y 3 años; sin embargo, para el área de transformación digital no hemos tenido rotación por el momento.

Actualmente el líder en transformación digital es Fernando Ríos Sarmiento, VP

Ejecutivo de Seguros Personales y Marketing Digital. Finalmente, el área de compensaciones ha elaborado una banda salarial diferente para tratar de retener a este talento escaso ya que otras Industrias como la Banca también están apostando por este cambio.

\section{MAPFRE}


Entrevistado: Pablo Trelles

Puesto: RRHH \& Estrategia Digital

En la parte de misión y visión tenemos protocolos muy alineados en los 5 continentes, al ser una multinacional, se encargan que las buenas prácticas que se realizan en la casa matriz de España, se replican en todos los países con funcionamiento Mapfre. Por otra parte, los valores son vitales para el buen funcionamiento de una aseguradora, enfocada a su slogan "la aseguradora Global de confianza" y es lo que quiere transmitir a sus clientes, ya que es confianza lo que finalmente vendemos por un servicio que al final quizás nunca se use. Es la única aseguradora y reaseguradora, y la única empresa que no pertenece a un grupo económico, como Pacifico, Interseguro que tiene respaldo

La cultura de la compañía es bien estructurada y jerárquica, debido al giro del negocio, es muy formal. A futuro se busca cambiar la mentalidad de la " empresa extranjera que vende seguros en el País", Estamos tomando acciones para no sentirnos lejano. Acciones internas para desarrollarse de manera externa y que los clientes digan " yo confío en esta empresa" y se sienta más cercana. Tratamos de mejorar tiempos en quejas, no queremos que esperes más de 8 días, ahora tenemos un sistema interno donde las personas competentes están dispuestas a ayudarte, con flujos de respuestas muy claros.

Uno de los grandes avances que tiene Mapfre es que normalmente la venta de seguros es a nivel de face to face, eso implica mucho tiempo. Mapfre está estableciendo una red digital para vender en una menor cantidad de tiempo por teléfono o por internet. Las acciones son mucho más rápidas y pueden vender 50 seguros en una hora. Tratamos mucho de involucrar las redes sociales y el plano digital en todos los colaboradores. Al ser una empresa de seguros que vende servicios, queremos que todo se fomente de manera digital. Queremos que las buenas prácticas hechas en Perú se hagan en todo el mundo donde esta Mapfre y viceversa, mantener una cultura de servicio Global. Nos mantenemos capacitados e informados a través del intranet. Tenemos oficinas virtuales desde donde se puede ver niveles de siniestralidad de los colaboradores, usos de EPS y toda la información que tenemos de nuestros trabajadores. 
Hacemos esfuerzos para lograrlo, estamos en campañas internas, no podemos revelarlo porque sigue siendo proyecto, sirve para posicionar esa nueva misión y visión en los colaboradores y estamos usando los canales virtuales de comunicación de la compañía.

Básicamente, todas las personas que trabajan en Mapfre tienen inducciones, y tienes que involucrarte al giro del negocio, tienes que hacerla sentir tuya y sentir que los objetivos del negocio son tuyos. Un trabajador de Mapfre está capacitado para alinearse a los objetivos de la empresa.

Perfil Innovador, que le guste trabajar en equipo, de relaciones interpersonales, colaborativo, aceptan feedback, mejorar, retroalimentación. Puedes entrar con la tranquilidad que vas a aprender y hacer una línea de carrera. Antes el canal digital no existía, antes el perfil era más frontal, ahora se busca una persona con capacidad de dar una respuesta más rápida, que puede solucionar un problema de una manera diferente.

El cambio es complicado, pero se puede lograr. La transformación digital está encargada desde la cabeza y es donde tienen que estar seguros de que se va lograr, que no sientan miedo o riesgo de las acciones que estamos realizando. Es el futuro del mundo y tenemos que estar con esos factores alineados. Hay áreas "afectadas", ya que la transformación los ha sacado de sus estatus QO. Creen que ya tienen buenos resultados, pero no se dan cuenta que podemos tener mejores resultados. Por otro lado, hay casos especiales donde la edad del trabajador ha sido fundamental en la resistencia al cambio, pero hay casos especiales donde no sucede.

La resistencia es por parte de una minoría, los cargos más altos están apostando por la transformación digital y les da todos los beneficios que ello conlleva. La resistencia es mínima, porque la empresa en general tiene un plan de trabajo y están viendo que tenemos resultados.

El cambio es una iniciativa propia que dará buenos resultados y como toda empresa busca lo mejor para seguir creciendo y mejorar. Se cree que se seguirá creciendo sin ningún problema, vamos a seguir aumentando en los agentes de canal digital donde ya somos 200 . Asimismo, hay personas con muchas personas que están liderando el cambio desde hace años, son gente que conoce bien el mercado y son quienes están tomando las riendas de este 
cambio. Por ejemplo, En marketing digital, tenemos 8 personas y en red digital son 200, 300 aproximadamente son digitales $10 \%$ del headcount. En cuanto al impacto que ha generado se observa el cambio al hacer las cosas y el enfoque. Son cambios positivos que han sido bueno para todos.

El equipo de transformación digital tiene aproximadamente 1 año, por lo cual la rotación no es alta. Mapfre brinda una línea de carrera y busca que su personal esté involucrado con la industria, aprenda de su trabajo y vida diaria. Las buenas prácticas hacen que sea un pilar para conservar a sus trabajadores. La persona que lidera al esquipo es la directora Silvana Orizoli, quien junto con otras gerencias trabajan para que estén alineados a os objetivos de translación digital.

La selección de personal es según la solicitud de las áreas, RR.HH. lanza la convocatoria, realiza gestión para concretar entrevistas directas con el jefe y se hace un cruce con el puntaje de las pruebas de selección de RR.HH. Consideramos que no es complicado el reclutamiento de los perfiles, puesto que existen personas con las capacidades necesarias para cumplir el perfil. Para los perfiles que tienen contacto directo con el proceso de transformación digital es importante darle un pluss económico, ya que tienen un valor agregado y diferenciado. Le tiene que gustar el negocio, si le parece aburrido el tema de seguros o servicios no se les va hacer fácil a la organización. Tenemos un buen ambiente de trabajo, beneficios, descuentos en los productos de la empresa, días libres por eventos importantes, capacitaciones, viajes al exterior, encuentras personas con las que aprendes, tenemos un programa para artes y buscamos darles virina a los jóvenes talentos.

\section{PACIFICO}

Entrevistado: Martin Ferradas

Puesto: Corporative recruitment chief

Como compañía de seguros tenemos un fin social. Proteger la estabilidad económica de nuestros clientes y que no se empobrezca ante un caso fortuito. Para ello, nosotros tenemos que tener la solidez necesaria para atender los siniestros que podamos tener. A nivel técnico ser muy finos, el equipo actuarial con el cálculo de reservas se preocupa para tener solvencias 
y agilizar procesos. La parte tecnológica y eficiencia de procesos es un punto clave para lo que se hace en la compañía. Hay muchos proyectos transversales para tener accesos más rápidos de la información y conocer mejor a nuestros clientes, con ello tendremos colaboradores ágiles en la atención a los clientes. Por otro lado, trabajamos mucho en mantener relaciones con clientes y bróker. Para ello, trabajamos con una segmentación más fina para identificar la demanda de sus negocios y ver el tipo de atención que debemos tener con ellos. Es decir, de una forma transversal para ofrecer una buena propuesta de valor.

Con nuestros clientes se está haciendo una calidad de atención en todos nuestros canales de contacto, por tal motivo se reestructuró el área. Actualmente, existe un área que hace anaytics para identificar los patrones de comportamiento de nuestros clientes para ver que necesitan que soluciones les podemos dar. También, tenemos el área digital, que se encarga de mejorar los productos ofrecidos a nuestros clientes y busca darles una mejor propuesta ante nuestra competencia. Desde Gestión humana damos soporte a todo esto, no somos recursos humanos si no administrativos en los perfiles, entramos a buscar personas que encajen con esta visión. Para que la gente conozca la misión y visión deben pasar por la inducción presencial y virtual donde contamos la cultura, lo que esperamos de ellos, valores y principios, con los cuales mostramos a dónde vamos. Hay mensajes periódicos de las gerencias para mostrar los resultados ver cómo estamos avanzando, cuáles son los retos de la compañía orientados a la satisfacción del cliente y dar soluciones innovadoras.

En cuanto a las iniciativas de proyectos para la transformación digita, realizamos concursos de ideas innovadoras donde parte del mismo concurso se comparte la metodología e involucra a los colaboradores.

En los procesos buscamos que nuestros colaboradores tengan las competencias de orientación al cliente, relaciones interpersonales, trabajo en equipo, precisamente, porque somos un negocio que está orientado a ver cómo se siente la persona. Pacífico es una compañía dinámica, flexible, orientada a la eficiencia, en búsqueda de resultados, orientados a la comunicación, relaciones horizontales, dinámicos y buscando siempre eficiencia.

Actualmente tenemos, 6 competencias transversales: atención al cliente interno y externo, la planificación y establecimiento de prioridades, toma de decisiones y solución de problemas, orientación a resultados, ética e integridad por la información que tenemos, capacidad de 
tener equilibrio de vida laboral. Las 6 competencias antes mencionadas es un previo a la transformación digital y en un futuro cercano buscaremos cambiar.

Tenemos un área de transformación digital desde hace un año, tiene como objetivo alinear la estrategia del negocio a la estrategia del área. Ver que estos sub objetivos de transformación sean lo que necesitamos como empresa, clientes y que sea a la velocidad que el negocio lo requiera. Formar al equipo fue dificil desde hacer sus oficinas hasta el reclutamiento, debido que no necesariamente necesitamos gente inteligente, si no que tenga visión distinta o que sea empático para captar al cliente.

En cuanto al cambio, no ha habido mucha resistencia, ya que estamos alienados con satisfacer al cliente y es lo que nos ha ayudado. Todavía no se da un cambio total, pero se va tener que dar está en proceso. Vamos a tener que cambiar cuando la transformación sea más concreta, se cambiarán procesos y formas de ver las cosas.

A nivel grupo credicorp tenemos el objetivo de transformar las empresas en digitales. Estamos siguiendo los pasos del banco, porque el mundo está cambiando y no podemos de dejar de crecer, adelantarse y no dejar que la competencia te coma.

No importa tanto el background que se tenga para el perfil del scramaster, no necesitas experiencia. Puedes haber tenido tu starup y tener éxito, dejar de lado la parte técnica y enfocarnos más en valores y competencias. Tiene que tener la capacidad de cambiar todo el tiempo y ser empático con la gente, vamos alineados a satisfacer al cliente, hacer algo más. Fuera de los perfiles del área de transformación digital, los colaboradores deben tener sensibilidad a las personas. Esto disminuye la resistencia al cambio y adoptar nuevas ideas, más disruptivos y receptivo a cualquier nueva idea.

El proceso de reclutamiento inicia con el levantamiento de perfil, reuniones con el cliente interno, definir la estrategia, canal interno o externo, filtros de $\mathrm{CV}$, expectativas y datos. Posteriormente, presentamos al cliente interno y vamos evaluando de manera presencial en entrevistas por competencias, luego aplicamos pruebas virtuales para conocer rasgos de personalidad, presentamos la terna y pasan por entrevistas de jefes o gerentes, dependiendo del puesto, se hace la oferta y cerramos el proceso. 
El proceso de selección para personal del área de transformación digital no es complicado, aunque hay características marcadas que son diferentes a otras partes del mundo, en nuestro País no son tan fuertes como en otras partes del mundo. Suelen buscar lugares con retos donde pueden crecer con oportunidades de desarrollo, como compañía tenemos lo que buscan.

En cuanto a las contrataciones, normalmente hay algunos rechazos de ofertas, pero nunca se debe al roll que ofrecemos. Esto sucede por las contrapropuestas de su actual empresa, otra propuesta económica y en otros casos solo quería probar en el mercado. Tenemos rotación baja, reclutamos practicantes 200 aproximadamente, es un banco de gente muy grande y el $30 \%$ aproximadamente se queda. Tienen su primer empleo y les damos lo que les interesa. Algunos se van, otros quieren regresar, algunos crecen en otro lado y luego vuelven, no vemos problema con nuestra rotación

Las personas que laboran en el área de transformación digital son más costosas, el mercado hace que sean, ya que son pocas las empresas que tienen laboratorios de innovación. Muchas empresas tienen filiales o casas matriz fuera y se alimentan de talento de afuera. Damos ciertos parámetros para ellos, por ejemplo, si tenemos 10 mil y tenemos 8 negociamos 8500 , vedemos otras cosas como compensación no remunerativa y la gente acepta por diversas condiciones. En otros casos si hemos sido restrictivos como los diseñadores, el área quería darles más pero no porque eran recién egresados.

\section{LA POSITIVA}

Entrevistado: Maria Pia Insausti

Cargo: Supervisora de selección

En cuanto a la Misión y visión no se tiene una actualizada a nivel corporativo, por lo tanto no es algo que estemos valorando en cuanto a un perfil de selección.

Lo que tenemos es un perfil de competencias que usamos tanto para la evaluación de desempeño y selección. Las competencias que requerimos son liderazgo, comunicación, impacto de influencia, innovación, creatividad, pero este momento no nos basamos en la misión y visión, porque no lo tenemos de manera corporativa. Muchas empresas están 
dejando de tener una visión y misión y pasan a tener simplemente un mensaje, palabras claves o una oración que describa a la compañía, en este momento es medio obsoleto.

Tenemos una cultura de puertas abiertas, hay una comunicación horizontal entre todas las gerencias. Un practicante puede acercarse al gerente de área o división sin ningún inconveniente, creo que estamos construyendo una cultura de innovación, creatividad y mejoras en los procesos. Dentro de la compañía tenemos varios proyectos estratégicos que buscan mejorar diferentes procesos y políticas para La Positiva del futuro.

Tenemos una gerencia de transformación digital dentro de la gerencia de MKT, es una gerencia que tiene menos de dos años y apunta a ver todo lo que son proyectos de transformación digital para la empresa. Para nuestro proceso de transformación digital, buscamos gente que sea creativa, innovadora y con alto nivel de pro actividad para hacer cambios y mejoras.

En cuantos a nuestras competencias buscamos gente que se pueda comunicar a todo nivel, comunicativo e impacto, trabajo en equipo, buen nivel de análisis para identificar cuáles son sus procesos de cambio y la pro actividad para poder proponer soluciones orientadas a resolver problemas, obtener resultados y a alcázar diferentes objetivos.

El proceso de cambio trajo consigo un cambio de cultura, porque queremos ser más creativos, innovadores. Vosotros teneos varios proyectos estratégicos para la mejora de la compañía. Por ejemplo: estamos cambiando el sistema core de la empresa orientada a las necesidades de la compañía, proyecto Matrix, entre otras. Contamos con un área de gestión del cambio y hemos tenido una serie de proyectos de cambio, desde cambiar el sistema SAP de la compañía hasta promover la innovación.

Las exigencias de contar con un nuevo perfil vienes desde las necesidades del mercado como por la Gerencia. Tenemos la necesidad de requerir personal con habilidades blandas y competencias, queremos contar con el mejor perfil del mercado.

En cuanto a nuestro proceso de reclutamiento, hacemos uso de nuestras bolsas especializadas, portales de empleo y también hacemos un proceso de handling para poder evaluar quienes son las personas que ocupan los puestos estratégicos dentro del mercado 
asegurador y poder atraerlas. En selección los evaluamos con distintas técnicas como entrevistas por competencias, evaluaciones de competencias etc. Esto va de acuerdo de la experiencia que solicitan o jerarquía que el usuario interno solicite. Las competencias antes mencionadas cruzan con todas las áreas, buscamos que las personas tengan todas esas competencias y las reforzamos. Hay programas con la universidad del Pacifico en habilidades blandas, talleres y capacitaciones.

La selección de un trabajador Millennials es muy similar a otras generaciones, pero tenemos que evaluar la motivación y cómo vamos a retenerlos en la empresa. Identificar los objetivos y metas está incluido dentro del proceso de selección para poder ejecutar un plan de retención más adelante. El proceso de selección dura aproximadamente un mes. En cuanto al tiempo de permanencia de los Millennials no tenemos un dato exacto, pero tenemos planeado para retenerlos la promoción interna, oportunidades internas para rotar por las diferentes áreas, postular a vacantes que tienen en su misma área, capacitación, eventos y temas de clima laboral. Todo lo ante mencionado permite generar un dinamismo y los colaboradores no busquen oportunidades fuera de la compañía.

Para el área de transformación digital nosotros no tenemos vacantes, por lo cual no hemos realizado la búsqueda de estos perfiles, ya que son tercerizados y lo maneja directamente la gerencia de área.

Adicionalmente nos proporcionaron un listado de competencias que se menciona en desarrollo. 


\section{Anexo 2. Encuestas a Millennials}

\section{ENCUESTA LABORAL MILLENNIALS}

Somos Bachilleres en la carrera de Administración y Negocios Internacionales de la Universidad Peruana de Ciencias Aplicadas. Estamos realizando nuestra tesis para obtener el grado de Licenciatura en Administración, por lo cual la presente encuesta busca identificar qué competencias manejan los millennials Peruanos de Lima Metropolitana.

Indicar nivel de estudio

Universitaria Incompleta

Universitaria Completa

No Universitaria

¿Cuál es tú situación laboral? (Tomando en cuenta practicas pre profesionales- profesionales o trabajo a tiempo completo)

Trabajo Actualmente

He trabajado, pero actualmente no

Nunca he trabajado 
¿En qué Industria trabajas? *

1. Minería

2. Salud

3. Agrícola

4. Banca

5. Retail

6. Seguros

7. Educación

8. Logística

9. Pesquera

10. Fuerzas armadas

11. Marítima

12. Aérea

¿En el último año te has presentado en algún proceso de selección? *

si

No

¿Has rechazado alguna oferta laboral en los últimos 6 meses? *

$\mathrm{Si}$

No 
¿Por qué rechazaste la propuesta laboral? *
Salario
Ubicación
Horario
Beneficios
Línea de carrera
Otra...

¿Cuál es el tiempo promedio que permanece en una empresa? *
6 meses - 1 año
1 - 2 años
2 - 3 años
3 a mas años

¿Qué te motivó a realizar tu último cambio laboral? *

Sueldo y beneficios

Oportunidad de crecimiento

Falta de desafíos / proyectos

Falta de reconocimiento

Conflicto con tu jefe

Reestructuración

Otra... 
¿Qué beneficio es el que más te motiva o te motivo en tu centro laboral? *

Sueldo y Beneficios

Oportunidad de crecimiento

Capacitación constante

Horario flexible

Clima laboral

Otra...

¿Cuál es la Industria que más te atrae? *

1. Minería

2. Salud

3. Agrícola

4. Banca

5. Retail

6. Seguros

7. Educación

8. Logística

9. Pesquear

10. Fuerzas armadas

11. Marítima

12. Aérea 
Estas conversando con tu compañero de trabajo y ves que pone sus manos en los bolsillos ¿Cuál de las siguientes alternativas consideras es la que mejor describe la postura adoptada por tu compañero?

Muestra Interés en la conversación

Transmite una actitud reprimida, ansiosa o reprimida

Muestra desinterés en la conversación

¿Con qué frecuencias tienes contacto con personas de otros Países? Ya sea virtual o presencial.

$\begin{array}{lllllll} & 1 & 2 & 3 & 4 & 5 & \\ \text { Nunca } & \bigcirc & \bigcirc & \bigcirc & \bigcirc & \bigcirc & \text { Siempre }\end{array}$

Tendencias del liberalismo promueven que quienes poseen más recursos deben pagar mas impuestos de quienes poseen menos.¿Cuál de las siguientes situaciones es compatible con la anterior?

En el País A, la tasa máxima de impuestos es $30 \%$ del salario de los habitantes.

En el País B, el Gobierno autoriza aumentar el impuesto a la Renta.

En el País C, el Gobierno quita los subsidios para los servicios públicos.

En el País D, el gobierno aumenta los impuestos de patrimonio y renta

Cuando se te presenta un problema ¿Cómo lo resuelves? *

Evalúas a detalle la causa del problema y realizas focus group para encontrar la solución

Buscas caminos alternativos y múltiples soluciones con tu equipo de trabajo, realizando una evaluación profunda de I

Buscas soluciones inmediatas sin consultar a tu equipo de trabajo 
¿Con qué frecuencia participas en capacitaciones o cursos de actualización?

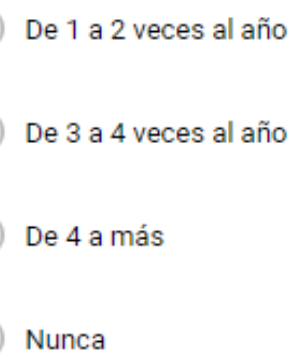

Considerando que la tecnología te puede dar facilidades para trabajar desde casa ¿Qué tipo de jornada laboral consideras que es mas efectiva para cumplir con tus objetivos profesionales y organizacionales?

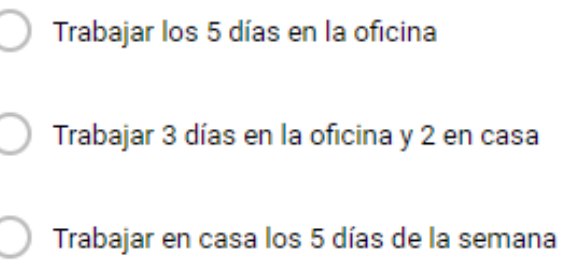

¿Qué tan importante consideras la comunicación dentro de las organizaciones?
1 2 3 4 5
Nada Importante
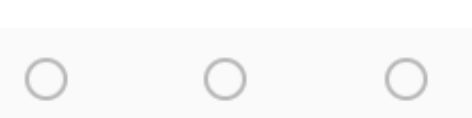
Muy Importante

¿Cuál es la mejor definición para el concepto "Big Data" *

Conjuntos de datos o combinaciones de conjuntos de datos cuyo tamaño (volumen), complejidad (variabilidad) y velc

Conjuntos de datos o combinaciones de conjuntos de datos cuyo tamaño (volumen) dificultan su captura, gestión, prı

Conjuntos de datos o combinaciones de conjuntos de datos cuyo tamaño (volumen), complejidad (variabilidad) y velc 
Edad *

Texto de respuesta breve

\section{Género *}

Femenino

Masculino

No precisa 